$P_{2}-P 785$

78-6287 (microfilm)

HARVARD UNIVERSITY

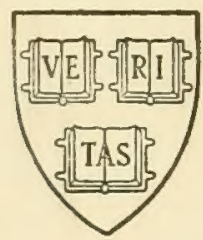

LIBRARY

OF THE

Museum of Comparative Zoology 


$P_{2}-P 785$

\section{CARTE GEOLOGIQUE DE LALGÉRIE}

Etant Directeurs MM. POMEL et POUYANne

\section{PALEONTOLOGIE MONOGRAPHIES}

BUBALUS ANTIQUUS

A. POMEL

CORAESPONDANT DE LIINSTITUT

\section{ALGER}

IMPRIMERIE P. FONTANA ET C', RUE D'ORLEANS, 29 
Yingeref

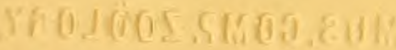

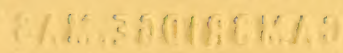




CARTE GÉOLOGIQUE DE L'ALGÉRIE

ÉTINT DIRECTEURS MI. POMEL ET POLYANNE

\section{PALÉONTOLOGIE}

\section{MONOGRAPHIES}





\section{CARTE GEOLOGIOUUE DE LALGERIE}

\section{PALEONTOLOGIE MONOGRAPHIES}

Etant Directeurs MM. POMEL et POUYANNE

\section{BUBALUS ANTIOUUS}

I'AR

A. PONEL

CORRESPONDANT DE L'INSTITUT

\section{A LGER}

IMPRIMERIE P. FONTANA ET Ci,, RUE D'ORLÉANS, 29 


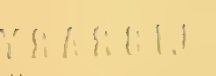

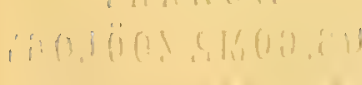

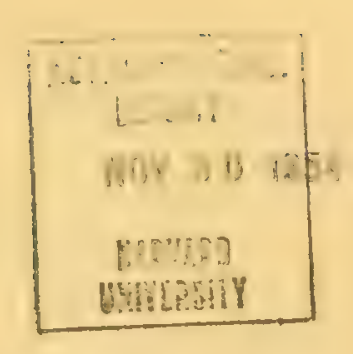

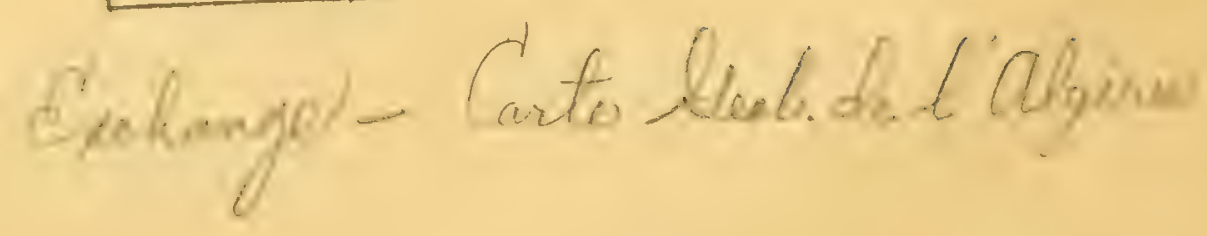




\title{
CARTE GÉOLOGIQLE DE L'ALGÉRIE
}

\author{
PALÉONTOLOGIE \\ MONOGRAPHIES DE VERTÉBRÉS \\ PAR
}

A. POMEL

CORRESPONDANT DE L'INSTITUT

LE BUFFLE ANTIQUE

(Bubalus (Arni) antiquus, Duvernoy).

\section{HISTORIQUE}

Cette espèce a été décrite sommairement et très bien caractérisée pour la première fois en 1851 , dans les comptes rendus de l'Académie des sciences, par le professeur Duvernoy (vol. 33, p. 595). L'auteur divise les bovidés en quatre genres: les Bœufs, les Bisons, les Buffles et les Ovibos et rattache à chacun d'eux une espèce fossile. Un modèle en plâtre d'une tête du musée de Londres, provenant de l'Inde, lui permettait alors d'indiquer pour le genre buffle une première espèce fossile ayant les proportions de l'Arni à grandes cornes. La présente espèce, la deuxiẻme, reposait sur une portion de cràne trouvée dans les fouilles pour les fondations d'un moulin appartenant à M. Fabre de Ribeauvillers, près de Sétif, sur les bords de l'Oued Bou Sellam. En 1859 un autre crâne fut découvert sur les bords du Rummel, près d'Aïn Smara. Il a été décrit par. M. E. Ollivier, pharmacien militaire, dans un opuscule publié ả Constantine.

Plus récemment un squelette presque entier a été découvert avec 
divers autres débris fossiles près de Djelfa par M. Dautrement. Il a donné lieu à diverses publications de M. Philippe Thomas (Société climatologique d'Alger, 1875 ; Société zoologique de France, 1882) et de Paul Gervais (Journal de zoologie, T. IV), etc, et rapporté au Bubalus antiquus de Duvernoy. C'est ce sujet, d'abord déposé au Musée de l'exposition permanente d'Alger', et maintenant conservé dans les collections de l'Ecole des sciences, qui nous a fourni les matériaux principaux de cette monographie.

Diverses indications ont été faites, depuis lors, de découvertes d'autres ossements de cet animal, mais sans détails descriptifs, et il me parait peu intéressant de les relater ici. Il en sera question lors des indications de la notice et de l'âge des gisements oủ on a recueilli ces débris, et après avoir déterminé le bien fondé des déterminations qui en ont été faites.

Les ossements de grands bovidés n'étant pas rares dans les terrains quaternaires de l'Algérie et leur détermination sans des éléments directs de comparaison présentant beaucoup d'incertitude, j'ai pensé qu'il serait utile de donner une iconographie ostéologique de cette espèce récemment éteinte et d'en donner la description pour en faciliter l'étude comparative avec les ossements de grands bœufs qui se trouvent avec les siens dans leurs gisements. On pourra même l'accompagner d'une représentation rustique de l'animal vivant, qui se trouve assez fréquemment gravée sur les rochers abrupts du Sud algérien par les hommes des temps préhistoriques, qui en ont été certainement les contemporains. Nos dessins sont la représentation fidèle de photographies à l'échelle reproduites avec soin par un habile dessinateur, MI. Ferrand, et de photographies de dessins rupestres préhistoriques prises par M. Flamand, un des collaborateurs du Service géologique de l'Algérie.

II. Rutimeyer a donné le nom de Bubalus antiquus à un bovidé dont des ossements ont été recueillis par B. Gastaldi dans une ca- 
verne de l'île Pianosa, mais sans les décrire ni indiquer aucun de leurs caractères. Rien n'autorise done à considérer ce nom comme indiquant l'espèce de Duvernoy. (Nouveaux mémoires de la Soc. helv. des Sc. Nat. Hist. nat. des Bœufs, $2^{\circledR}$ partie, p. 39).

\section{LA TÊTE}

Pl. I, fig. 1-3. Pl. II, fig. 1-3.

La tête du buffle fossile de l'Algérie porte vigoureusement empreints les caractères de ce sous-genre de bovidé. Pl. I, fig. 2 et 3 au 1/5 vue en dessus et en dessous; Pl. II, fig. 2 et 3 aussi au 1/5 de profil avec corne cassée et par derrière; Pl. I, fig. 1, au 1/10 montrant l'envergure des noyaux osseux des cornes, figure complétée par retournement de photographies: Pl. II, fig. 1 au 1/10 de profil oblique (vu du $3 / 4$ en perspective pour montrer la courbure d'ensemble). Un front fortement bombé en tous sens, très dẹveloppé en largeur, s'étend presque des orbites jusqu'au voisinage de la crête occipitale sans former de chignon avec cette derniẻre. Des côtés de ce front partent des noyaux osseux de cornes extrêmement allongés, presque aussi larges que lui, triangulaires å la base avec un fort angle en arrière et une face antérieure plus étroite que les autres, les angles s'émoussant de plus en plus au delà, de sorte que la section devient elliptique vers le milieu et près du bout. Prolongeant la direction arquée du front, èlles s'inclinent d'abord un peu en dehors et en avant; puis elles se recourbent en arrière en se relevant un peu vers leur extrémité et forment ensemble deux croissants conjugués en forme d'arc, dont les extrémités, distantes de $2^{\mathrm{m}} 40$, dépassent peu en arrière le plan occipital et le niveau du front. Les orbites obliques, en avant, sont presque à peu près à fleur et très peu bordés, leur bord supérieur étant un peu relevé en bosse.

Les frontaux naissent un peu en avant de la ligne des yeux, ne 
tardent pas à se synostoser complètement entr'eux et se bombent bientôt en une surface trẻs rugueuse, plus convexe suivant l'axe qu'en travers et trés étendue en ce sens entre les bases des cornes. Les trous surorbitaires doubles et inégaux, situés dans le prolongement des sulures des naseaux avec le lacrymal, sont au commencement du bombement et à la hauteur du bord antérieur de la base des cornes. La région comprise entre les sillons qui vont à la sulure des naseaux est déprimée. La suture avec le lacrymal part de l'angle latéral des naseaux et va un peu obliquement se terminer vers une forte échancrure de la marge orbitale, représentant le trou préorbitaire. La rugosité cesse à peu près au droit du bord postérieur des cornes, formant une ligne sinueuse qui doit ètre au moins très voisine de la suture du temporal, absolument oblitérée.

L'insertion des cornes se fait par une sorte de pédicule de quatre ou cinq centimètres de longueur, précédant le cèrcle très régulier des aspérités formant l'origine des cannelures du noyau osseux. Les fortes rugosités qui leur font suite sur les frontaux s'en détachent bien, quoique très fortes, de manière qu'on pourrait se demander si elles n'étaient pas en rapport avec une expansion cornée; elles s'arrêtent vers le pariétal par un cercle très accusé de pierrures, qui ne diffère de celui de l'origine des noyaux osseux que par l'absence de cannelures. Ces cornes sont assez fortement creusées de lacunes grandes et petites, celles-ci vers les bords, celles-lả au centre, au-travers d'un tissu très résistant; près de l'extrémité il n'y a presque plus qu'une forte porosité celluleuse. Les cannelures qui sillonnent la surface sont assez inordinées, dont quelques-unes plus fortes, mais sans régularité. Un tronçon du sommet de vingt centimètres de longueur n'en a presque plus, mais porte un sillon assez creux sur chaque angle; il est du reste assez fortement comprimé.

La face est bien nettement contractée et atténuée en avant, à partir des orbites. Les os naseaux, très distincts et pas synostosés, pé- 
nètrent ensemble en forte saillie angulaire dans une échancrure aiguë des frontaux. Ils s'élargissent asse\% fortement en avant et se bombent de plus en plus en voùte, jusqu'à la suture intermaxillaire, de laquelle ils s'affranchissent bientôt pour se terminer en pointe lancéolée, presque aiguë ; ils forment alors un auvent assez étendu sur la fosse nasale, conservant toujours leur convexité transversale, combinée à une autre dans le sens de l'axe, qui donne une forme busquée au profil.

Le lacrymal est assez étendu sur la joue et y forme une bande en trapėze presque aussi large que longue, tronquée carrément vers sa suture antérieure avec le maxillaire.

L'intermaxillaire est en lame étroite, qui s'atténue vers le sommet pour s'enclaver sur environ trois centimètres de long entre le nasal et le maxillaire dans la direction de leur suture. Il descend très obliquement en avant de ce dernier, en s'élargissant un peu en écaille dans la fosse nasale; puis au bas il s'épate en une lame de cinq centimètres de longueur, qui reste dans le plan du palais et à peu près dans la direction du bord extérieur du maxillaire. Son extrémité est trés obtuse, presque tronquée et forme avec sa correspondante du côté opposé un museau crùnien large et comme émarginé, qui est un peu exagéré sur notre sujet par suite du bâillement de la suture. Les trous incisifs, un peu déformés et incomplets, paraissent avoir été larges et courts. Le plan de cette partie du palais est à dix centimètres au dessous de l'extrémité des naseaux, qui elle-même est ả huit centimètres en arrière de l'aplomb du bout du museau.

Le maxillaire occupe une large étendue sur le côté de la face, remontant rapidement avec l'intermaxillaire jusque derrière l'auvent des naseaux, qu'il suit sur une certaine longueur pour redescendre rapidement en arrière contre le lacrymal et le jugal. En ce point son bord supérieur à l'aplomb des arrière-molaires est à treize centimètres au dessus de la ligne de leurs alvéoles. La suture avec le 
lacrymal est droite et à peine oblique, celle avec le jugal descend d'abord un peu plus obliquement en arrière et en se coudant un peu pour aller contourner l'extrémité de la carène sousorbitaire du jugal, qu'elle suit ì une faible distance en dessous, en partie du moins, pour s'abaisser encore au delà et aller contourner la région alvéolaire. Celle-ci se prolonge fortement en arrière de la dernière molaire en une sorte de grosse apophyse obtuse, limitée par deux sinus profonds de plus de deux centimètres, formés d'un côté avec le jugal, de l'autre avec le palatin et dont l'extrémité est à plus de six centimètres de la derniẻre molaire. L'ensemble de cet appendice se présente sous l'apparence d'alvéole dentaire; sur notre sujet une fracture de l'os près de la dent donne l'idée d'un bord alvéolaire troué par une poussée d'un germe dentaire, mais, en réalité, il n'y a ni alvéole, ni germe dentaire et la série des arrière-molaires étant complète, il n'y a qu'une simple illusion. (La partie comprise entre les sinus pourrait appartenir au lacrymal, mais la sulure est indistincte). La suture avec le jugal ne s'en détache qu'un peu au delà du sinus; elle suit ensuite de très près le contour de la proéminence maxillaire, va ranger de très près aussi l'alvéole de la dernière molaire, puis s'infléchit en dedans pour aller rejoindre sa correspondante opposée, après avoir donné lieu à un trou palatin qui s'ouvre au milieu de la longueur. Le sinus qui en résulte est un quadrilatére irrégulier, plus large que long, pour le palatin qui s'y encastre jusqu'au niveau du milieu de la deuxiẻme arrière-molaire. Dans son ensemble la face extérieure du maxillaire est un triangle irrégulier, plus allongé à l'angle antérieur, largement tronqué vers le haut. La carène sous-orbitaire du jugal s'y prolonge en une étroite bande rugueuse, qui s'arque vers le bas pour se mettre en contact avec une longue et forte aspérité régnant au dessus de la zone alvéolaire, plus accentuée vers son point de confluence avec la bande descendante. Ces bandes, surtout l'inférieure, correspondent à un bossellement de la face, dont ces lignes âpres forment en quelque 
sorte les arètes. L'inférieure se termine en arrière et près du trou sous-orbitaire qui s'ouvre en forme de fente verticale peu ouverte et peu étendue, au dessus de l'aplomb de la première avant-molaire el au tiers inférieur de la hauteur du maxillaire. La face palatine du maxillaire se resserre un pen entre les avant-molaires, puis se contracle au devant d'elles par un évidement de la paroi interne, qui s'atténue et s'efface vers les intermaxillaires, l'extrémité de la face palatine étant en spatule tronquée el portant les trous incisifs.

Le jugal, dont on a indiqué plus haut les sutures avec le lacrymal et le maxillaire, contribue à compléter le cadre de l'orbite qui est médiocrement marginé et s'ouvre asse\% obliquement en avant et en bas. Ge cadre est ovale subtriangulaire, le côté inféro-antérieur étant notablement plus étroit et le grand axe étant oblique dans la direction qui va des molaires au devant du front. Une très forte carène sousorbitaire saillit en lame épaisse au tiers de la distance entre l'orbite et le bord alvéolaire, et sert d'origine à l'arcade zygomatique, qui après avoir donné une branche post-orbitaire allant se souder au frontal devant la base de la corne sous la forme d'une lame large et courte pour former le cadre orbitaire, se prolonge en arrière en baguette de plus en plus étroite, rectiligne, longuement contiguë avec la correspondante du temporal et notablement divergente en dehors et en arrière, de telle sorte que cette partie de la tête ne mérite nullement le nom d'arcade.

Le pariétal est assez difficile à limiter; si ce n'est à l'aide de ses connexions habituelles; on ne distingue pas de sutures avec les frontaux, mais on peut très raisonnablement admettre que cette limite est indiquée par celle des deux zones de rugosités des frontaux et de surface unie du pariétal. Cette ligne est assez ondulée et remonte un peu plus haut sur le vertex et elle s'étend même un peu sur le pédicule des cornes à sa partie postérieure. Elle s'abaisse latéralement pour passer daus la fosse étroite mais profonde qui s'étend sous les 
noyaux osseux des cornes jusqu'a la l'égion orbitaire. La surface du vertex s'incline assez fortement en arrière, en suivant là convexité du front; elle est peu allongée dans celte direction et se contracte sur les côtés en deux sinus étroits, contigus aux cornes et qui sont l'origine de la fosse post-orbitaire. Ces sinus étranglent médiocrement la zone pariétale qui se termine devant la limite supérieure do lá face occipitale en y formant ensemble la crête bien anguleuse, mais d'une faible saillie et sans apparence de chignon.

L'occipital, synostosé avec l'interpariétal, est très notablement incliné en dessous puisque son plan fitit avec l'axe de la tête un angle de $45^{n}$ environ; l'angle émoussé avec le pariétal supérieur élant à peu près de $80^{\circ}$. C'est un large disque demi-circulaire, en arc assez largement émarginé au sommct, assez étroitement, mais fortement bordé à lat marge avec des surfaces d'attaches musculaires plus développées en étendue qu'en saillies. Les condyles occipitaux forment ensemble environ le tiers de l'étendue de la base; en dehor's des apophyses pseudo-mastoïdiennes qui sont épaisses mais non saillantes; le temporal doit fournir de chaque coité partie ou totalité d'une forte tubérosité, très rugueuse, qui est encore dans le plan occipital et fait partie des extrémités de la courbe générale de la crête. Il en résulte que la face occipitale est remarquablement élargie, ayant trente-cinq centimètres d'étendue contre quinze seulement de hauteur. Lorsque le cràne est posé sur ses condyles et vu par derrière dans l'axe de la tête, il laisse voir au dessus de la crête, surmontant la zone pariétale, une partie notable de l'arrière des frontaux dans le prolongement de la courbe des chevilles osseuses des cornes; et sous la base de celles-ci latéralement se montre l'échmerure profonde et étroite qui les sépare du pariétal.

Les condyles sont peu saillants en arrière et fortement élalés; les bords se rapprochent fortement en dessous de manière à former une échancrure profonde et étroite dans la partie inférieure du tron ncci- 
pital. Celui-ci est presque parallélogrammique, plus large que haut. Les tubérosités basilaires qui suivent les condyles sont arrondies et assez fortes, séparées latéralement par un sinus arrondi. Le sphénobasilaire est en triangle lancéolé à pointe acuminée au delà de la deuxième paire de tubérosités qui est très peu développée; ses ailes ptérygoïdiennes sont assez rapprochées par suite du rétrécissement. notable du canal des arrière-narines, du reste peu développées et flinquées des lames ptérygoïdiennes internes, celles-ci se prolongeant de la mème manière sur les parois internes des ailes détachées du palatin.

Les palatins pénètrent en forme de large lame tronquée, formant environ le sixième de l'étendue du palais; les connexions avec les maxillaires en ont été indiquées plus haut. Les ailes ptérygoïdiennes vont un peu en divergeant en avant, élargissant ainsi la fosse dont le plancher se termine par un sinus arrondi au niveau du bord postérieur des arrière-molaires. Celte partie diffère peu de ce qu'elle est dans le sous-genre des bœufs, sauf dans la saillie moindre des ailes.

Le temporal, synostosé avec le rocher, constitue la partie la plus remarquable de cette tête de buffle. On a vu qu'il contribue à élargir l'occiput par un épatement considérable de la partie mastoïdienne, qui s'arrondit un peu en dehors ell se relevant faiblement au dessus de la ligne tangeante au bord inférieur des condyles. Le rocher doit constituer une bonne partie de cette proéminence; mais je n'ai pu limiter ses connexions. La caisse est petite, peu saillante et comme pincée, très allongée transversalement et encastrée entre le basilaire et le temporal; clle se prolonge en un long conduit auditif marqué par des lignes de fissuration, mais ne paraissant dans l'empàtement qu'à sa partie la plus saillante par' son ouverture, qui aftleure l'angle extrème. Le temporal, proprement dit, ne se distingue du reste que par une surface plus lisse séparée par une bande rectangulaire et rectiligne dont la crête inférieure va directement aboutir vers le trou 
auditif. Le plancher glénoïdien ainsi limité est sur un plan plus élevé : après avoir fourni une lame étroite du còté du trou auditif, il se resserre brusquement, porte une large facette presque plane, occupant une grande partie de sa surface; elle s'abaisse un peu en arrière en une crête arrondie près du bord postérieur interne. En avant de la facette il forme un grand sinus en demi-cercle accompagné d'un deuxiẻnı plus petit du côté du sphénoïde et séparé par une saillie triangulaire. L'attache de l'arcade zygomatique donne en avant une branche presque grèle, très peu oblique, sans courbures, qui s'appuie bientòt sur l'apophyse du jugal pour former une arcade presque droite, à peine convergeante en avant jusqu'à la branche post-orbitaire; elle est trẻs rapprochée du bord inférieur du noyau osseux des cornes et contribue beaucoup à resserrer la fosse temporale. La réduction des saillies habituelles de la face inférieure de l'arrière-crâne et l'élargissement de cette partie donne une physionomie particulière d'aplanissement à toute cette région.

Explication de l'iconographie: I'l. I, fig. 1, au $10^{\circ}$ de grandeur naturelle, cràne vu de face pour montrer l'envergure des cornes, ou, pour être plus correct, des chevilles osseuses, leur partie cornée étant plus prolongée; on a complété la figure par une extrémité bien conservée. L'une des cornes étant brisée, on a achevé la représentation par une photographie retournée.

Pl. II, fig. 1, au $10^{\circ}$ de grandeur naturelle, cràne vu de profil, et de $3 / 4$ en avant pour montrer en perspective la courbure d'ensemble des cornes. Le crâne étant à l'échelle, celles-ci ont des proportions exagérées.

Pl. I, fig. 2, au 1/5 de grandeur naturelle, crâne vu de face, les chevilles osseuses sont supposées brisées.

Pl. I, fig. 3, au 1/5 de grandeur naturelle, cràne vu par le dessous, les chevilles osseuses supposées brisées. 
Pl. II, fig. 2, au 1/5 de la grandeur naturelle, crìne vu de profil. La cassure du bord antérieur tombant presqu'à la marge de l'orbite ; celle du bord inférieur masque en partie l'arcade zygomatique. L'intermaxillaire manque d'un côté et sa suture externe est marquée par le bord du maxillaire; cette suture étant écailleuse on voit son bord du côté opposé sur la paroi interne de la fosse nasale. L'extrémité de la corne opposée paraît en arrière.

Pl. II, fig. 3, au 1/5 de la grandeur naturelle, crâne vu par la face occipitale, montrant les rugosités frontales à leur terminaison.

\section{MENSURATION DES PARTIES DU CRANE}

Longueur du cràne du bord incisif à l'occiput........ $0,630^{\mathrm{mm}}$

aux condyles........ 0,600

Distance du bord incisif à la $1^{\text {re }}$ prémolaire ......... 0,160

à la fosse post-palatine...... 0,310

à la suture palato-maxillaire.... 0,260

à l'apophyse post-glénoïdienne.. $\quad 0,500$

Longueur des intermaxillaires.............. 0,210

- des maseaux.................. 0,260

Distance du bord incisif au bord orbitaire antérieur..... 0,320

à la racine antérieure des cormes. 0,420

Longueur du front de l'os du nez à l'arrière des rugosités. 0,240

1 listance de ces rugosités it lit crète mecipitale....... 0,110

Etendue du bord incisif .................. 0,140

Plus petite largeur du palais derrière les trous incisifs... 0,060

entre les arrière-molaires... 0,100

Plus grande largeur du palais entre les $1^{\text {r.s }}$ arrière-molaires $\quad 0,120$

Plus grande largeur des naseaux au bout de la suture in-

termaxillaire.............. 0,100

des mèmes èn suivant la convexité... 0,120 


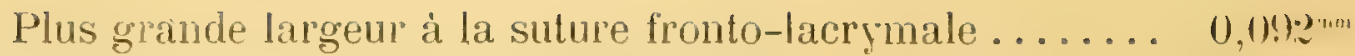

Largeur du museau vers le bord incisif ........... 0,150

- devant le trou sous-orbitaire....... 0,1311

- $\quad$ au dessus de la $2^{\circ}$ arrière-molaire.... 0,190

- devant les orbites.............. 0,2:25

- $\quad$ au bout de la carène jugale vers la suture $\quad 0,210$

- derrière les orbites........... 0,235

Distance du trou sous-orbitaire au bord des orbites..... 0,160

Distance entre les bords inférieur's des orbites........ 0,220

- entre les bords extérieur's des trous sus-orbitaires 0,110

- entre les bases antérieures des cornes....... 0,240

- entre les bases postérieures des cornes....... 0,330

I.ongueur d'une corne en suivant la courbure extérieure... 1,500

en ligne droite (corde de l'arc) .... 1,015

Distance des sommets des deux cornes........... 2,100

Flèche du double croissant au dessus de l'occiput..... 0,500

Epaisseur antéro-postérieure de la base des cornes..... 0, 0,170

- verticale au bord antérieur............ 0,100

Pourtour du pédicule des cornes.............. 0,440

- de la base des cornes............... 0,470

- des cornes au milieu de leur longueur....... 0,350

Diamètre vertical au mème point.............. 0,100

- antéro-postérieur au mème point.......... 0,130

Longueur du pédicule des cornes.............. 0,030

Largeur du front derriere les curnes ............ 0,400

Distance des sinus du pariétal derrière la base des cornes. 0,230

Largeur de l'occiput d'un méat auditif à l'autre....... 0,330

Distance du bord externe d'un condyle à l'autre...... 0, 0, 20

Largeur du trou occipital................. 0,040

Hauteur de la crête occipitale au dessus du bord inférieur du condyle....................... 0,1201 
Hauteur de la crête au dessus du trou occipital....... 0,102

Etendue de l'étranglement basilaire............ 0,070

- d'un bord externe à l'autre des $1^{\text {res }}$ bosses basilaires 0,085

Distance entre la pointe interne de la caisse et le méat... 0,140

Largeur de la caisse au milieu............... 0,025

Longueur du sphéno-basilaire.............. 0,120

Largeur verticale de lia paroi qui limite en arrière le plancher glénoïdien...................... 0,045

Largeur de l'arrière-crâne à l'origine de ce plancher et des arcades zygomatiques................. $0,2(60)$

Largeur du plancher de la facelte glénoïde......... 0,070

Plus faible distance des crêtes ptérygoïdiennes postérieures $\quad 0,045$

Largeur du canal ptérygoïdien à l'extrémité des ailes palatines.......................... 0,060

Dislance de l'arrière-molaire au bord postérieur glénoïdien. 0,200 - entre le sinus jugo-maxillaire et le bord antérieur glénoïdien .......................... 0,155

Distance entre le fond du sinus palatin et l'échancrure intercondylienne..................... 0,240

Distance externe entre les bords de l'arcade zygomatique à la hauteur de la suture palato-sphénoïde........ 0,250

Largeur du crâne entre les bouts de la crête sous-orbitaire du jugal au droit des $3^{\text {es }}$ arrière-molaires......... 0,210

Largeur du cràne entre les tubérosités du maxillaire au droit des $3^{\text {es }}$ avant-molaires.............. 0,200

Plus petit axe des orbites.................. 0,068

Plus grand axe des orbites................ 0,075

Hauteur du jugal devant l'apophyse post-orbitaire...... 0,035

- derrière la dite apophyse.......... 0,020

Largeur de l'apophyse post-orbitaire............ 0,035

Longueur verticale de l'apophyse post-orbitaire....... 0,030 
Distance du bord de l'orbite au pédicule de la corne.... $0,015^{\mathrm{mm}}$ Hauteur de la base de la corne au dessus de l'arcade.... 0,025

\section{LES DENTS}

Pl. 11, fig. 4. PI. IV, fig. 1 et 2. Pl. IX, fig. 1 et 2.

Malgré que l'on connaisse maintenant une notable quantité de débris de cet ancien buffle, et au moins 6 crànes, sa dentition est encore peu connue. La mandibule et ses dents manquent absolument, ou du moins il n'y a pas certitude d'attribution des quelques dents isolées qu'on pourrait considérer comme telles, n'ayant d'autre guide que leur grande taille; elle pourrait tout aussi bien les faire attribuer à un très grand bœuf, qui fera l'objet d'une autre monographie.

Dents supérieures. - On ne connait positivement que les arrièremolaires supérieures du sujet principal de ce travail, avec les alvéoles des avant-molaires. (Pl. II, fig. 4. G. N. ; mâchoire vue par la couronne); l'état de détrition des molaires assez avancée indique un animal plus qu'adulte, comme le prouvent aussi les synostoses de beaucoup de pièces de la tête. La série des trois molaires mesure $110^{\mathrm{mm}}$. Les alvéoles des trois avant-molaires sont conservées et mesurent $60^{\mathrm{mm}}$, ce qui donne pour la série totale $170^{\mathrm{mm}}$. Ces dents ont la structure générale de celles des bovidés; la couronne, un peu détériorée. montre un double croissant lacunaire, dont les branches sont longues, presque également larges, obtuses, à parois peu ondulées ou anguleuses. La profondeur de ce croissant indique pour le pilier externe de chaque lobe une forme subcylindrique el beaucoup d'épaisseur; les internes sont également épais et sont flanqués d'une colonnette interlobaire robuste, aplanie sur sa face, ou même marquée d'un sillon. Derriẻre les angles internes en avant et en arriẻre est une encoche qui marque un sillon sur le bord de ces deux faces. La muraille extérieure présente une arête marginale saillante, une côte obtuse très 
rapprochée, puis un large sillon bordé par l'arête médiane, qui ici semble faire parlie du lobe postérieur dont les deux sillons sont étroits et-profonds entre les arètes et la còte qu'elles enclavent.

La première est presque carrée, $33^{\text {man }}$ de large sur $34^{\mathrm{mnn}}$ d'épaisseur. La seconde est plus grande, $43^{\mathrm{mm}}$ de large sur 38 d'épaisseur; elle est plus étroite en dedans par suite d'une obliquité de sa face postérieure. La troisième est en trapèze, $35^{\mathrm{mm}}$ de long sur 30 d'épaisseur; son côté interne est bien plus court que l'externe par suite d'un rétrécissement égal des faces antérieures et postérieures. Pour les avant-molaires nous n'avons que les alvéoles triradiculées, deux racines extérieures et une plus étendue intérieure pour les $3^{\circ}$ et $2^{\circ}$; une externe, une interne et une antérieure moins inégales pour la première. Les dimensions sont : pour la $1^{\text {re }}, 12^{\mathrm{mm}}$ de long et $15^{\mathrm{mm}}$ de large; pour la $2^{\circ}, 18^{\text {mm }}$ de long et $16^{\mathrm{mm}}$ de large; pour la $3^{\mathrm{e}}, 21^{\mathrm{mm}}$ de long sur $20^{\mathrm{mm}}$ de large. Les dents correspondantes s'élargissant au sortir de l'alvéole devaient avoir un peu plus d'étendue à la couronne. La série des prémolaires était relativement plus courte que dans les bœufs ordinaires, $6 / 11$ de l'étendue des arrière-molaires au lieu de 7/11.

Les séries des arrière-molaires sont légèrement divergentes en avant ; celles des avant-molaires, au contraire, sont convergentes du même côté par suite d'une inflexion qui donne à la série totale une forme arquée, à concavité du côté du palais. La distance entre les bords antéro-extérieurs des deux premières alvéoles est de $125^{\mathrm{mm}}$; celle entre les bords antéro-extérieurs des deux premières arrièremolaires est de $175^{\mathrm{mm}}$; celle entre les bords postéro-extérieurs des deux dernières molaires est de $150^{\mathrm{mm}}$.

Je crois pouvoir attribuer à la même espèce de buffle deux dents supérieures trouvées dans les sondages artésiens de Brédéah (prise d'eau de la ville d'Oran, à 30 kilom. à l'Ouest de cette ville). L'une d'elles (Pl. VI, fig. 1 à $4, a b c d$ ) est une arriẻre-molaire, probablement la première, ayant appartenu à un sujet adulte, mais jeune 
encore et ayant peu entamé les croissants de sa couronne. Elle appar tient à la màchoire droite, mais figure ici comme gauche, le dessin n'ayant pas été fait au miroir. Elle a dans sa partie comparable les mêmes dimensions et porte les sillons des faces latérales des piliers, dont les traces ont été signalées sur les dents usées du sujet typique. Elle ne porte que des traces de cément, qui s'est probablement détaché, car la surface finement rugueuse de l'émail indique qu'il était abondant. Le fùt est remarquablement allongé, plus de $75^{\mathrm{mm}}$; il s'amincit vers la couronne en sẻlargissant à peine, mais se resserre sensiblement d'avant en arrière vers la base, oủ son épaisseur est au contraire remarquable. Les sillons vers les angles latéraux des piliers internes sont très marqués; le postérieur commence un peu au dessus de la base par une étroite scissure, s'élargissant un peu sur une dépression qui s'étale et s'efface avec lui près de la couronne. Le sillon antérieur commence au collet et s'accentue vers la couronne en se rebordant de plus en plus sous forme d'une petite arête en gradin; il y a en outre une dépression en gouttière superficielle en dedans de chaque arête marginale. La colonne interlobaire est épaisse, étalée dans l'angle et marquée d'un sillon qui du côté de la couronne devient un méplat; elle n'atteint pas l'extrémité des lobes et la détrition ne l'a pas encore entamée.

A la surface extérieure on voit une arête marginale antérieure obtuse, très saillante et rapprochée d'une côte arrondie en fort relief, séparée de l'arête par un étroit et profond sillon, très peu élargi vers la couronne; au contraire cette côte est séparée par une assez large gouttière de l'arête médiane, qui semble appartenir uniquement.au lobe postérieur. Cette arête très en relief est séparée de la côte médiane suivante par un étroit el profond sillon et celle-ci est séparée d'une arête marginale très saillante par un sillon aussi prof ond mais qui s'élargit du côté de la couronne; les lacunes semi-lunaires entre les piliers sont plus anguleuses ou ondulées que dans les dents du 
sujet typique; mais cette différence doit tenir aux modifications que la détrition apporte avec l'àge à leur configuration sur la couronne. Celte dent diffère surtout de celle des bœufs par la forte saillie de ses côtes el arêtes extérieures et la profondeur et l'étroiteșe des sillons qu'elles limitent, sauf pour le sillon médian qui est un canal remarquablement plus élargi, par l'épaisseur de la colonnelte interlobaire et par le fort sillon marginé de la face antérieure du pilier interne du lobe antérieur. Epaisseur de la dent à sa base $30^{\text {mum }}$, à son bout $23^{\mathrm{mm}}$; largeur à la base $30^{\mathrm{nm}}$; largeur au bout $36^{\mathrm{mm}}$.

L'autre dent (Pl. VI, fig. 2, $a b c d$ ) est probablement une troisième avant-molaire du même sujet, dont elle représente en quelque sorte l'un des lobes; mais elle est notablement plus courte dans son fùt, $45^{\mathrm{mm}}$ au lieu de $7 \mathrm{öm}^{\mathrm{mn}}$; la face extérieure porte une grosse côte étalée séparée des arêtes latérales très obtuses mais saillantes par des sillons évasés vers la couronne, surtout l'antérieur, qui font un peu diverger ces arêtes. La face interne a son pilier comme contracté en une grosse côte par un sillon postérieur qui s'accentue vers la couronne et par un sillon antérieur partant de la base, fortement bordé par une arête obtuse en forme de colonnette non détachée prenant l'apparence d'un rudiment de lobe antérieur. En somme, c'est une disposition très analogue, avec exagération de la structure, à la moitié de la première arrière-molaire. La grande disproportion qui existe entre cette avant-molaire et l'arrière-molaire pourrait faire concevoir des doutes sur la légitimité de ce rapprochement; mais il semble que ces doutes ne pourraient que se rapporter à l'altribution à un même sujet, qui me paraît rester toujours très probable, mais non à la question d'identité d'espèce. Cette avant-molaire représente trop bien le type de structure d'une moitié de l'arrière-molaire pour qu'on hésite à les rapprocher. On pourrait toutefois conclure de cette différence que le système des prémolaires ne.supportait pas seulement une réduction de développement dans la longueur totale de la série 
comparée à celle des arriẻre-molaires, mais aussi une forte réduction dans l'allongement du fùt de ces avant-molaires, qui devaient résister moins longtemps à l'usure par détrition. Cette dent mesure $45^{\mathrm{mm}}$ de hauteur de fût, $20^{\text {mm }}$ de longueur sur la couronne, $15^{\mathrm{mm}}$ vers la base, $20^{\mathrm{mm}}$ d'épaisseur å la couronne, $23^{\mathrm{mm}}$ au dessus de la base. La partie rétrécie du pilier interne entre les deux sillons s'élẻve à $10^{\mathrm{mm}}$ d'épaisseur. Les figures de la Pl. VI sont réduites aux 3/5.

Dents inférieures. - Depuis que ce qui précède a été écrit, j'ai pu observer au Musée de la ville de Constantine, grâce à l'obligeance de M. Prud'homme, son conservateur, une arrière-molaire inférieure, probablement la première, dont la taille et le gisement ne me laissent pas de doute sur son attribution au buffle antique. Elle a eté trouvée, en effet, dans les alluvions de l'Oued Seguen, d'où proviennent trois, au moins, des crànes connus de cette espèce.

Cette dent (Pl. IX, fig. 1) est probablement une première arrièremolaire; elle a la forme générale de celle des bœufs; elle est prismatique, formée de deux lobes, chacun composé de deux demi-cylindres s'emboitant de manière à produire des croissants concentriques par la détrition de la couronne. Le milieu des deux cylindres s'épaissit beaucoup, comme dans la généralité des bœufs et les espaces, laissés libres entr'eux, se contractent de manière à prendre la forme d'un 8 de chiffre presque régulier. La face externe porte dans l'intervalle des lobes une longue colonnette bien développée jusqu'au plan de la couronne de détrition et bien adhérente; les piliers de cette face sont épais, très obtus et presque aplanis à leur base. Leur face antérieure porte deux sillons légers, ou faibles cannelures, parallèles entr'eux et aux bords; la face postérieure présente une faible arête séparant un côté intérieur presque uni et un còté extérieur substrié parallèlement; il y a aussı dans le pli externe des deux lobes une cannelure plus ou moins marquée au niveau de la colonnette et de chaque côté. 
La face interne présente aussi une profonde et large dépression en gouttière entre les lobes, comme chez les bovidés en général; mais cette gouttière chez les bœufs part des côtes médianes de chaque lobe et ne montre ordinairement aucune arête ou cannelure accessoires. Ici, au contraire, cette gouttière porte sur ses bords deux cannelures appartenant chacune au bord de son lobe respectif, tandis que chez les boufs ordinaires ces cannelures sont atrophiées, sauf dans le germe qui en porte toujours les indices aux premiers débuts de la détrition; puis chaque lobe est réduit sur cette face à son arête marginale et à sa grosse côte médiane. Il semble cependant y en avoir encore une représentation dans le gros tubercule aigu qui s'élève au fond de la gouttière chez le bos elatus du pliocène de Perrier (qui certainement n'est que le bos etruscus de Falconer); mais cette espèce n'appartient pas au sous-genre des bos tels qu'ils sont interprétés maintenant, ni même à celui des bisons ou aurochs, ainsi que j'avais cru pouvoir l'admettre; mais, d'après Rutimeyer, elle se rattache à celui des bibos, et d'après Falconer à celui des amphibos, qui est au contraire rapproché par Rutimeyer des vrais buffles. Cette pointe, en tout cas, représenterait seulement l'origine condensée des deux arêtes normales; elle n'a rien de comparable à la structure de notre buffle. Elle s'observe parfois dans une espèce algérienne qui se rapproche à cet égard du buffle antique, quoïque d'un autre sousgenre.

Notre dent présente en définitive pour chaque lobe à la face interne, une arête marginale partant de la base, une très épaisse côte médiane et une arête bordant celle-ci du côté de la gouttière interlobaire; au lobe antérieur les sillons formés par ces arêtes et la côte médiane sont subégaux, étroits et s'atténuent jusqu'auprès de leur origine vers la base; au lobe postérieur ces sillons sont un peu plus larges et moins atténués à leur origine. Celui qui a voisine la gouttière est plus superficiel. Son arête est plus obtuse et moins proéminente. La gout- 
tière elle-même est plus anguleuse dans son fond à mesure qu'elle s'éloigne de la base. Il n'est pas inutile de signaler que les particularités décrites se modifient par suite de l'usure de la dent et que l'on trouve parfois chez les boufs ordinaires des rudiments plus persistants de cette disposition qui n'a de valeur ici que par sa forte et permanente caractérisation. La dent ici décrite était déjà notablement usée et est environ réduite par la détrition aux 2/3 de sa longueur et a par conséquent perdu la plus grande partie de son fùt susceptible de variation.

Une autre molaire inférieure (Pl. IX. fig. 2), probablement une $2^{e}$, a été trouvée dans un autre gisement près d'Alger avec une phalange incontestablement du buffle antique; elle présente les mêmes caractères généraux que la précédente; mais elle est bien moins usée à sa couronne et a une autre physionomie. Les lacunes en croissant de cette couronne n'ont pas encore pris leur forme de 8 .et l'épaisseur de la dent est bien moins grande, comme dans les germes: La colonnette interlobaire a encore sa pointe bien au dessous du plan de détrition. Le lobe antérieur de la muraille interne produit une sorte d'aile débordante sur la gouttiẻre formant la terminaison de l'arête correspondante. La lame externe postérieure s'étale en arriẻre pour former une autre aile débordante en lobule à la couronne. Ce n'est en somme qu'une exágération de ce qui existe dans les germes des dents des bœufs ordinaires, oủ il n'en restera rien après une certaine usure par détrition. Dans la dent fossile, au contraire, les arêtes et sillons persisteront. Toutefois le sillon marginal postérieur de la face interne restera un peu plus large que dans la précédente et le postérieur du lobe antérieur plus étroit et plus atténué, un peu moins prolongé vers la base. L'arête qui le limite; plus prolongée au contraire, restera plus nettement isolée de la gouttière par un pli rentrant. Cette dent est donc sur le même type que la précédente et appartient à peu près certainement au buffle antique. 
MENSURATION

fro aт.-mol. 2yo ar.-mol.

Hauteur du fùt de la dent........

$45^{\mathrm{mm}} \quad 65^{\mathrm{mm}}$

Largeur au milieu du fùt........ 30 à $32 \quad 33$ à 35

Epaisseur vers la base du fùt..... 15 à $18 \quad 14$ à 20

On a figuré mème planche IX, pour la comparaison et de grandeur naturelle, trois autres arrière-molaires supérieures de bovidés.

Fig. 4 provient du terrain pliocène du Coupet, près de Langeac, et a peut-être appartenu à une espèce d'antilope boodonte; les rudiments d'arêtes de chaque côté de la fosse interlobaire sont bien marqués quoique moins forts.

Fig. 3 provient d'un gisement néolithique de l'Oued Kniss, près d'Alger. Il n'a qu'un rudiment de l'antérieure de ces mêmes arêtes et la détrition ne tardera pas à le faire disparaître; c'est la conformation des bœufs actuels.

Fig. 2 provient d'un gisement mésolithique silué à Aboukir et présente moins de différence avec le buffle antique. Mais la fosse interlobaire est moins large et les arêtes, qui la bordent, moins détachées de la côte médiane de chaque pilier ; la réduction et même l'atrophie de la colonnette interlobaire externe indiquent peut-être un type plus éloigné des vrais bos. Il en sera de nouveau question dans une autre monographie.

\section{LE RACHIS}

Pl. I, fig. 4 à 6 . Pl. II, fig. 6 à 8 . Pl. III, fig. 1 ì $r$.

Les vertèbres cervicales ne nous sont qu'en partie connues, trois sur sept: l'atlas, l'axis et la cinquième ou sixième cervicale. L'atlas (Pl. I, fig. 4-5-6) présente à sa partie antérieure la contre-partie des 
condyles occipitaux; l'arc neural est médiocrement développé et forme en dessus une simple bosse étalée pour toute apophyse épineuse. Le bord antéro-supérieur est émarginé en arc très ouvert ; l'inférieur est beaucoup plus échancré, formant de chaque côté un angle qui accentue la profondeur du sinus, pour recevoir le col du basilaire. Les facettes articulaires pour les condyles descendent en s'arrondissant dans le sinus et se rapprochent derrière le fond de l'échancrure sans cependant arriver à confluer. L'arc neural inférieur porte à l'arrière un gros mamelon rugueux.

La face postérieure porte en bas une facette semi-circulaire dont les côtés s'élargissent en s'arrondissant el s'inclinent un peu en dehors, pour l'articulation avec l'axis. Des apophyses transverses en lames naissent presque à la hauteur du bord condylien et s'élargissant en ailes qui descendent au delà de la facette pour l'axis, donnant à l'ensemble la forme d'un trapèze régulier, émarginé en croissant à son côté postérieur, qui est le plus grand. Ces ailes présentent contre le corps de l'os du côté supérieur une fosse profonde percée de trous vasculaires, dont deux s'ouvrent près l'un de l'autre dans le canal médullaire sous la facette condylienne, tandis qu'un troisième traverse sur la face supérieure, puis rentre dans la paroi pour s'ouvrir à l'intérieur de l'arc. La face supérieure de la lame apophysaire est formée d'un simple mẹplat et sa marge postérieure est épaissie.

MENSLRATION

Diamètre vertical de l'articulation condylienne ...... $0,055^{\mathrm{nm}}$

Diamètre vertical comprenant les deux tubercules ..... 0,105

Diamètre transversal de l'articulation condylienne ..... 0,120

Plus courte longueur de la face inférieure......... 0,050

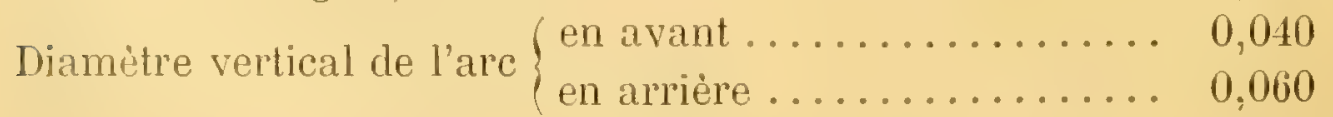

Largeur du canal médullaire.............. 0,045 
Distance des angles antérieurs des apophyses transverses. $0,190^{\mathrm{mm}}$ - postérieurs _ $\quad 0,250$ Longueur de l'aile apophysaire ............. 0,115 Saillie de l'aile au delà de la facette articulaire...... 0,065

L'axis (Pl. II, fig. 5, 6, 7) présente à sa face antérieure la plateforme articulaire en demi-cercle sur laquelle s'appuie l'atlas, resserrée du côté du canal médullaire par une épaisse et haute apophyse odontoïde qui sert de pivot à l'atlas. Cette partie appartient au corps de la vertébre qui se termine en arrière par une facette concave et profonde en forme d'ellipse tronquée par le canal médullaire pour recevoir la tête du corps vertébral suivant. Derrière cette plateforme à bord anguleux très saillant le corps de l'os est fortement contracté et il s'en détache trois arêtes divergentes dont la médiane forme une carène obtuse sous le milieu du corps et dont les latérales vont se transformer au bord en apophyses transverses triquètres, courtes et robustes, descendant par leur bord postérieur presque jusqu'au bord de la facette concave.

Entre la carẻne médiane inférieure et les arêtes règnent deux dépressions triangulaires avec rugosités ; à. la base antérieure de l'apophyse transverse, et du côté supérieur, s'ouvre le trou cervical qui vient du dedans à la base de l'apophyse odontoïde; puis extérieurement il replonge dans l'os pour sortir, très réduit en calibre, latéralement près de la facette postérieure. L'are neural porte en dessus une apophyse épineuse en forme d'épaisse lame trapézoïdale, épaissie encore à son bord supérieur qui se relève en arrière. Son angle antérieur surplombe notablement le canal rachidien; le bord postérieur projette en arrière et en dehors deux apophyses, ovalaires comprimés portant en dessous une facette ovale pour l'articulation avec la vertèbre suivante : 
MENSURA'ION

Longueur du corps de la vertèbre.............. 0,095 avec l'apophyse odontoïde $\quad 0,120$

Longueur de l'are neural entre les sinus de sa base.... 0,070

Distance du sinus antérieur au bout de la facette postérieure 0,100 Plus grande étendue transverse de la facette pour l'atlas. o 0,120

de J'apophyse odontoïde. . 0,055

Plus grande largeur verticale de la facette pour l'átlas... 0,045

Plus petit diamètre du corps vertébral .......... 0,080

Diamètre transversal de la cavité articulaire........ 0,055

- vertical $\quad-\quad \ldots \ldots \ldots, 0,055$

- tranversal du canal médullaire........... 0,035

Hauteur du canal médullaire............... 0,028

Distance des extrémités des apophyses transverses..... 0,165

Hauteur au dessus du trou médullaire du bord antérieur de l'épine........................... 0,035

Hauteur au dessus du trou médullaire du bord postérieur de l'épine.............................. 0,075

Longueur de la crète de l'apophyse épineuse........ 0,100

Distance du bord extérieur des apophyses articulaires ... 0;095

Hauteur de la facette au dessus de l'apophyse transverse. o, 0,060

Les autres cervicales (Pl. III, fig. 1-2-3-4) ne sont connues que par une seule qui peut être une $5^{\circ}$ ou une $6^{\circ}$; elle est un peu petite pour le sujet décrit et doit appartenir à un autre trouvé dans le même lieu. Son corps est assez court et oblique, terminé en avant en une très forte convexilé ovalaire tronquée du côté du canal médullaire; en arrière il porte une forte concavité elliptique pour la tête de la vertẻbre suivante. Ce corps vertébral porte sept apophyses: l'arc vertébral en compte trois, une épineuse de médiocre saillie, de forme triangulaire très obtuse; deux articulaires en lames transverses sub- 
horizontales et portant en avant et de còté des facettes ovales placées à la face supérieure et en arrière des facettes inférieures prolongées en forme de violon jusque près de la base de l'axe neural. Le corps vertébral présente au niveau du plancher inférieur du canal médullaire deux apophyses transverses, courtes tréquètres, portant à leur base un large trou cervical arrondi et court; deux autres apophyses descendantes se détachent au dessous de ce trou cervical et de la face inférieure du corps vertébral en forme de lames aplanies mais épaisses, en fer de hache et divergentes du côté infẻrieur.

\section{MENSURATION}

Longueur du corps vertébral en dessus avec la tête articu-

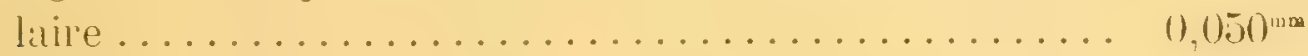

Longueur du corps vertébral en dessous avec la tête articulate ...................... 0,085

Hautrur de la cavité articulaire.............. 0,055

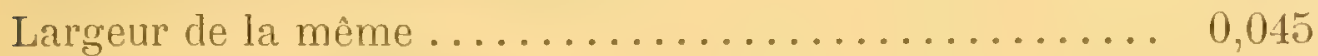

Hauteur du trou médullaire .................. 0,030

Largen au milieu du trou médullaire. . . . . . . . . . . 0,030

Distance longitudinale des facettes articulaires........ 0,080

- transversale des bords extérieurs des apophyses arliculaires ......................... 0,100

Longueur de l'alpophyse transverst. . . . . . . . . . . . 0,040

Plus petite longueur de lare nemial ru dessus . . . . . . . 0,050

Longueur de l'apophyse descendante au bord antérieur . . 0,050) au bord postérieur... 0,040

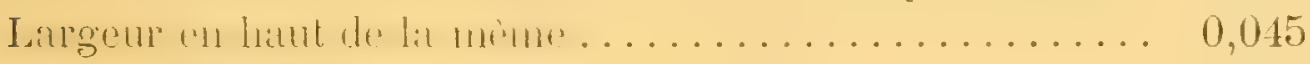

- en has...................... 0,065

Distance transverse en dehor's des angles antérieurs..... 0,090

postérieurs.... (0,080

Hauteur de l'apophyse épineuse (restaurée)......... 0,050 
Hauteur de la tête articulaire antérieure......... $0,04.5^{\text {num }}$

Largeur de la même sous le canal médullaire ....... 0,030

Plus grande saillie de la même.............. 0,025

Les vertèbres dorsales (PI. III, fig. 5) sont en série incomplète par absence des quatre premières: elles sont certainement au nombre de treize, comme dans les buffles vivants connus, ainsi qu'en témoigne la série complète des côtes qui seront décrites dans un paragraphe suivant. Ces vertèbres articulées entr'el'es forment une série légèrement concave en dessous. En dessus les apophyses épineuses, presque contiguës, se dressent comme une muraille continue, mais s'abaissant ver's l'arrière. La cinquième dorsale doit commencer la série de celles dont les apophyses épineuses se dégradent en arrière. Le corps est nettement caréné en dessous par une crète peu saillante. La facette articulaire postérieure est très peu concave (flèche de $8^{\mathrm{mm}}$ ), ronde, un peu en losange; l'antérieure est convexe dans les mêmes proportions (c'est-à-dire très peu), de forme subarrondie en écusson. Son bord supérieur latéral est émarginé par la dépression que produit une facette articulaire concave de forme ovalaire pour une partie de la tête supérieure de la côte: cette côte dont la surface articulaire supérieure est presque didỵme appuie son autre partie sur une facette concave ovalaire regardant en arrière, qui repose en partie sur le bord du corps vertébral de la vertèbre suivante et en majeure partie sur la base antérieure de son apophyse transverse.

Cette dernière est robuste, peu saillante en dehors et juste assez pour porter du côté extérieur une facette un peu en ginglyme, assez grande, regardant en avant et un peu en bas pour recevoir une autre facette de côte. Au côté antérieur, elle forme une saillie·épaisse en avant, touchant aux facettes de l'arc neural, de forme irrégulièrement triquètre, tronquée presque au niveau extérieur de sa facette propre. Le canal médullaire est un peu déprimé; en arrière il se 
prolonge en quelque sorte dans deux facettes, presque contiguës suboblongues, qui forment la base postérieure de l'apophyse épineuse. Les facettes correspondantes du côté antérieur s'agencent par embrication sous les postérieures de la précédente vertẻbre, en formant une lame amincie et débordant faiblement en avant l'entrée du trou médullaire.

L'apophyse épineuse est une longue lame presque d'égale largeur, assez comprimée, un peu arquée pour augmenter sa flexion en arrière, qui est de $35^{\circ}$ avec le rachis. Sa surface est pourvue de rugosités irréguliẻres et éparses et son sommet, un peu épaissi el tronqué obliquement en pied de biche, se fait remarquer par de plus fortes rugosités d'insertion tendineuses. A son origine s'ouvre un trou vasculaire qui vient du canal à travers la base de l'apophyse transverse du côté postérieur; cetle ouverture est simple ou double, sans régularité.

\section{MENSURATION}

Longueur du corps vertébral au bord inférieul ...... $0,070^{\mathrm{mm}}$

Largeur du corps vertébral en avant............ 0,058

en arrière............ 0,060

Hauteur du corps vertébral en avant et en arrière...... 0,060

Largeur antérieure du canal médullaire........... 0,025

Hauteur du canal médullaire. . . . . . . . . . . . . 1),090

Distance d'un bord extérieur à l'autre des facettes neurales antérieures........................ 0,047

Distance d'un bord extérieur à l'autre rles facettes neurales postérieures..................... 0,045

Longueur antéro-postérieure de l'apophyse transveise. . . 0,045

Saillie du bord antérieur de l'apophyse transverse . . . . 0,030 postérieur de la même........... 0,025

Plus grande épaisseur de lapophyse transverse....... 0,020 
Largeur inférieure de la même $\ldots \ldots \ldots \ldots \ldots \ldots \ldots, 0,045^{\mathrm{mm}}$

Longueur de l'apophyse épineuse ............. 0,280

Largeur de sa partie inférieure ............... 0,045

- de sa partie supérieure .............. 0,050

Epaísseur de son extrémité ............... 0,030

Plus petite épaisseur au milieu.............. 0,015

Les vertèbres qui suivent, $6^{\circ}, \tau^{\circ}, 8^{\circ}, 9^{\circ}, 10^{\circ}, 11^{\circ}, 12^{\circ}$, ne présentent aucune différence essentielle avec la $5^{\circ}$, si ce n'est dans quelques détails de proportion entre les facettes articulaires, soit pour les côtes, soit pour les ares vertébraux, et dans le raccourcissement notable des apophyses épineuses à partir de la septième jusqu'à la treizième qui est la plus courte et n'a plus que $80^{\mathrm{mm}}$ de longueur, en même temps qu'elle se redresse de manière à avoir son bord postẻrieur presque vertical. Mais cette dernière vertèbre, faisant transition ver's les lombaires, présente quelques particularités à signaler.

Le corps de la vertẻbre est sensiblement plus court, 65 au lieu de $70^{\mathrm{nm}}$; la facette articulaire tend à devenir un peu plus transverse et la carène inférieure est bien plus obtuse. La facette costale de la partie antérieure externe du corps est beaucoup moins étendue et celle de l'apophyse transverse est très réduite et paraît avoir un tissu moins dense que les autres facettes; elle termine la branche postérieure de l'apophyse transverse qui est plus détachée. D'un côté de l'articulation vertébrale postérieure est encore une très petite facette latérale, qui indique la présence d'une côte rudimentaire; elle est limitée à la marge du corps vertébral et n'est qu'à peine représentée sur le côté opposé de la vertèbre: ce n'est sans doute qu'une anomalie.

Le lobe antérieur de l'apophyse transverse est très détaché du postérieur et semble refouler la facette neurale contiguë de manière à en relever le bord et à la rendre concave, indiquant un épaississement 
de la facette correspondante de la $12^{\circ}$ vertèbre. Les facettes neurales postérieures sont complètement transformées; elles ont passé du dessous de l'auvent formé par l'arc au dessous de l'épine et se sont portées sur le côté en se pliant en une convexité cylindroïde inférieure et une concavité supérieure en canal, qui doivent s'encastrer, comme en forme de mortaise, dans les facettes à contre-partie de la première dorsale. Un assez grand trou s'ouvre dans le pied de l'arc neural près de son bord postérieur: l'apophyse épineuse a son bord antérieur arqué par l'obliquité de sa partie inférieure et par le redressement de sa partie supérieure pour marquer la disposition de cette partie dans les lombaires qui suivent. Cette vertèbre peut être absolument caractérisée comme une ambiguë entre les séries dorsale et lombaire.

MENSURA'TION

Longueur de l'apophyse épineuse de la $5 \ldots \ldots \ldots \ldots 0,270^{\mathrm{mm}}$

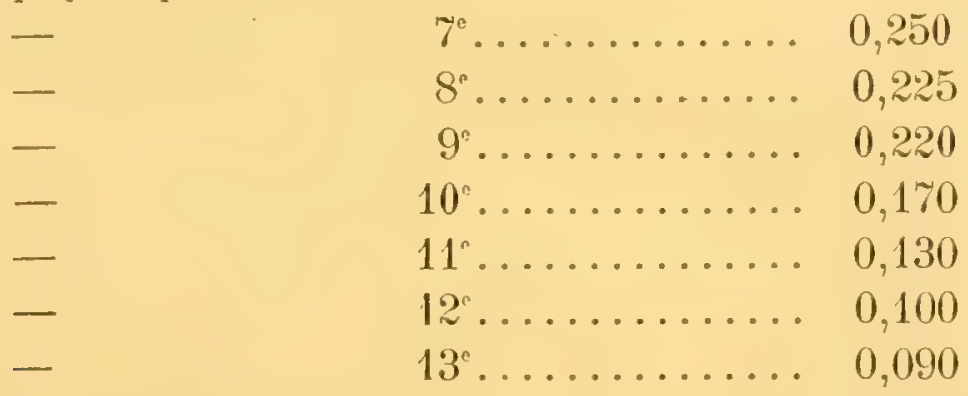

Longueur du corps de la $13^{c}$ vertẻbre............ 0,060

Hauteur du corps vertébral en avant............ 0,055

Largeur $\quad-\quad \ldots \ldots \ldots \ldots \ldots . .6,060$

Plus grande distance des bouts des apophyses transverses 0,135

Largeur de l'apophyse épineuse à sa base......... 0,047 y compris l'apopinyse articulaire... 0,075

Plus petite largeur de l'apophyse............. 0,040

Longueur du sommet................... $\left.0,0, x^{1}\right)$

Son épaisseur....................... $0,(1) 20$ 
Hauteur de l'apophyse au bord antérieur.......... $0,100^{\operatorname{mar}}$

au bord postérieur........... 0,070

Saillie en arrière des facettes neurales.......... 0,030

Les lombaires (PI. III, fig. 6-7), au nombre de six, forment une série très homogène à peu prẻs rectiligne dont les apophyses épineuses sont en forme de larges lames un peu obliquement tronquées au sommet avec l'angle antérieur légèrement infléchi en avant. Elles ont à peu près la même hauteur, mais pas la mème largeur. Ce sont les $3^{e}, 4^{e}$ et $5^{e}$ qui sont les plus larges. La dernière est plus oblique en avant et plus séparée des autres. Les facettes articulaires antérieures sont relevées en crampon sur leur apophyse et de telle sorte qu'on ne peut rapprocher les vertèbres qu'en les introduisant en forme de tiroir ou à coulisse, et elles sont si serrées que les six vertèbres, une fois réunies, restent én place en prenant la série par chaque bout. Les facettes antérieures regardent en haut et en dedans tandis que les postérieures regardent en bas et en dehors.

Les apophyses transverses sont très inégales et par leur ensemble forment avec le sacrum une longue ellipse. Celles de la premiẻre lombaire sont étalées en croix, droites, en lame tronquée au bout. Celles de la seconde sont un peu plus larges, plus longues, d'abord droites, puis plus ou moins coudées vers le milieu, la partie extérieure s'amincissant et s'élargissant en angle récurrent qui peut arriver à toucher le bout extérieur de l'apophyse de la première; il en rẻsulte une boucle ovalaire presque fermée. La troisième lombaire a ses apophyses en croix à bords antérieurs presque droits, les postérieur's un peu convexes, de manière à rétrécir le bout qui est plus ou moins tronqué et dépasse celui de la vertèbre précédente. La quatriẻme a ses apophyses encore plus allongées, atténuées et bien plus étroites, surtout au bout, arquées avec l'extrémité dirigée un peu en avant. La cinquième est plus étroite encore, arquée, à concavité anté- 
rieure, dépassant en longueur la précédente, mais pourvue en avant prẻs de l'extrẻmité d'une pointe récurrente, crochue, qui rappelle celle de la deuxième lombaire. La sixième est encore plus étroite, même à sa base, toujours très mince, falciforme, tronquée au bout: en général, la minceur du bord n'a pas permis une parfaite conservation et il n'est pas impossible que toutes ces apophyses ne se soient terminées avant leur extrémité par un crochet récurrent, comme les seconde et cinquième, pour relier toute la série par de courts ligaments en un plateau ainsi fortement consolidé, dont les bords se continuaient avec ceux du sacum. Le corps des vertèbres s'épaissit sensiblement vers l'arrière de la série; la carène inférieure est de moins en moins marquée, très obtuse et à la fin presque effacée.

MENSURATION

$1^{\text {re }}$ Lombaire :

Largeur de l'apophyse épineuse au milieu......... $0,045^{\text {man }}$

Apophyse transverse, largeur à la base.......... 0,040

- $\quad$ - au milieu............ 0,035

- au bout............... 0,025

- $\quad$ longueur................. 0,060

2 Lombaire :

Largeur à sa base de l'apophyse transverse......... 0,050

— au milieu........................ 0,040

- avec la pointr récurrente............. 0,075

— à l'extrémité .................... (0,030

Longueur. . . . . . . . . . . . . . . . . . . . . . 0, 0,110

Apophyse épineuse, largeur au milieu ............ 0,050

$3^{\circ}$ Lombaire :

Longueur du corps vertébral en dessous ............ 0,070

Hauteur de la face articulaire antérieure.......... 0,052 
Largeur de la mème face .................... $0,060^{\text {mm }}$

Hauteur de la face articulaire postérieure ........ 0,055

Largeur de la mème face................ 0,065

Distance des extrémités des apophyses articulaires neurales

du même côté ...................... 0,120

Largeur de l'apophyse épineuse au milieu......... 0,065

au sommet......... 0,070

Hauteur de l'apophyse épineuse devant......... 0,065

derrière........... 0,045

Distance des saillies apophysaires neurales antérieures... 0,087

- des bords de leurs facettes articulaires....... 0,045

A pophyse transverse, largeur à la base.......... 0,050

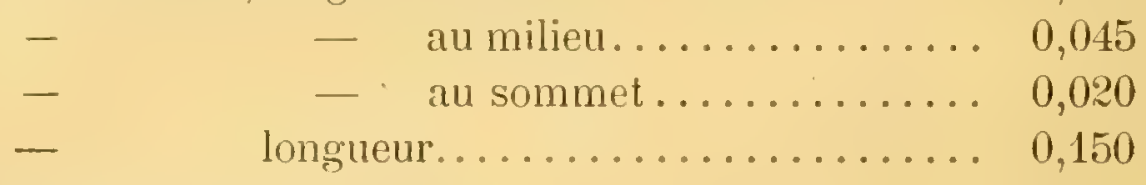

4 Lombaire :

Largeur au milieu de l'apophyse épineuse........ 0,060

Apophyse transverse, largeur à la base........... 0,050

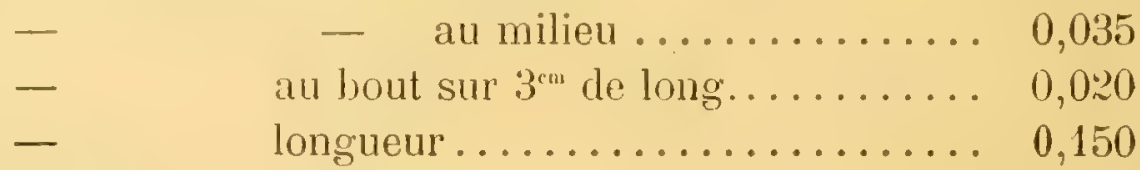

5 Lombaire :

Longueur du corps vertébral .............. 0,070

Hauteur de la face antérieure................ 0,055

Largeur $\quad-\quad \ldots \ldots \ldots \ldots \ldots \ldots \ldots \ldots \ldots \ldots, 0,063$

Hauteur de sa face postérieure............... 0,050

Largeur $\quad-\quad \ldots \ldots \ldots \ldots \ldots \ldots \ldots \ldots .6,075$

Largeur à la base de l'apophyse transverse ........ 0,035

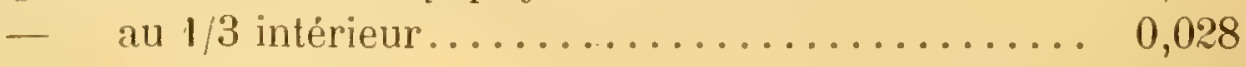

- au $1 / 3$ extérieur ................... 0,018 
Largeur avec le crochel récurrent............ 0,040.m

- à l'extrémité ................... 0,015

Longueur de la même................. 0,170

Largeur au milieu de l'apophyse épineuse......... 0,060

$6^{\mathrm{e}}$ Lombaire :

Longueur du corps vertébral............... 0,070

Hauteur de la face articulaire antérieure......... 0,055

Largeur de la même....................... 0,070

Hauteur de la face articulaire postérieure ......... 0,045

Largeur de la mème.................... 0,090

Largeur à la base de l'apophyse transverse........ 0,040

- a a $3^{\mathrm{cm}}$ de la base de l'apophyse transverse..... 0,030

- au milieu $\quad$ - $\quad \ldots \ldots 0,020$

à l'extrémité $\quad$ - $\quad \ldots \ldots .0,015$

Longueur de l'apophyse trinsverse............. 0,150

Largeur au milieu de l'apophyse épineuse......... 0,050

Le sacrum (Pl. III, fig. 6-7. Pl. VI, fig. 1-2) est constitué par cinq vertèbres soudées entr'elles en une masse pyramidale destinée ả supporter l'iléon en lui donnant une assez grande surface d'adhérence. Ce sont les deux premières vertẻbres qui donnent cette surface par un large et saillant empâtement de leurs apophyses transverses; cet empàtement se continue au delà, sur les apophyses équivalentes des troisième, quatrième et cinquième vertèbres en s'atténuant de plus en plus cornme saillie et épaisseur de manière à se terminer avec le corps de la dernière vertèbre sacrée en une sorte d'auvent au dessus du détroit du bassin.

L'apophyse antérieure, celle de la première vertẻbre sacrée, se détache du bord antérieur du corps vertébral et de l'apophyse articulaire de l'arc neural par un gros trone d'apparence cunéiforme en avant, puis étalé et aminci en dehors en une sorte daile. La seconde 
vertẻbre se comporte de même en donnant origine à un deuxième tronc beaucoup moins épais et moins saillant, distinct à la base mais* soudé bientôt en un empàtement général, à surf̣ace subplane, de forme quadrilatẻre en trapẻze irrégulier, regardant un peu obliquement en arrière et en haut en laissant un sillon au pied des apophyses épineuses. Cet empâtement se prolonge même en arrière comprenant les apophyses transverses des $3^{\circ}, 4^{\circ}, 5^{\circ}$ vertèbres sacrées, mais avec une épaisseur très réduite et comme un simple parement de muraille appliqué contre l'axe vertébral et ne donnant aucune surface d'adhérence au bassin. Il s'atténue en carène latérale débordant la face inférieure des corps des vertébres et s'amincit encore vers la dernière vertèbre sacrée en deux ailes un peu divergentes en arrière, à extrẻmité tronquée, portant dans son émarginure la face postérieure du corps de la dernière vertèbre, très réduit en dimension.

La face inférieure du sacrum est concave dans les deux sens transverse et longitudinal, surtout par suite de l'inflexion de la masse apophysaire transverse; et de l'arcure très évidente des corps vertébraux. Ceux-ci sont à peine convexes en travers et leur suture assez évidente va se perdre dans une fosse de plus en plus étendue et profonde qu'elle est plus antérieure. Ces fosses correspondant aux espaces intervertébraux des apophyses transverses, se divisent plus ou moins en trous ou cinaux pour le passage des faisceaux vasculaires ou nerveux; la derniẹre paire est peu profonde et très développée.

La face antérieure du sacrum montre un canal médullaire trigone, assez grand, se rétrécissant en arrière au point de ne plus former à l'extrémité qu'une lacune en croissant, du reste en proportion de la réduction du corps vertébral qui la porte. L'apophyse articulaire de l'arc est épaissie notablement et ses facettes, tout en s'amplifiant, se simplifient en un simple demi-cylindre glénoïde, formant cul-de-sac à son extrémité. Les apophyses épineuses sont toutes soudées entre elles en une forte lame en muraille homogène et continue et leur 
sommet s'épaississant forme un gros bourrelet, surtout épaissi sur la dernière et plus encore sur la pénultirme, tandis qu'il est à peine marcqué sur la première.

Celle-ci est en effet encore pr'esque dégagée de l'empàtement qui envahit les suivantes, elle différe peu de la dernière dorsale; mais elle est un peu plus étroite el n'a pas de tendance à s'infléchir en avant; il n'y a que l'angle postérieur de son sommet qui soit envahi par l'empàtement; la soudure avec la seconde est mince et bien marquée par un sillon. La seconde apophyse épineuse est beaucoup large dès la base el elle s'élargit encore vers le haut en fer de hache. La troisième est presque aussi large à sa naissance, mais elle ne s'élargit pas vers le haut comme la précédente. La quatrième n'est guẻre plus large que la première et elle est plus courte, s'inclinant un peu en arrière. La cinquième est encore plus courte et un peu plus inclinée; ces trois vertẻbres sont en arrière de l'épatement d'adhérence au bassin.

Aucune des vertibres coxygiennes n'est connue. Elles devaient être bien réduites.

\section{MENSUKATION}

Longueur du sacrum. .................. 0,260

Hauteur de la facette du premier corps vertébral. . . . . . 0,040

Longueur de la même................... . 0,080

Hauteur du canal médullaire................. 0,030

Longueur du premier corps vertébral mesurée dessous . . 0 0,060

- du deuxiẻme $\quad$ _ n $\quad \ldots \quad \ldots 0,060$

- du troisième $\quad$ - _ _ _ $\quad \ldots 0,050$

- du quatrième _ _ _ _ _ . $\quad \ldots 0,045$

- du cinquième _ _ _ _ _ _ $\quad \ldots, 045$

Hauteur du corps de la cinquième lombaire . . . . . . . . 0,034

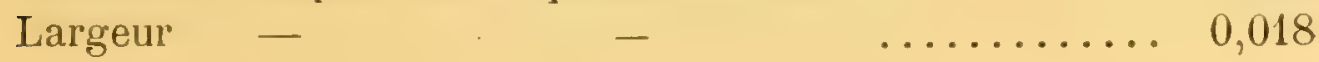


Hauteur du canal médullaire de la même ......... 0,008

Largeur — $\quad \ldots \ldots \ldots \ldots \ldots, 0,032$

Distance du bout du sacrum à l'extrémité de l'iléon...... 0,270

Distance des extrémités supérieures des lobes apophysaires 0,300

- des angles inférieurs de l'épatement d'adhérence. 0,200

Epaisseur verticale de la face antérieure de l'apophyse épineuse .......................... 0,110

Distance des bords extérieurs des facettes glénoïdes.... 0,075

Distance des trous rachidiens sous le sacrum, $1^{\text {re }}$ paire... 0,065

$\therefore$ paire... 0,055

$3^{\text {e }}$ paire... 0,040

$4^{\text {e }}$ paire.... 0,035

Plus petite largeur du sacrum au niveau de la $3^{\text {e }}$ paire... 0,090

Largeur du bord postérieur du sacrum........... 0,120

Largeur de la première apophyse épineuse......... 0,040

Hauteur de la mème ................... 0,060

Largeur de la seconde.................. 0,070

Hauteur de la même ........................... 0,070

Largeur de la troisième.................. 0,050

Hauteur de la même ..................... 0,065

Epaisseur au sommet.................... 0,050

Largeur de la quatrième................... 0,035

Hauteur de la même................... 0,040

Largeur de la cinquième................. 0,020

Hauteur de la même................... 0,030

\section{LES COTES}

Pl. IV, fig. 3.

Nous possédons toutes les côtes plus ou moins complètes d'un côté de notre sujet principal et celles qui sont incomplètes sont représentées, soit par leur correspondante du côté opposé, soit par celles d'un 
autre sujet un peu plus grand, provenant du même gisement. A l'aide des vertëbres connues, nous avons pu en rélablir la série et les figures à peu près dans leur position relative sur le squelette. Leur nombre est de treize; elles ont toutes deux apophyses articulaires, sauf la dernière qui n'a que la terminale bien développée. Les apophyses ne présentent pas de grandes différences entr'elles ; leurs facettes se modifient faiblement de l'une à l'autre côte, soit dans leur étendue, soit dans leur surface ondulée. La tète s'articule en même temps sur le bord contigu de deux corps vertébraux et l'apophyse qui vient en dehors s'appuie sur une facette de l'apophyse transverse de la vertèbre suivante.

La première côte est presque cylindrique, à peu près droite, un peu épaissie en massue à son extrémité ; le col est très court et l'apophyse extérieure le surmonte. La seconde lui ressemble beaucoup; mais elle est un peu aplatie, légèrement incurvée avec convexité antérieure et elle est notablement plus longue. La troisième est encore un peu plus longue; elle est plus aplatie en longue spatule plus arquée, à convexité antérieure et commence à se cintrer. La quatriẻme et la cinquième sont incomplètes à leur partie inférieure; elles paraissent peu différer par leur partie supérieure; mais vers leur milieu elles sont très sensiblement plus élargies; à en juger par une autre côte de mème numéro, elles devaient, surtout la cinquième, se rétrécir un peu à l'extrémité assez largement tronquée; l'arqure et le cintrage sont un peu plus marqués. Il commence à s'y produire un léger coude un peu en deliors de l'articulation et en haut du dos et la côte s'épaissit en ce point, avec un méplat latéral plus large en arrière qu'en avant.

La sixieme a son col plus dégagé, plus courbe; elle est encore assez étroite, à section quadrangulaire vers le haut, élargie et aplatie vers le $1 / 3$ supérieur, puis un peu rétrécie et épaissie au $1 / 3$ inféricur; elle est nettement tronquée à l'attache du cartilage. La 
septième est aussi coudée, mais un peu plus fortement et un peu plus loin du sommet. Elle est plus épaisse avec méplats ou gouttières sur les còtés, plus marqués, puis elle s'aplatit et s'élargit dans son milieu pour faire comme la précédente par une atténuation en largeur, un épaississement dans le sens contraire et une troncature très nette au bout. Le col s'allonge un peu en se redressant et la tête arrivant à hauteur du lubercule portant les facettes pour l'apophyse transverse, finira par la dominer dans les suivantes. La précédente côte avait vers son milieu son bord convexe en avant et son bout un peu déjeté en arrière. Ce mouvement des bords est à peine marqué dans celles-ci.

Les huitiẻme et neuvième se ressemblent beaucoup; la partie supérieure est fortement courbée, saus coude; le col s'allonge et devient de plus en plus oblique en avant. Leur épaisseur en haut est moindre, mais les bords sont encore tronqués. Vers la moitié supérieure elles s'élargissent notablement et plus que dans le reste de la série; puis elles se resserrent à peine et sont peu épaissies à la troncature. Le cintrage est à son maximum ou presque. La dixième n'en diffère que parce qu'elle est un peu moins élargie, ayant ses bords presque parallèles dans les $2 / 3$ de sa partie inférieure; elle est arquée de manière à pousser son extrémité inférieure en avant, comme les deux précédentes; c'est la plus longue et la plus cintrée.

Les deux suivantes se ressemblent assez et avec la précédente; elles sont de plus en plus courtes, mais pas beaucoup plus; un peu élargies sur une grande partie de leur milieu, elles s'atténuent sensiblement près du bout. Le col prend de plus en plus l'arqure de la còte dont le tubercule antérieur s'efface de plus en plus. La treizième n'a que l'articulation pour le corps vertébral bien développé ; le tubercule articulaire pour l'apophyse transverse est très effacé et sa facette très réduite et tout à fait sessile; elle est notablement plus courte, médiocrement cintrée. Sa partie supérieure peu arquée s'élar- 
gil insensiblement ver's le bas et ses bords restent parallèles dans une assez grande longueur.

Le sternum n'est connu que par deux tronçons; l'un de l'extrémité antérieure correspondant aux deux premières côtes. Il est très robuste, un peu en forme de pique de carte dont la pointe très épaisse devait être remontante. Un autre est de la partie médiane du sternum et assez fruste en plaque quadrangulaire assez épaisse.

\section{MENSURATION}

$1^{\text {rc }}$ Gôte. Loñgueur, tête articulaire non comprise..... $0,310^{\mathrm{mm}}$

Largeur au milieu ................ 0,03ð

Largeur de l'extrémité sternale.......... 0,050

Saillie interne de la tête articulaire........ 0,040

$2^{e}$ Côte. Longueur sous la tête articulaire........... 0,410

Largeur au milieu ................. 0,045

- en bas.................. 0,040

$3^{\complement}$ Côte. Longueur sous la tête articulaire.......... 0,470

Largeur au $1 / 3$ supérieur . . . . . . . . . . 0,040

- au $1 / 3$ inférieul ............. 0,050

4 Còte. Longueur?

Largeur au $1 / 3$ supérieur ............ 0,050

$5^{\circ}$ Gôte. Longueur?

Largeur au $1 / 3$ supérieur . . . . . . . . . . 0,050

(i" Côte. Longueur. . . . . . . . . . . . . . . . . . . . . 0,580

Largeur au $1 / 3$ supérieur . . . . . . . . . . . 0,050

- inférieur............. 0,060

- au bout sternal ........... 0,050

千 Còte. Longueur.......................... 0,630

Largeur au $1 / 3$ supérieur . . . . . . . . . 0,050 
$7^{\mathrm{e}}$ Côte. Largeur au 1,3 inférieur.............. $0,060^{\mathrm{mm}}$

au bout sternal............... 0,060

$8^{e}$ Côte. Longueur sous la tête articulaire.......... 0,670

totale jusqu’à la tête articulaire...... 0,730

Largeur au $1 / 3$ supérieur.............. 0,045

- au $1 / 3$ inférieur................ 0,065

- au bout sternal,............... 0,065

Y Côte. Longueur sous la tête articulaire.......... 0,680

- avec $\quad$ - $\quad \ldots \ldots \ldots \ldots . .6,740$

Largeur au $1 / 3$ supérieur.............. 0,040

- au $1 / 4$ inférieur............... 0,060

- au bout sternal ................ 0,050

$10^{\circ}$ Côte. Longueur jusquiau tubercule extérieur....... 0,650

Largeur totale suivant la courbure......... 0,830

Largeur au $1 / 3$ supérieur ............. 0,040

- au $1 / 3$ inférieur................ 0,050

Largeur au bout sternal ............... 0,055

$11^{\circ}$ Côte. Longueur jusqu'au tubercule interne ....... 0,640

- totale suivant la courbure........ 0,720

Largeur au milieu .................... 0,050

- au bout sternal ............... 0,040

12 Côte. Longueur jusqu'au tubercule externe ....... 0,620

- totale suivant la courbure........ 0,690

Largeur au milieu ................. 0,060

- au bout sternal............... 0,050

$13^{\circ}$ Côte. Longueur jusqu'au tubercule $\ldots \ldots \ldots \ldots \ldots \ldots \quad 0,450$

totale suivant la courbure........ 0,520

Largeur au milieu .................. 0,060

- au bord sternal............... 0,050 


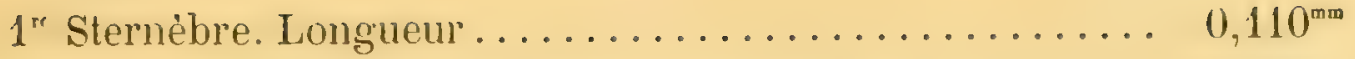

Plus grande largeur en haut.......... 0,075

Plus petite à l'étranglement médian...... 0,050

Epaisseur verticale en arrière ........ 0,060

Longueur de la face articulaire costale ... 0,075

Plus grand intervalle des faces articulaires costales.................. 0,035

Autre sternèbre de rang indéterminé. Longueur...... 0,070

Plus grande largeur transversale ...... 0,100

Plus petite largeur (vers l'étranglement) $\ldots \quad 0,090$

Epaisseur verticale au milieu.......... 0,030

sur les côtés........ 0.040

\section{LE MEMBRE ANTÉRIEUR}

Pl. V.

L'omoplate (PI. V, fig. 1-2), par sa conformation, rappelle celle des bovidés; elle est cependant plus trapue, plus étalée du côté spinal. Sa forme générale triangulaire est plus élargie dans le haut avec un rétrécissement vers le tiers inférieur auquel participent les deux bords. L'acromion forme, à une petite distance de la facette glénoïde, une lame saillante à angle droit, près du bord antérieur, et s'étend en s'éloignant assez de ce bord jusqu'au côté supérieur vers lequel elle s'abaisse progressivement dès le $1 / 3$ supérieur de la longueur pour finir en une simple carène basse. Le coracoïde est en forme de gros tubercule oblique au dessus du bord glénoïdien, en se creusant en dessous du côté interne d'une fossette qui construit une sorte de crochet. La cavité glénoïde est en ovale émarginé à son bord extérieur.

Au dessus de la tubérosité coracoïde les deux bords sont parallèles dans le tiers inférieur ; puis ils divergent, le bord antérieur en res- 
tant mince; le postérieur en se terminant par un bourrelet épaissi én haut saus envoyer aucune récurrence de crête ou de rugosités sur la face inférieure, simplement parsemée de quelques rugosités. Le bord spinal est formé de deux parties rectilignes réunies angulairement au bout de l'acromion, l'antérieure courte, la postérieure longue correspondant aux deux compartiments de la surface extérieure. Le compartiment antérieur est moins étroit que chez les bœufs. Une forte rugosité d'insertion tendineuse existe sur le bord postérieur à l'opposé et un peu au dessus du coracoïde.

MENSLRATION

Longueur du bord antérieur de l'omoplate $\ldots \ldots \ldots \ldots \ldots, 0,475^{\text {inm }}$

$$
\begin{aligned}
& \text { — } \quad \text { - postérieur ................. 0,425 } \\
& \text { - } \quad \text { - supérieur................. } 0,300
\end{aligned}
$$

— de la crête de l'acromion............. 0,400

Saillie de l'acromion à l'origine.............. 0,045

à la partie la plus élevée........ 0,050

Diamètre transverse de la cavité glénoïde.......... . 0,090

antéro-postérieur ............... 0,070

Largeur de la tête inférieure, y compris le coracoïde... . 0,125

- de l'os au tier's inférieur............... 0,100

L'humérus (Pl. Y', fig. 3-4-5-6-7) ressemble beaucoup à celui du bouf; le corps de l'os est beaucoup plus robuste et paraît plus flexueux par suite d'un développement plus grand de la crête deltoïdienne, qui forme un angle très marqué et saillant à peu près à milongueur de l'os. Le bord extérieur de cette partie est parallèle au bord intérieur au lieu de s'effacer insensiblement en descendant de la tubérosité. La carène qui descend de cet angle sur la face antérieure de l'os s'atténue assez vite vers l'articulation, près de laquelle elle s'oblitère. 
La tète supérieure est volumineuse; sa facette articulaire déborde bien en arrière, côté oủ elle s'incline; sa tubérosité externe est allongée d'avant en arrière et forme une assez forte saillie au dessus de la face articulaire; son bout se creuse latéralement en un crochet bien moins proéminent que chez les bœufs, plus ouvert, plus obtus, pour limiter la large coulisse bicipitale. La tubérosité antérieure est épaisse, mais courte ; sa carène bordant la coulisse bicipitale est très accusée et son sommet déborde beaucoup plus que chez les bœufs et dépasse en avant la tubérosité externe. Son prolongement vers l'angle bicipital est très rugueux et porte une sorte de disque presque éburné, pour insertion tendineuse.

La tête inférieure est assez fortement élargie; mais c'est surtout du côté externe; car du côté interne, elle reste dans le prolongement rectiligne du bord interne du corps de l'os. La poulie est formée à partir du côté interne par une portion franchement cylindro-conique, se continuant dans une gorge de poulie assez ouverte, mais bien limitée, qui se prolonge dans la fosse olécranienne. La carène obluse qui la limite extérieurement est très peu évịdée en dehors et prolonge sa déclivité externe dans un condyle conoïde, qui diffẻre notablement de ce qu'il est chez les bœufs. Cette partie est surmontée à l'arrière d'une fosse triangulaire qui se creuse entre la poulie médiane et le bout de la branche externe de la fosse olécranienne. Cette branche est plus robuste que dans l'humérus des bœufs et sa troneature et saillie extérieure ne contribue pas peu à donner du caractère à la forle courbure du côté externe du corps de l'os.

\section{MENSURATION}

Longueur de l'os du côtẻ extérieur ............ $0,390^{\mathrm{mm}}$

du côté intérieur............. 0,350

Du haut de la coulisse bicipitale à la gorge de poulie condylienne......................... 0,310 
Diamètre antéro-postérieur de la tête glénoïdienne ..... 0,110 transverse $\quad \ldots \quad \ldots \ldots 0,100$

Longueur antéro-postérieure de la tubérosité extérieure.. 0 0,120

Distance de cette tubérosité à l'angle deltoïde........ 0,170

Plus grand diamètre antéro-postérieur de la tête supérieure de l'os............................. 0,135

Saillie de la tubérosité en avant de la tête articulaire.... 0,060

Plus grand diamètre transversal de la tête supérieure en arrière ......................... 0,150

Diamėtre transversal des tubérosités supérieures...... 0,110

Profondeur de la coulisse bicipitale............. 0,035

Largeur de la coulisse à son bord supérieur........ 0,050

à sa face antérieure.......... 0,060

Longueur de la coulisse sur la face antérieure....... 0,050

Plus grand diamètre transverse du corps sous les tubérosités ......................... 0,120

Plus petites épaisseur et largeur du corps sous l'angle deltoïdien ........................... 0,070

Etendue transversale de la tête inférieure de l'os...... 0,120 de la poulie articulaire $(5+3+3) \cdot 0,110$

Epaisseur du condyle interne............... 0, 0,120 externe................ 0,080

Hauteur du condyle interne............... 0,070 externe .................. 0,040

Largeur de la tête inférieure du côtẻ postérieur...... 0,110 - de la fosse olécranienne.............. 0,040 Longueur de la fosse olécranienne............ 0,050

Le radius ( $\mathrm{Pl} . \mathrm{V}$, fig. 8-9-10-11-12) est un os trapu, très large, courbé avec sa concavité en arrière : sa face antérieure est assez fortement convexe mais inégalement et ondulée; la face postérieure 
est au contraire aplanie ou même un peu concave. La facette articulaire supérieure est en ligne sensiblement oblique à l'axe de l'os et verse un peu en dedans. Son gynglime est la contrepartie de la poulie de l'humérus: une concavilé du côté intérieur très étendue; un bourrelet en contre-gorge assez étalé ; une gorge assez profonde à fond presque aigu et une concavité terminale peu étendue d'avant en arrière et à bord extérieur traversant en dedans pour la forme conoïde du condyle extérieur. La tête elle-mème de l'os est assez fortement étalée latéralement et élarģie avec de très fortes rugosités pour insertions tendineuses et ligamentaires; une d'elles forme même un disque très remarquable par son aspect spécial et sa grande étendue au sommet interne de sa face antérieure.

La tête inférieure du radius est également dilatée et oblique à l'axe dans le même sens que la supérieure, sa face antérieure est subaplanie entre deux saillies carénées qui n'atteignent pas l'extrémité et ont une direction oblique comme tout le corps de l'os qui se porte nettement en dedans. Le côté interne de l'os est marqué d'une aspérité rugueuse en forme de petite crête descendant des rugosités du sommet pour aller se terminer, après une inflexion, près de la facette du semi-lunaire. La tète articulaire est plus épaisse en dedans qu'en dehors et se contracte en quelque sorte pour porter la série complexe des facettes articulaires, qui est relativement au corps de l'os de dimensions restreintes. La plus grande, celle pour le scaphoïde, puis celle médiane du semi-lunaire se creusent en rigole vers la face antérieure, puis se courbent en arrière en forle convexité qui est en même temps plus ou moins en gorge de poulie. La facette du cunéiforme est en partie constituée par la tête inférieure tout à fait synostosée du cubitus, et forme avec elle une sorte de selle. Cette surface articulaire, très conforme à celle des bœufs, présente cependant des particularités que la description sommaire est impuissante à traduire clairement, mais dont l'iconographie peut donner une idée. 
Le cubitus est presque entièrement soudé au radius et s'insėre sur le bord externe de sa face postérieure, qu'elle déborde même entre les deux têtes articulaires et y forme une sorte de carène triquètre bien plus déclive en dedans et séparée du corps du radius extérieurement par un étroit sillon en forme de demi-canal. Cette carène s'élargit en dehors el se contracte en dedans sur une courte longueur au dessus de la parlie synostosée de la tête inférieure. Au dessus l'adhérence au corps du radius se fait par des engrenages de rugosités, jusqu'à une lacune surmontée par l'épatement de la base de l'olécrane. Celle-ci est de nouveau adhérente de la mème manière et en somme assez légèrement, car il est fréquent dans les gisements ossifères que cette partie se détache avéc tout l'olécrane. Cet épatement couvre plus de la moitié postérieure de la tête radiale, qui le déborde cependant un peu en dehors.

La facette articulaire du cubitus est en portion d'arc de contrepoulie, mais a sa base où elle s'applique très exactement contre le bord du radius par de petites facettes, elle se bilobe inégalement, le lobe interne large et continuant le relief médian de la tête du radius, le lobe externe plus avancé, plus petit, plus détaché, élargissant la poulie pour le condyle externe de l'humérus. L'olécrane proprement dit constitue une apophyse étendue en arrière et en haut en forme de large lame peu épaisse qui se termine par un épaississement terminal en forme de tubérosité allongée dans le sens de la lame et destinée aux insertions tendineuses. En arrière de l'articulation la lame est encore assez large, amincie au bord et va, en se rétrécissant insensiblement à partir de la lacune de soudure, prendre la forme triquètre décrite plus haut. Dans son ensemble le cubitus est bien plus robuste dans le haut que chez les boufs, surtout dans son olécrane plus étalé, plus large, et dans son corps, plus serré contre le radius et bien plus marginal. 
MENSURATION

Longueur interne ou externe du radius........... $0,360^{\text {min }}$

Longueur de la poulie articulaire supérieure........ 0, 0,110

Diamètre transversal de la tête supérieure......... 0,130

Largeur de l'os au milieu.................. 0,080

y compris le cubitus....... 0,090

Epaisseur antéro-postérieure au sommet......... 0,065

$$
\begin{aligned}
& \text { - } \quad \text { au milieu............ } 0.050 \\
& \text { en bas.............. } 0,065
\end{aligned}
$$

Espace transversal occupé par les facettes inférieures (40

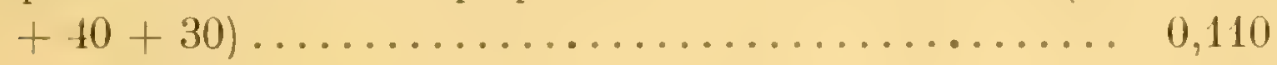

Diamètre transversal de la tête inférieure (cubitus compris) 0,130

Longueur de l'olécrane du bẹ au sommet ......... 0,140

Plus petite épaisseur de la lame olécranienne..........

Longueur de l'olécrane de la facette radiale externe au sommet......................... 0,170

Etendue des facettes de la base de l'olécrane accolées au radius............................ $0,0,0$

Curde de l'arc olécranien ................. 0,045

Largeur de la base olécranienne en arrière de la facette radiale............................. 0,075

Largeur du cubitus pour le versant au dehor's....... 0,015

au dedans......... 0,020

Largeur de sa surface radiale .............. 0,030

Plus grande largeur de l'olécrane............. 0,110

Plus petite largeur $\quad-\quad \ldots \ldots \ldots \ldots \ldots \ldots \ldots \ldots \ldots \ldots \ldots \ldots$

Etendue de la tubérosité terminale ............ 0,090

Son épaisseur....................... 0,055

Le carpe et le métacarpe sont malheureusement bien moins connus que le reste du squelette. On ne possède un peu certainement qu'un 
cunéiforme, figuré par sa face externe $(13, \mathrm{Pl}$. VII $)$ et qui parait avoir appartenu au squelette typique; c'est un os bien difficile à décrire et même à dessiner, en raison de sa complication de facettes, de bosses et d'aspérités, qui ressemble à celui des bocufs, mais avec des détails différentiels que la comparaison immédiate fait seule reconnaître. En somme, la face supérieure présente en dehors une selle profonde descendant sur la face extérieure pour la tête du cubitus et en partie pour la fossette extérieure du radius; une facette oblongue verticale est presque contiguë en arrière pour un pisiforme qui devait être très développé; à la face inférieure est une facette à peine convexe devant un bourrelet qui sert d'appui au prolongement en arlière de cette facette et à la base de la facette du pisiforme. En somme, c'est un os fortement ligamenté.

\section{MEENURATION}

Diamètre antéro-postérieur de l'os au milieu........ 0,045 de la base avec la tubérosité

postérieure......................... 0,050

Hauteur en avant de la selle cubilale........... 0,040

Hauteur de la facette du pisiforme............. 0,032

Largeur $\quad \ldots \ldots \ldots \ldots \ldots \ldots, 0 \ldots \ldots$

Largeur maximum de la facetle pour l'unciforme . . . . . 0,015

Longueur antéro-postérieure ............... 0,045

Il ne serait pas impossible que l'on dût considérer comme ayant appartenu a buffle antique certains débris de métacarpiens remarquables par leurs dimensions et leur forme trapue, qui ont été trouvés dans les grottes d'Oran. Si l'on peut estimer leur dimension, c'est à l'aide de certains détails de forme se reproduisanl sur des tronçons différents; mais ce n'est qu'une approximation que je crois pouvoir 
donner ici à titre de renseignement complémentaire pour aider à les reconnaitre, le cas échéant:

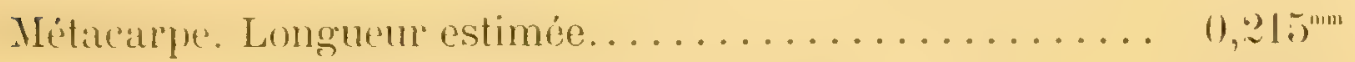

Largeur transverse au sommet......... 0,080

au milieu............. 0,058

¿t la base............. 0,096

Le pied n'est pas mieux représenté: car on ne peut lui attribuer quiune phalange onguéale figurée (19 à 20, Pl. VII) avec beaucoup de doute : car elle ne présente pas avec celles incontestables du pied de derrière des différences assez grandes qu'on ne puisse altribuer à des variations individuelles. Telles: ıne facette articulaire moins développée dans tous les sens, la facette pour le sézamoïde plus étendue, la face inférieure un peu plus large, moins anguleuse en avant; les rugosités el petites tubérosités qui bordent la facette, surtout en haut, bien moins développées. La deuxième phalange, qui à la rigueur pourrait s'artịculer avec la précédente et qui est figurée au dessous, de 14 à $1 \%$ dans la même planche, diffẻre trop peu de ses analogues du pied de derrière. Il y a d'habitude de bien plus grandes disproportions dans les bovidés, et l'on doit attendre de nouvelles découvertes pour des renseignements plus précis sur la structure du pied antérieur du buffle antique.

\section{LE MEMBRE POSTERIEUR}

(I). VI-VII-VIII

Le bassin (Pl. VI, fig. 1-2) est remarquable par l'ampleur de ses dilatations et de ses tubérosités, indiquant une grande puissance musculaire dans l'arrière-train. L'iléon à sa naissance porte une lame élargie et amincie au dessus de sa cavité cotyloïde : puis il forme une branche cylindroïde montante qui ne tarde pas à s'élargir 
brusquement en une grande lame épaisse triangulaire, obliquement transverse, dont un côté semi-circulaire, mince, forme le bord spinal, et fait face obliquement en avant pour donner attache aux deux premières vertẻbres du sacrum, dont les apophyses transverses concrétées s'épatent pour répondre à ce disque. Le deuxiẻme côtẻ qui est le supérieur s'étale fortement en dehors et un peu en avant avec une courbe supérieure légèrement concave; il s'épaissit très notablement vers son extrémité pour se terminer dans une tubérosité, mousse, d'apparence même tronquée et subtrigone. Le troisième côté en descend en courbe rentrante formant un bord épaissi pour se fondre avec la branche originelle près de sa dilatation.

L'ischion synostosé à l'iléon continue la lame amincie surmontant la cavité cotyloïde et de forme arquée, puis la carẻne s'effaçant, le corps de l'os s'épaissit, devient enfin triquètre et se termine en arrière par une grosse tubérosité tronquée, trigone, à angles également en tubérosités. Le supérieur s'élẻve en arrière d'une forte courbe carénée; un deuxième se porte en dehors et fait saillie; le troisième, situé en bas, forme en même temps le sommet de la forte échancrure qui suit en dessous la symphyse pubienne. La réunion de l'iléon et de l'ischion forment la plus grande partie de la cavité cotyloïde; le pubis forme le reste en laissant entre lui et l'ischion une seissure et une échancrure ; dans son ensemble cette cavité est elliptique et regarde latéralement et en dessous.

Le pubis est en lame assez étroite, médiocrement épaisse, qui se porte en dessous et en dedans en s'arquant pour aller se souder à son homologue du côté opposé, après s'être aminci et s'être prolongé en arrière en donnant lieu à une longue symphyse. Ces branches récurrentes du pubis forment ainsi le plancher du bassin et, en se soudant à la partie contiguë de 'l'ischion, elles limitent une lacune assez grande de forme ovalaire et qui est le trou ovale. La soudure du pubis et de l'ischion est très promptement synostosée. La conca- 
vité antérieure du bord pubien porte en son milieu une sorte de mucron et, entre lui et le bord cotyloïde, un petit crochet ouvert en dedans; la face inférieure est carénée le long de la symphyse avec un bourrelet en avant et une faible tubérosité en arriẻre.

Le bassin constitue un ensemble bien plus robuste, plus large et plus court que celui des bœufs. Ses branches sont bien moins flexueuses, ses tubérosités plus épaissies sont moins en crochet; les branches ischiaques sont plus dans le prolongement des branches iliaques subparallèles entr'elles et ne produisent pas le rétrécissement postérieur qui avec son allongement sensible forme presque la caractéristique de celui des boeufs.

\section{MENSURATION}

Distance des soinmets extérieurs des tubérosités iliaques. $\quad 0,680^{\mathrm{mm}}$ Plus petite distance des bords spinaux de l'iléon...... 0,100 Distance extérieure des branches de l'iléon sous la dilatation ......................... $0,3: 010$

Distance intérieure des mêmes branches......... 0,220

Distance d'un bord intérieur de cavité cotyloïde à l'autre. . 0,240

$$
\text { extérieur — } \quad \ldots \quad 0,340
$$

Distance des lames surmontant la cavité cotyloïde..... 0,190

Distance des tubérosités externes de l'ischion........ 0,360

supérieures de l'ischion ....... 0,210

- $\quad$ inférieures (angle de l'échancrure post-pubienne) ................... 0,140

Distance pubienne des trous ovales............. 0,060

Distance de la cavité cotyloïde au crochet du pubis..... 0,030 au bout antérieur de sa symphyse pubienne..................... 0,100

Distance de la tubérosité iliaque extérieure à la tubérosité exterieure de l'ischion................. 0,570 
Distance de la tubérosité iliaque extérieure à la tubérosité supérieure de l'ischiont................. $0,5: 0^{\mathrm{mm}}$

Etendue du bord supérieur de l'iléon............ 0,300

Diamètre transversal de la cavité cotyloïde......... 0,090

- longitudinal _ $\quad \ldots \ldots \ldots \ldots 0,100$

Longueur du trou ovale................... 0.120

- de la symphyse pubienne................... 0,270

Epaisseur du pubis devant le trou ovale.......... 0,150

Distance du bord postérieur du trou ovale à l'extrémitẻ de l'ischion ......................... 0,190

Distance de la tubérosité ischiaque au début de la dilatation iliaque ........................ $0,3 \approx 0$

Distance du sommet de l'iléon au bord de la cavité cotyloïde 0,320

- de la cavité cotyloïde à la tubérosité ischiaque.. 0,200

- de l'extrémité extérieure de l'iléon au bord du sacrum............................... 0,200

Etendue de la dilatation iliaque de l'extrémité extérieure au sinus que fait son bord spinal avec le sacrum..... 0,280

Largeur de la lame montante au dessus de la cavité cotyloïde........................ 0,080

Longueur de chaque bord du triangle de la tubérosité ischiatique............................ 0,130

Le fẻmur (Pl. VI, fig. 3-4-5-6-7) ressemble beaucoup à celui des bœufs dans ses parties essentielles; mais il est plus robuste; sa tête supérieure porte une tête articulaire saillante en dedans sur un col très court, d'abord en portion de sphère regardant en haut, puis se prolongeant en dehors sur le col en forme de lobe un peu moins étendu, convexe et séparé par une gorge de poulie presque superficielle; de sorte que l'ensemble de la têtte articulaire est d'une forme oblongue, un peu didyme dans le sens transversal. Chez les bœufs 
cette disposition est bien moins accusée. Le grand trochanter forme à l'opposé de la tête articulaire une forte tubérosité longitudinale, non oblique comme che\% les bœufs, bien saillante en dehors du col, très élevée au dessus, mais sans faire de crochet et sans le resserrer. Il part de ce grand trochanter une ligne âpre qui descend avec des sinuosités jusqu'à la fosse tendineuse qui surmonte le condyle externe.

Le petit trochanter est bien nettement saillant en dedans sous forme de tubercule; le bourrelet qui en part en se courbant pour rejoindre le grand trochanter forme avec lui une fosse plus profonde, plus étendue, plus large dans son fond et plus cachée du còté postérieur par le bord du trochanter.

Le corps de l'os est presque cylindrique à diamètre assez égal sur une certaine longueur, puis il est sensiblement accru auprẻs des extrémités qui se renflent en têtes articulaires. Les condyles sont presque égaux; subglobuleux, peu ou pas pincés comme ils le sont dans les bœufs, surtout l'externe; ce dernier a en dehors une faible tubérosité. Ces condyles font une forte saillie en arrière, ils sont très détachés entr'eux et assez indépendants de la poulie rotulienne dont l'antérieur est séparé par une fossette qui interrompt la carène et l'externe par une dépression. La poulie rotulienne est très oblique en dehors, très inégale par suite de la grande différence de niveau de ses arêtes, qui lui donne l'apparence d'ètre déjetée en dehors. L'arête interne est plus élevée que l'externe comme dans les bœufs; mais elle paraît avoir été beaucoup moins épaissie et moins obtuse à son sommet, oủ une éraillure le masque un peu dans la partie prolongée sur le corps de l'os à la face antérieure. La poulie est plus droite, à arêtes non flexueuses et plus parallèles.

Cette tète inférieure de fémur est très volumineuse et a un diamètre antéro-postérieur du côtẻ interne considéráble. Cependant le développement transversal de la tête supérieure surpasse celui antéropostérieur de la tête inférieure comparativement aux bœufs, oủ ces 
dimensions sont très inégales tandis qu'elles sont à peu près égales chez notre buffle. Les condyles paraissent aussi relativement plus développés par rapport à la hauteur de la poulie rotulienne. L'excavation pour insertion tendineuse du bord postéro-interne qui avoisine la tête inférieure est assez forte mais médiocrement élargie et une comparaison attentive de nos figures avec l'iconographie ostéologique des bœufs fera reconnaitre des différences suffisantes pour permettre de différencier les fémurs appartenant à ces deux types.

\section{MENSURATION}

Longueur extérieure du fémur.............. $0,480^{\mathrm{mmr}}$

intérieure du même .............. 0,450

Largeur transversale de la tête supérieure ......... 0,200

Distance du petit trochanter au sommet du grand...... 0,200

au bord de la tête articulaire. 0,060

Longueur transversale de la tète articulaire ........ 0,100

Largeur antéro-postérieure de la même ......... 0,070

Largeur transverse du corps de l'os à la hauteur du petit trochanter ........................ 0,210

Largeur du corps de l'os vers le milieu.......... 0,060

Epaisseur du corps de l'os au même point.......... 0,070

Diamètre extérieur d'un condyle à l'autre.......... 0,140

Distance de l'extrémité du condỵle externe à la fosse tendineuse.......................... 0,095

Diamètre antéro-postérieur de la tête inférieure, poulie et condyle compris, côté interne.............. 0,150

Diamètre antéro-postérieur de la tête inférieure, poulie et condyle compris, cité externe............. 0,170

Hauteur de la poulie rotùlienne, côté interne ........ 0,120

Moindre largeur de la poulie................ 0,050

Plus grande largeur de la poulie............ 0,070 
Le tibia (Pl. VII, fig. 1-2-3-4-5) est conformé comme celui d'un grand bovidé massif et les diffẻrences de détail qu'il peut présenter avec celui du bcuf actuel sont plus faciles à dessiner qu'à décrire et consistent le plus ordinairement en proportions dans les longueurs ou les épaisseurs. La tête supérieure a sa tubérosité antérieure plus épaissie et plus saillante ainsi que l'arête qui en descend. Les condyles sont plus séparés entr'eux et leur crête est moins saillante et plus obtuse. La face postérieure de l'os est hérissẻe de nombreuses crêtes grêles mais saillantes. L'articulation inférieure n'a rien de particulier que son ginglyme serré et sa facette péronienne bien développée. L'os péronien n'est pas connu.

MENSURATION

Longueur du coité externe ................. (), 1.30

- du côté interne ................. 0,400

- au bord antérieur................. 0.420

Diamètre transversal de la tête supérieure.......... 0,140

— antéro-postérieur de la même........... 0,100

Epaisseur de la tète de l'angle péronien à la tubérosité antérieure......................... 0,100

Largeur des facettes condyliennes, chacune......... 0,060

Largeur du corps de l'os vers le milieu ............. 0,070

Epaisseur du corps de l'os vers le milieu........... 0,050

Diamètre transverse de la tête inférieure........... 0,090

- antéro-postérieur du côté interne......... 0,070

Largeur de la facette astragalienne ............ 0,065

péronienne............... 0,020

L'astragale (Pl. VII, fig. 6-7. Pl. VIII, fig. 1-2-3) est un osselet relativement épais et trapu qui ne présente avec celui des bøufs que des diffẻrences peu importantes. La poulie tibiale est presque abso- 
lument semblable. Cependant la facette intérieure qui reçoit comme une coulisse la facette marginale de la maléole ne s'élargit pas en cupule à son extrémité et le cran d'arrêt de cette coulisse, au lieu d'être déjeté en dehors, se porte plutôt en dedans en forme de petite tubérosité; à l'autre côté de la poulie tibiale, le cran d'arrêt est à peine marqué et n'est pas accompagné d'une dépression au dessous. La face calcanéenne postérieure est plus large et elle est séparẻe de la facette cubo-scaphoïdienne par une faible dépression marquée d'un frou au lieu de l'être par un sillon très marqué, terminé en dehors par un trou et s'étendant jusqu'au bord interne, tandis que, en ce dernier point, il y a un sinus étendu qui interrompt les facettes marginales et se ferme orthogonalement sans aboutir à la dépression. Du même côté, sous le crochet qui s'appuie sur la plateforme du calcanéum, l'espace libre de facette articulaire s'arrête à la marge voisine sous forme de sillon, mais se relève en s'étalant sur la face externe de l'appendice en crochet, au lieu de se prolonger en gouttière descendant au delà de la marge. La gorge de la poulie tibiale présente aussi des différences dans la disposition des surfaces non envahies par le tissu éburné des faces articulaires; son extrémité inférieure est plus élargie et plus fortement creusée.

MENSURATION

Longueur de la face externe................ 0,090.

interne................ 0,085

Largeur de la poulie tibiale à sa partie supérieure..... 0,060

Largeur en avant de la poulie cubo-scaphoïdienne..... 0,064

Plus grande largeur de la face externe........... 0,050

de la face interne............ 0,055

Hauteur de la face postérieure calcanéenne......... 0,060

Plus grande largeur de la même face........... 0,046 
Le calcanéum (Pl. VII, fig. 6-7. Pl. VIII, fig. 4-5) est très robuste dans toutes ses parties; sa plate-forme fait en dedans une saillie très épaisse en tous sens; son appendice se dirige obliquement en arrière et la facette qu'il porte se rétrécit du côté interne en s'arrondissant. L'apophyse péronéo-cuboïdienne, fortement épaissie, a sa facette pour le péroné très développée et renforcée en dedans et elle s'applique exactement sur les creux et saillies de la face externe de l'astragale. L'apophyse talonnière porte sur sa face postérieure, empiétant sur les faces latérales, surtout l'extérieure, des sillons et des aspérités longitudinales. Cette face très obtuse s'élargit notablement en arrière pour se terminer par une dépression vers la tubérosité; la face antérieure, un peu plus épaisse que la postérieure, est d'abord aplanie et épaissie au dessus de l'astragale, puis elle s'arrondit pour finir par une tubérosité marginale qui est dépassée par celle du côté postérieur. Les faces latérales sont larges et s'atténuent vers le bout en s'y épaississant pour élargir la tubérosité terminale, qui est bilobée dans le sens vertical. Il est difficile de trouver un os qui porte à un plus haut degré l'empreinte de la puissance musculaire par ses impressions tendineuses.

\section{Mensuration}

Longueur totale du calcanéum ............. 0,170

Distance de l'extrémité de la facette cuboödienne au bord postérieur de la facette astragalienne.......... 0,050

Distance de la même extrémité au bord antérieur de la même $\quad 0,075$ - de la facette péronéenne au bout postérieur de la cuboïdienne....................... 0,075

Diamėtre transversal de la facette astragalienne...... 0,050 antéro-postérieur de la même ........... 0,045

Epaisseur antéro-postérieure de la saillie apophysaire de la même.......................... 0,040 
Saillie apophysaire en dessus............... $0,030^{\mathrm{mm}}$

Epaisseur transversale, y compris la saillie apophysaire.. 0,060

Epaisseur du corps apophysaire talonnier devant...... 0,030

derrière ..... 0,025

Largeur du même..................... 0,055

Largeur transverse de la tubérosité terminale ....... 0,050

- antéro-postérieure de la même .......... 0,045

Le cubo-scaphoïdien (Pl. VII, fig. 6-7. Pl. VIII, fig. 6-7) est court mais élargi en tous sens. Sa facette astragalienne a ses fosses presque égales et la côte qui les sépare se termine par une petite crête arquẻe pour la fosse qui termine la poulie de l'astragale. La facette cuboïdienne est large et dépasse en arrière la crête précédente, en étant séparée par une fosse ovale. La facette du cuboïde est subtriangulaire à bords un peu ondulés; celle du cunéiforme est presque aussi grande, mais oblongue; elle se continue dans une autre petite sur un plan un peu plus abaissé pour le deuxiẻme cunéiforme. Ces deux os nous sont inconnus.

Derriére la facelte cuboïdienne en est une autre transversale et allongée qui en est bien séparée par un sillon; elle est à l'opposé de la partie supérieure de la facette calcanéenne, affleurant la même tubérosité. En arrière du cunéiforme, l'os forme une forte tubérosité irrégulière contre laquelle s'appuie le lobe remontant de la partie interne postérieure de la face astragalienne.

\section{MENSURATION}

Largeur de la face astragalienne............. $0,060^{\text {mm }}$

Largeur totale, la face calcanéenne comprise........ 0,075

Diamètre antéro-postérieur de la facette astragalienne au milieu............................... 0,040

Dianètre antéro-postérieur de la mème au bord interne.. 0,050 
Diamètre antéro-postérieur au bord externe, la calcanéenne comprise............ $0.055^{-\operatorname{mm}}$

total du côté interne ....... 8,0 8

Facelte pour cunéiforme, longueur totale (du scaphoïde). . 0,055

largeur............... 0,025

Facette du cuboïde, longueur................ 0,040

plus grande largeur.......... 0,030

Facette postérieure du même, longueur transverse..... 0,030

largeur antéro-postérieure.. 0,010

Hauteur au devant du cuboïde............... 0,030

- derriere le cuboidr............... 0,040

- du scaphoïde à son crochet remontant....... 0,050.

Le métatarsien (Pl. VII, fig. 8-9-10-11-12) continue à présenter cel aspect robuste des autres parties des membres. La face de sa tête supérieure est exactement la contre-partie du cubo-scaphoidien; il n'y a pas à y revenir. L'espace libre du centre des facettes est très enfoncé et porte des ouvertures de trous pour faisceaux vasculaires, dont un va aboutir à la face postérieure sous l'origine de la tête. Cette tête est assez peu dilatée et accompagnée tout autour et surtoul à l'angle interne de fortes rugosités ressemblant presque à des exostoses. Le corps de l'os s'atténue un peu en approchant du militieu.

Il est quadrangulaire avec le côté interne un peu plus large et convexe; l'externe également concave et plus étroit; le postérieur à peu près de même largeur, un peu versant en dehors avec fossette vers le haut au fond de laquelle aboutit le canal vasculaire cité plus haut et une gouttière superficielle, d'abord marginale externe, puis se bifurquant en descendant et s'oblitérant au delà du milieu; la face antérieure la plus étroite porte un sillon en gouttière assez large, mais se resserrant au bas de l'os en un canal demi fermé qui se continue dans la scissure qui sépare les condyles. La tête infé- 
rieure est plus élargie que la supérieure pour porter ces condyles, qui sont divisés en deux gorges inégales par une forte carène obtuse.

La face postérieure est faiblement et régulièrement convexe ayant au bout quelques ondulations et bosselures se fondant plus ou moins avec les creux et reliefs des condyles. Il y a sur la face antérieure à l'origine de la contraction du sillon deux plis en forme d'impressions superficielles, qui bifurquent de ce sillon et vont en se courbant, en bas et en dehors, gagner les bords épaissis qui surmontent les condyles. Ceux-ci ont une conformation normale.

\section{MENSURATION}

PHus grande longueur du métatarsien derrière...... $0,270^{\mathrm{mm}}$

Plus grande longueur du métatarsien devant....... 0,255

Largeur de la tête supérieure............... 0,070

Epaisseur de la tête supérieure .............. 0,060

Diamètre antéro-postérieur du corps de l'os au milieu... 0,043

- transversal du corps de l'os au milieu....... 0,043

Largeur de la gouttière de la face antérieure au milieu... 0 0,018

Largeur transversale des condyles ............ 0,080

Diamètre antéro-postérieur du corps à la contraction de la gouttière................................ 0,035

Largeur de l'os au même point.............. 0,050

Plus grande épaisseur antéro-postérieure au dessus des condyles........................... 0,040

Distance en arrière des carènes de chaque condyle ..... 0,040

Distance des bords externes des condyles du même côté.. o 0,078

Les premières phalanges (Pl. VII, fig. 10. Pl. VIII, fig. 8-9) sont hautes et épaisses et leurs tubérosités latérales et postérieures portent ces empreintes vermiculées qui ont été signalées sur les autres parties du squelette destinées aux insertions tendineuses et ligamen- 
teuses; les poulies pour les condyles du métatarsien sont bien adaptées à une articulation serrée. La face interne du corps de l'os est très élevée et forme à la face inférieure une grosse tubérosité presque étendue à la facette articulaire inférieure; elle fait une forte saillie à la face inférieure faisant avec une autre tubérosité plus courte du bord opposé une goutlière ou dépression divisée en deux par une traverse qui laisse en haut une grande fosse en cupule arrondie échancrée par le sillon de la poulie.

Cette tubérosité extérieure n'est bien développée que vers le haut de la face, s'atténue en petite carène au dessous de la traverse; mais elle se termine par un tubercule épaté et mousse avant d'atteindre le bord de la poulie. La poulie pour la deuxième phalange est oblique, inégale, son lobe interne étant moins large et plus élevé que l'externe; la face supérieure de l'os est bien convexe et verse plus en dehors qu'en dedans. A la face articulaire supérieure et en arrière des deux faces séparées par la gorge des poulies, est une facette pour un sésamoïde qui s'applique contre la gorge de poulie du métatarsien, pour constituer avee son homologue voisin la glissière tendineuse. Nous avons un de ces sésamoïdes figuré à la Pl. VIII, fig. 14. Cet osselet ne présente rien de remarquable; il est épais et oblong.

\section{MENSURATION}

Longueur extérieure de la phalange........... $0,068^{\text {mm }}$

- intérieure $\quad$ - $\quad \ldots \ldots \ldots \ldots \ldots, 0,0 \%$

Hauteur de la poulie articulaire supérieure........ 0,038

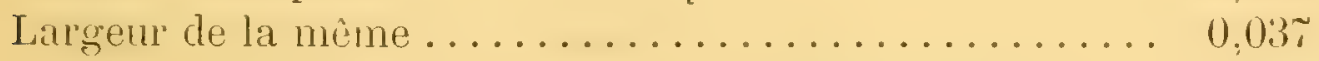

Largeur antéro-postérieure de la face interne en haut.... 0,045

externe en haut... 0,045

Longueur de la tubérosité inférieure interne........ 0,010

Largeur de la poulie de la facette articulaire inférieure ... 0,038

Plus grande épaisseur de cette articulation......... 0,030 
Largeur de la face inférieure au milieu........... $0,035^{\mathrm{mm}}$ entre les tubérosités et la facette inférieure .................... 0,035

Sésanıoïde, longueur de la facette............. 0,028

- largeur $\quad$ - $\ldots \ldots \ldots \ldots \ldots \ldots, 0,016$

- épaisseur de l'os à la base du côté externe... 0,018

- _ du côté interne... 0,010

Les deuxièmes phalanges (Pl. VIII, fig. 10-11-12. Pl. VII, fig. 1014-15-16-17) donnent lieu aux mêmes remarques générales comparées à celles des bœufs, beaucoup plus courtes et plus épaisses: elles sont en rapport avec les premières phalanges. La face articulaire supérieure est en courte poulie oblique, mais large. La facette pour la phalange onguéale est en poulie oblique aussi et à côtés inégaux, l'interne remontant plus haut et formant à lui seul le sommet obtus et versant en dehors. Sous la facette supérieure se développent deux tubérosités, l'externe plus épaisse et moins saillante, l'interne un peu pincée et plus proéminente. Le corps de la phalange est court et bien contracté au dessus de la tête inférieure. On peut constater encore-ici ces mêmes surfaces d'attaches tendineuses et ligamentaires fortement vermiculées, rugueuses, qu'on serait tenté parfois de prendre pour des rudiments d'exostoses.

MENSURATION

Longueur de la phalange à la face interne $\ldots \ldots \ldots \ldots, 0,050^{\text {mm }}$

externe........... 0,050

Largeur de l'articulation supérieure........... 0,038

- transverse de l'os en dessous de l'articulation.... 0,040

Hauteur de la facette supérieure ............. 0,024

- de l'os avee ses tubérosités à la face supérieure. 0 0,040

Plus petite largeur à l'étranglement............ 0,034 
Plus petite épaisseur à l'étranglement.......... 0,028 Plus grande largeur de la facette pour la $3^{\circ}$ phalange ... 0,033 Sa largeur vers la partie la plus terminale ......... 0,030 Hauteur de la poulie inférieure............... 0,040

Distance de son sommet au sommet de la facette supérieure 0,030

Les phalanges onguéales (Pl. VII, fig. 10-18-19-20) sont pourvues d'une facette articulaire supérieure peu différente de celle de liı deuxième phalange à deux lobes inégaux, l'interne plus court et plus large, l'extérieur plus étroit, plus long et nettement arqué pour produire l'inflexion du côté interne. Il y a autour de cette facette comme une auréole d'excroissances ressemblant à des exostoses, surtout ver's le haut; et en dessous une assez forte tubérosité plus saillante vers l'angle extérieur inférieur accentue l'obliquité. La phalange est triquètre dans son ensemble avec atténuation de la face antérieure pour se terminer en bord presque tranchant. La face antérieure est bien convexe, très étendue du côté interne et sa surface est bordée extérieurement d'une zone comme fibreuse fortement et finement striée par des sillons qui se dirigent vers les bords, ceux de l'arrière plus grossiers que les autres; des trous de canaux sont épar's, dont quelques-uns plus grands forment une rangée bordant la zone fimbriée.

La face interne est limitée en haut par une arête un peu courbe portant les mêmes fimbriations, limitant une zone évidée en dessous et en arriẻre et qui rétrécit la face inférieure. Celle-ci est oblongue, un peu arquée par évidement de la partie postérieure du bord interne; elle est légèrement convexe, hérissée de petites aspérités en éventail et épaissie en arrière en une tubérosité aplanie à tissu presque éburné et avec rugosités : cette tubérosité forme une forte saillie à l'angle externe. La face supérieure porte au dessus de cette tubérosité et au bas de la contre-poulie une facette ovalaire pour un sésamoïde, qui :s'applique sur la facette de la seconde phalange. 
Cet os est en forme de table épaisse parallélogrammique portant une facette équivalente, et ses deux lobes cupulés sont inégaux, le plus large en dedans, le plus étroit et moins creux en dehors. Sa face externe ou postérieure forme deux glissières de tendons assez superficielles, mais très bien marquées. Cet os est figuré $13 \mathrm{Pl}$. VIII.

On connaît deux phalanges onguéales très semblables entr'elles, mais dont l'une est un peu plus petite, avec l'ensemble de la facetle pour la seconde phalange un peu moins large, et dès le début j'avais un instant pensé que la plus grande pouvait appartenir au pied de devant. Nais la différence des proportions doit être bien plus grande entre les deux pieds et la petite phalange doit appartenir comme l'autre au pied de derrière, soit à un sujet plus jeune, soit à un individu d'un sexe différent, ou plus simplement à une variation qui en somme serait assez faible; la petite est figurée Pl. VIII, fig. 10-11-12.

\section{MENSURATION}

Longueur de la phalange de la base de la facette à l'extrémité antérieure .................... $85^{\mathrm{mm}} 80$

Hauteur de la facette articulaire............. $36 \quad 36$

Hauteur de l'os au même point.............. $50 \quad 50$

Hauteur de la face interne devant la couronne de tubérosités $\quad 40 \quad 35$

Largeur de la facette................... $34 \quad 30$

Largeur de la face.inférieure vers le rétrécissement.... 3532

Largeur du talon..................... $38 \quad 30$

Largeur du sésamoïde .................... 35

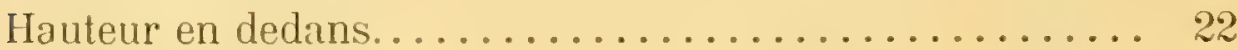

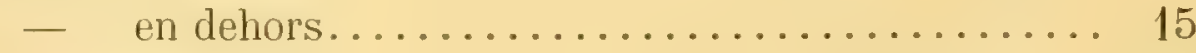

Epaisseur de l'os....................... 10 


\section{AFFINITESS DU BUFFLE ANTIQUE}

Cet animal fossile se fait surtout remarquer par un énorme développement en longueur des chevilles osseuses de ses cornes, arquées en double croissant conjugué, comme un arc à flèche à double courbure. Cette disposition tient ả ce que ces chevilles, tout en s'abaissant sensiblement à leur naissance, se dirigent d'abord un peu en avant et continuent leur courbure en arrière et un peu en dehors en se relevant sensiblement. Leur extrémité, malgré leur grande longueur, ne dépasse pas beaucoup l'occipital dans le profil général de la tête.

Comme dimension des cornes, cette tête rappelle le type du grand buffle Arni des Indes; mais dans ce dernier les chevilles sont disposées en simple croissant moins étalé ; elles sont triquètres avee le côté inférieur plat, tandis que dans le fossile leurs angles sont plus effacés, le côté inférieur est bien convexe et l'antérieur, le plus étroit, ne tarde pas aussi à s'arrondir. Les orbites, chez l'Arni, sont plus éloignées de la base des cornes et très fortement marginées, au lieu d'être presque à fleur et presque contiguës à cette base comme dans le fossile; dans ce dernier la région temporale est bien plus étendue; l'occiput plus indépendant et plus élargi par suite de l'épaississement de la région du rocher temporal. Les affinités sont done bien plus apparentes que réelles.

Les autres buffles indiens, dont les chevilles osseuses des cornes sont beaucoup plus courtes, ne présentent pas une grande différence de structure pour le crâne et surtout pour les orbites, et à ce point de vue ils n'ont pas plus d'affinités avec notre fossile qui certainement n'appartient pas au type indien. Les auteurs ne sont pas d'accord sur la question de spécification dans ce type indien; mais du fait que certains n'y voient que des variétés ou des nuances de races, on peut admettre qu'aucune d'elles ne se rapproche davantage du Bubale antique. 
Parmi les buffles africains de l'époque actuelle, que l'on a proposé de réunir en groupe parce que leurs chevilles osseuses sont demicylindriques et plates en dessous, celui du Cap diffère du fossile par ses chevilles courtes, tombantes en dehors, épaissies et comme tubéreuses sur le frontal et plates en dessous. Les orbites sont aussi plus semblables à celles de l'Arni, par la saillie de leur marge et leur éloignement de la base des cornes. Il en diffère cependant un peu moins par son occiput plus étalé, plus bas, mais séparé du frontal par une zone pariétale moins étendue.

Le buffle à courtes cornes de la côte de Guinée (bubalus brachyceros) a ses orbites plus rapprochées de la base des cornes que les autres espèces vivantes, mais encore bien moins que dans le buffle antique et beaucoup plus marginées. Les cornes sont étalées presque horizontalement à leur base, mais dirigées en arrière dès leur début et du reste larges, plates en dessous et courtes. L'occipital rappelle davantage le fossile par'sa grande largeur due au dévelppement de la région du rocher temporal; mais il est beaucoup moins incliné en dessous et la zone pariétale, moins oblique, est bien moins étendue derrière les cornes, dont la base est plus élevée sur la fosse postorbitaire.

Le buftle antique est donc un type particulier, à caractères spéciaux, qui ne permettent de le confondre avec aucun des groupes qu'on a proposé d'établir dans la série, même avec les formes fossiles des terrains tertiaires indiens, décrites sous les noms de $A m-$ phibos acuticornis et Hemibos triquetricornis Falconner. C'est un type qui rompt un peu la conception d'un groupe géographique naturel africain ; car il est totalement indépendant des deux espèces vivantes, actuellement connues dans cette région africaine. Il me semble que l'établissement de sá généalogie ancestrale serait, dans l'état actuel de nos connaissances, très difficile à établir. 


\section{LES PROPORTIONS GÉNERALES}

La longueur du corps prise sur le squelette est de deux mètres quatre-vingt-quinze centimètres du bord incisif jusqu'à l'extrémité postérieure des ischions. Celle de l'animal vivant, du museau à l'origine de la queue, devait être très approchée de trois mètres; c'est une très grande taille. La hauleur de la croupe, d'après le squelette, était $1^{\mathrm{m}} 70^{\mathrm{c}}$; celle du garrot est incertaine par absence du carpe et métacarpe; mais elle devait atteindre $1^{\mathrm{m}} 85^{\circ}$, calculée d'après les éléments connus.

La longueur totale du squelette se décompose dans les éléments suivants :

Longueur de la tête du bord incisif aux condyles...... $0,600^{\text {mm }}$

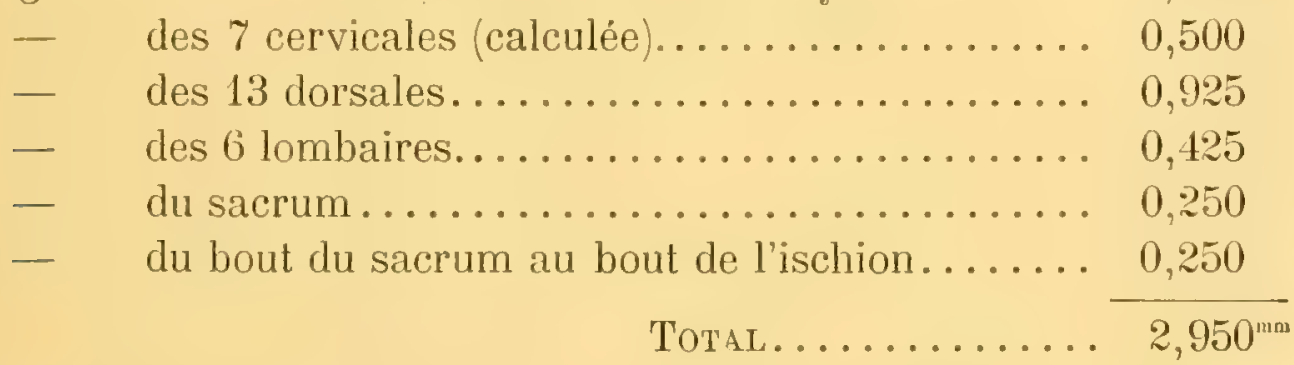

La cage thoracique, de la $1^{\text {re }}$ à la $13^{\circ}$ còte, a environ $1^{\text {mn }}$ de longueur mesurée vers le milieu des côtes; son grand diamètre transversal n'a pu être mesuré. La plus grande largeur des reins, mesurée sur les plus longues apophyses transverses des vertėbres lombaires, est de $0^{m} 400$. La plus grande largeur de la croupe, mesurée d'une extrémité à l'autre des iléons, est de $0^{\mathrm{m}} 650$.

Les proportions de diverses parties des membres ne sont pas dans les mêmes rapports que chez le buffle, dont les dimensions ont été données par G. Cuvier dans ses recherches sur les ossements fossiles. L'humérus est notablement plus court, puisqu'il indiquerait une taille 
au garrol plus courte de vingt centimètres. Le radius serait peut-être un peu plus long ou au moins proportionnel à celui du buffle. Le canon est inconnu. Le fémur est dans les proportions voulues pour la taille à la croupe. Le tibia, au contraire, est encore plus raccourci que l'humérus; enfin le métatarsien présente des proportions intermédiair'es à celles des deux os précédents.

On a vu, du reste, par les tableaux de mensuration, que tous les os en général sont extrêmement robustes et indiquaient, par leurs proportions aussi bien que par leurs attaches tendineuses, une puissance extraordinaire. Ce devait être un animal de plaine marécageuse, car la fréquentation des forêts ne devait pas lui être facile.

\section{VARIATIONS}

Les variations de formes, qu'on a pu observer jusqu'ici dans le buffle antique, ont une assez faible importance. Elles consistent en de simples petites différences dans les longueurs et épaisseurs de certaines parties du squelette. Sur les sujets trouvés ensemble dans les gisements de Djelfa, pour les bassins, par exemple, les grandes longueurs ne diffèrent pas de plus de un à deux centimètres. Pour les cornes il y a peut-être plus de différences; mais on sait que leur croissance se prolonge longtemps et que leur grand développement peut être attribué au grand àge. Ainsi la distance du bout de la corne au synciput est de un mètre dans un sujet de l'Oued Seguin que l'on a cité comme très adulte, tandis qu'elle devait être d'un mètre quinze centimètres dans le sujet de Djelfa réputé plus jeune, mais que sa dentitiou ne rajeunit guère. Ce genre de variation est aussi attribuable à la différence de sexe et enfin ả la variation individuelle. Quelquefois aussi une restauration maladroite, comme celle du fossile de Rouïba, pourrait laisser croire à de plus grandes différences, si la maladresse n'était pas reconnue. En somme, ces variations sont comprises dans des limites très étroites et sans importance. 
1I. P. Thomas, dans une note insérée au Bulletin de la Société géologique de France (1886, page 141) en a signalé qui auraient une plus grande importance. Elles consisteraient dans le développement d'une bosse ou tubérosité médio-frontale longitudinale se bifurquant en arrière pour se confondre avec la crête occipitale; en une crête transversale au dessus de la suture fronto-nasale établissant une scission marquée entre le cràne et la face; en une crête occipitale plus saillante et plus régulièrement incurvée avec profonde échancrure semi-lunaire supérieure ; en des chevilles de cornes absolument prismatiques, tandis que celles de Djelfa sont arrondies à leur base. Ges faits ne me paraissent pas avoir une signification aussi importante, même au point de vue de la théorie de la concentration du système osseux; plusieurs même sont susceptibles de rectification après examen des piẻces même, sans doute comparées de souvenir.

La surface d'apparence exostosée du frontal m'a paru formée d'un tissu adventif, qui se développait plus ou moins suivant les sujets et avait peut-être quelques relations avec le développement de la base des étuis cornés. La bosse médio-frontale qui en fait partie se retrouve sur le crâne inscrit sous le $n^{\circ} 126$ du Musée de Constantine, au milieu et vers le haut de la région frontale presque unie sur une grande étendue, non encore envahie par les rugosités. On retrouve cette tubérosité à l'état subrudimentaire, mais très distincte sur le cràne de Djelfa, où la partie exostosée est bien développée et ne laisse en arrière qu'un étroit intervalle médian lisse. La crète postérieure, qui sépare le front de la zone pariétale, y est bien développée et mamelonnée surtout près de la base postérieure des chevilles osseuses. Elle ne va pas se confondre en arrière avec la crète occipitale, mais elle n'y va pas non plus sur le crâne de l'Oued Seguin, oủ elle en est séparée, comme dans le crâne de Djelfa, par une zone pariétale bien unie et sans aspérités. A ce point de vue les deux crânes sont presque absolument conformes. 
Le plus grand espacement de l'orbite sous la base des chevilles osseuses des cornes est d'une quantité négligeable par rapport à la différence qui existe entre le buffle antique et les autres espèces comparées et ne saurait servir à la recherche des affinités et de la généalogie. Quant aux cornes il n'est pas exact d'affirmer qu'elles sont arrondies à leur base dans le buffle antique. La figure 2 de la Pl. II montre que ces cornes sont trigones vers leur base avec l'angle postérieur plus allongé et un peu émoussé. Ce n'est donc qu'une différence de nuances.

Il y a certainement des différences entre les divers sujets connus, mais seulement dans le développement de certaines particularités et non dans celui de caractères singuliers qui ne se manifestent pas.

\section{LES GISEMENTS DU BUFFLE ANTIQUE}

La pièce osseuse qui la première a permis de créer l'espèce a été découverte dans des fouilles pratiquées sur les bords de l'Oued bou Sellam, près de Sétif, dans les alluvions et les dépôts limoneux des niveaux les plus inférieurs de la vallée et appartenant à la dernière phase quaternaire. Ces dépôts paraissent tellement liés aux cours d'eau actuels dans lesquels ils ont creusé leur lít, qu'il semblerait que leur formation leur est due. Mais l'immensité des surfaces recouvertes est hors de proportion avec les phénomènes météoriques actuels de la région; les cours actuels seraient incapables de pareils atterrissements ; ceux-ci caractérisent un tout autre régime.

On peut en dire autant du bassin du Rhumel, qui a fourni plusieurs crànes de cette espèce, dont un trouvé à Aïn Smara, plusieurs autres à l'Oued Seguen; ils sont tous dans les berges érodées des cours d'eau actuels, provenant des alluvions graveleuses ou limoneuses qui ont rempli tous les bas-fonds de la région sur une épaisseur variable et dans des conditions de dépôl absolument identiques à celles que l'oro- 
graphie actuelle de la région permettrait de nos jours avec un régime alluvionnaire d'une intensité tout autre que celle de l'époque acluelle; c'est encor'e une formation des derniers temps quaternaires. Les ossements du buffle y sont associés à ceux du cheval, de l'âne, d'un grand bouf nommé primiginius mauritanicus par M. P. Thomas, d'un autre bœuf de plus petite taille comparable à celle des bœufs actuels du pays, de l'alcélaphe bubale, du chameau et d'autres petits ruminants. Des silex taillés y ont été observés, mais ils sont rares. C'est en somme une faune imparfaitement connue, mais qui appartient évidemment à la derniẻre phase quaternaire.

Le gisement de Djelfa d'où proviennent les principaux éléments de cette monographie est encore de même nature el de même composition que les précédents; c'est un dépôt argilo-marneux et peut-être d'anciens marécages ayant comblé la partic la plus basse de la vallée; on y trouve, en effet, des hydrobies. M. P. Thomas, qui a assisté à leur découverte, ou du moins a vu le gisement peu après, y indique le cheval, des ruminants, un grand oiseau, non déterminés.

Tous les gisements énumérés ci-dessus sont situés dans la région des hauts plateaux sétifiens ou maurétaniens; mais plusieurs autres, moins riches il est vrai, se trouvent dans la zone du Tell.

A Bougie, dans les escarpements du cap Carbon, existe une caverne presque au niveau de la mer, qui a été fouillée par M. Béguin pour en extraire des phosphorites. Parmi les débris osseux qui n'ont pas été précipités à la mer se trouve une phalange onguéale un peu détériorée mais qui doit très probablement avoir appartenu au buffle antique. Peut-être y a-t-il aussi quelque fraģment de métacarpien. J'ai pu y reconnaître en outre un rhinocéros encore indéterminé, d'autres ruminants trop incomplètement connus, mais plus particulièrement un cervidé tellement anormal dans sa mandibule que je l'ai soupconné longtemps de présenter un cas pathologique, mais que j’ai dù accepter comme normal après la découverte d'autres piè- 
ces identiques dans un autre gisement éloigné. C'est le cervus pachygnatus.

Près de Rouïba, dans la Mitidja orientale, des fouilles exécutées pour des travaux publics dans le lit de l'Oued Hamiss ont amené la découverte d'un crâne très bien caractérisé du buffle antique: il gisait dans un conglomérat caillouteux récent. Malheureusement il est mutilé ; la corne qu'il avait encore conservée a été brisée et elle a été maladroitement restaurée, de manière à perdre son faciès et à ne pouvoir servir aux comparaisons. Toutefois, la partie de l'orbite conservée et le frontal, par sa convexité et ses rugosités, ne peuvent laisser aucun doute sur sa détermination. Ces ossements que j'ai vus, lors de leur découverte, à l'Exposition permanente des produits de l'Algérie (aujourd'hui supprimée), étaient accompagnés d'autres débris osseux parmi lesquels divers fragments de canine inférięure d'un hippopotame, beaucoup trop incomplets pour permettre une détermination, mais suffisants pour caractériser le genre. Nalheureusement ils sont maintenant égarés. La portion de cràne se trouve actuellement dans les collections de l'Ecole supérieure des sciences d'Alger.

Plus près d'Alger, dans une grotte fouillée par le docteur Bourjot, entre le cap Caxine et Guyotville, on a trouvé une première phalange et une molaire, ayant certainement appartenu au buftle antique. L'àne, le cheval, un bœuf de la taille de ceux du pays, l'antilope de Maupas, le chameau, des chiens, de grands felis, l'homme à tibia platycnémique, des outils en pierre, en silex taillé, des poteries grossières ont été trouvés dans le même gisement qui certainement appartient aux derniers temps préhistoriques. L'antilope de IIaupas, une des espèces les plus remarquables, se retrouve dans des gisements voisins avec des débris bien caractérisés de l'Elephas africanus confirmant la détermination de cet àge.

Aux environs d'Oran des recherches trẻs fructueuses ont étẻ exécutées dans des grottes préhistoriques. MIM. Thomasini et Pálary, 
puis M. Doumergue ont recueilli de nombreux ossements de grands bœufs qu'en raison de leur grande taille on a considéré comme pouvant avoir appartenu au buffle antique; mais un examen plus attentif m'a montré qu'ils appartenaient pour la plus grande partie à une grande espèce du sous-genre bœuf, proprement dit; toutefois, j'ai la conviction qu'une révision plus comparative à l'aide de l'iconographie présente fera reconnaître la présence de ce buftle dans ces gisements remarquables, et déjà je n'ai plus de doute pour quelques-uns d'entre eux. En tout cas, les animaux auxquels ils sont associés font tous partie de la dernière faune néolithique et je me propose de faire connaitre bientôt certains des types les plus remarquables.

Un peu plus à l'ouest d'Oran, aux sources de Brédéa, des sondages pour le captage des eaux artésiennes, jaillissant dans le marais, ont ramené quelques ossements, gisant dans un atterrissement recouvert par une formation travertineuse. Il y avait deux dents décrites plus haut qui ne laissent aucun doute sur leur spécification. Des débris de poterie et quelques débris d'autres ruminants plus petits ont été ramenés à la surface et leur étaient certainement associés. C'est encore là un gisement trop peu connu des derniers temps néolithiques.

Il ne m'a pas été donné de constater la présence du buffle antique dans des stations qui me paraissent plus anciennes que les précé-dentes. Ni à Ternifine, ni à Aboukir, ni à la pointe Pescade et autres localités oủ les plages marines émergées ont fourni des ossements fossiles, je n'ai rien observé qui pût lui être rapporté. MI. Thomas a attribué au buftle antique divers débris considérés comme plus anciens, et qui seraient pliocènes d'après lui. La pièce déterminante est une extrémité de noyau osseux de corne trouvée dans les sables du Mansoura, près de Constantine. Cette corne est bien moins effilée, moins déprimée, à surface bien plus rugueuse que dans les pièces de Djelfa que j'ai pu lui comparer. Je ne pense pas que sur un pareil document on puisse baser une détermination cerlaine d'espèce, en 
raison surtout de la variabilité que comporte un pareil ossement. Tout ce qu'il est possible de dire c'est que c'est un bout de corne de grand bovidé.

L'âge du gisement est aussi sujet à contestation ; je n'y reconnais pas les espèces de ce que j'appelle le quaternaire ancien ou pléistocène. M. Thomas lui attribue aussi un tibia et un astragale de gisements de ce dernier àge; mais il ne paraît non plus y avoir aucune certitude sur cette attribution, puisque dans un travail antérieur cet auteur dit que ces os, comparés aux mêmes os du Bubalus antiquus, en diffèrent notablement par les proportions relatives de leurs diverses parties et les attribue au bos primigenius mauritanicus.

En conséquence, je considère la présence de cette espèce comme trẻs douteuse dans ces gisements qui, manifestement plus anciens que tous ceux relatés ci-dessus, contiennent une faune non comparable. Ce serait cependant une question intéressante à résoudre, pour déterminer la durée probable de l'existence de cet animal dans le nord de l'Afrique en même temps que d'autres colosses comme lui qui ont aussi disparu, tels que éléphants, rhinocéros, hippopolames, elc., à une époque certainement préhistorique, antérieure à l'emploi des métaux, mais relativement très rapprochée de la phase géologique actuelle.

\section{REPRÉSENTATIONS RUPESTRES}

Si les débris osseux de cet animal sont rares encore dans les gisements préhistoriques de la province d'Oran, en compensation on y trouve en plusieurs points de remarquables documents sur les formes extérieures et les attitudes de l'animal lorsqu'il vivait. La race d'hommes dont il était le contemporain n'était pas dépourvue d'aptitudes artistiques et a laissé sur des surfaces plus ou moins unies de rochers verlicaux des dessins d'un certain nombre d'espèces qui devaient 
habiter en mème temps qu'elle le massif atlantique. Ces dessins sont en général des profils tracés par des lignes nettes et profondes et sous forme de vrais sillons polis, et cela certainement avec des outils en pierre éclatée ou aiguisée. Ces dēssins rupestres sont surtout fréquents dans la région des Ksours oranais; on en retrouve au Maroc. De Vigneral en a relevé dans la vallée de l'Oued Cherf. Barth en a observé aussi dans son voyage au Soudan; plusieurs voyageurs les ont étudiés dans le Sud Oranais et divers croquis en ont été relevés, quelques-uns publiés, et il en a été question dans diverses publications; mais il manque encore une élude d'ensemble sur eux.

Le Service de la Carte géologique de l'Algérie a pensé qu'il serạit utile, au point de vue paléontologique, de faire recueillir des dessins authentiques de ces images rupestres pour s'assurer s'il n'y aurait pas parmi elles des représentations d'animaux ayant appartenu aux faunes quaternaires, dont on ne connait actuellement que les ossements. Il a chargé un de ses collaborateurs, M. Flamand, chargé de conférences à l'Ecole des sciences d'Alger', en même temps que d'une mission géologique dans le sud-ouest de l'Algérie, de rechercher et de photographier toutes les pierres écrites de cette région (c'est le nom que leur donnent les Arabes, Hadjar Mektouba); la moisson a été abondante.

Nos prévisions se sont réalisées, et parmi des représentations difformes ou bizarres nous avons retiouvé celle de types aujourd'hui disparus, ce qui fait remonter l'époque de leur exécution aux temps préhistoriques, à celle de la pierre polie au moins. M. Flamand a constaté, et cela ressort clairement de l'examen de ses photographies, qu'il y avait dans ces dessins rupestres et enchevêtrés plusieurs types appartenant à des époques distinctes et que l'on peut reconnaître à leur superposition.

La plus ancienne époque est la plus intéressante par la facture de ses dessins que l'on peut presque dire artistique el ayant réellement 
pour but de copier la nature. C'est à celle-là que nous devons le plus de renseignements paléontologiques, qui valent ceux que nous ont laissés dans l'Aquitaine les hommes de l'époque du renne. La seconde époque comprend des dessins plus superficiellement gravés, fantaisistes ou même enfantins et certainement dégagés de tout souci d'exactitude et de naturel. Ils sont, à n'en pas douter, le produit d'une race d'hommes bien inférieure à celle qui l'a précédée et beaucoup moins anciens, à en juger par l'aspect moins patiné de ses gravures et leur mélange et leur superposition aux anciennes. Nous ne pouvons en tenir compte au point de vue zoologique.

Je ne saurais émeltre un avis sur la question de savoir s'il faut attribuer à cette même race les nombreuses gravures de caraclères d'apparence libyques, en tout cas très archaĩques, couvrant également les dessins plus anciens de tout âge et confusément de grandes surfaces libres. Ce ne serait pas impossible, mais il m'a semblé qu'on ne pourrait faire á cet égard que des hypothèses gratuites.

Enfin, les musulmans ne peuvent rien avoir ajouté à la collection des images d'animaux, puisque c'est interdit par le Coran, mais ils y ont tracé certaines de leurs formules de croyant. On y trouve même associés des souvenirs encore plus modernes relatant le passage de nos soldats par le chiffre de leurs régiments. Je ne sache pas que les Romains, ces épigraphistes émérites, en aient fait autant, soit qu'ils n'aient pas occupé les régions propices à cela, soit qu'ils aient réservé leur choix pour leurs monuments érigés tels que leurs miliaires et leurs pierres votives.

La profusion des caractères considérés comme libyques est réellement remarquable, mais dans un ordre absolument confus, el je ne sais s'il sera possible d'en opérer une'lecture et d'espérer en tirer des documents historiques qui seraient bien précieux. C'est à recommander aux épigraphistes. Dans cette publication il ne peut être question que des documents zoologiques utilisables et on pour'a se convaincre 
par la suite de ce travail qu'ils ont une grande valeur et qu'ils ajouteront un chapitre des plus instructifs sur la composition de la faune des derniers temps néolithiques. M. Flamand a publié sur ces pierres écrites des documents qui intéressent surtout les études anthropologiques et prépare en ce moment une publication plus étendue qui est sous presse actuellement.

Dans cette monographie il ne sera question que des figures pouvant être attribuées au buffle. La planche $\mathrm{X}$ est consacrée à la reproduction des photographies rapportées par M. Flamand. Des cinq sujets qu'elle représente, quatre le sont seulement au trait qui est d'ailleurs la seule chose utilisable que comporte ce genre de gravure: le cinquiẻme sujet, qui est le principal, est destiné à donner en même temps une idée de l'agencement de ces dessins et de l'état de la surface sur laquelle ils ont été exécutés; c'est la reproduction à l'échelle approximative de 1/18 d'un des sujets les plus remarquables par ses grandes dimensions qui devaient approcher beaucoup de la grandeur naturelle. La taille en est pour le garrot de $1^{m} y 1$ et pour la croupe de $1^{\mathrm{m}} 53$. L'étude du squelette nous a donné $1^{\mathrm{m}} 85$ et $1^{\mathrm{m}} 70$ pour ces mesures respectives. G'est une différence sans importance, car elle peut se rencontrer entre des sujets d'àge ou même de sexe un peu différents et pouvait bien du reste ne pas rentrer dans les préoccupations de l'artiste.

Gette concordance de taille, la disposition en croissant à deux courbes, bien ouvert et rejeté en arrière, la forme très busquée du museau, bien marquée sur le squelette et sans doute exagérée par les parties charnues du mufle et des lèvres, ne laissent guẻre de doute que ce soit bien le buffle antique que les anciens artistes aient voulu représenter, et ce signalement ne convient, en effet, à aucun autre animal des faunes vivantes et fossiles. On ne peut pas s'attendre à une représentation harmonique de ses formes, car la connaissance de la perspective devait être très imparfaite. 
Les corps sont représentés de profil, mais les cornes sont figurẻes presque de face sans que la tête participe à ce mouvement; on sent bien cependant qu'il y en a un léger sentiment dans le raccourcissement de la corne fuyante. Les jambes ont certainement une épaisseur exagérće, rappelant plutôt celles du rhinocéros et encore mieux celles de l'hippopotame. Les ergots et les sabots paraissent être figurés d'une façon dans laquelle l'imagination de l'artiste a plus travaillé que l'observation; il y avait, en effet, une difficulté à vaincre pour conserver le caractère bisulque d'un pied vu de profil et l'on pouvait plus mal réussir à faire un accroc à la perspective. En fait, la phalange de ces sabots n'est guère plus forte que chez les bœufs de grande laille; elle est moins étalée et moins plate en dessous. Les ergots n'y sont pas figurés.

La ganache est manifestement barbue à une pelite distance en arrière du menton et semble être suivie d'une autre touffe de poils plus en arrière, mais cette partie paraît avoir été retouchée et corrigée et en outre des poils l'artiste pourrait bien avoir voulu représenter autre chose. Quoiqu'il en soit, il y a là une particularité distinctive pour notre animal. Il n'y a que les jeunes buffles du Cap qui portent des poils en barbe ou en crinière; les adultes en sont totalement dépourvus.

L'avant-train de l'animal est d'une puissance extraordinaire. La tête est basse, inclinée, portée sur un cou court et en apparence dépourvu de fanon. Le garrot est très arqué et comme bossu et sa courbe supérieure se fond de chaque côté soit sur le front, soit sur le dos. L'arrièretrain est bien moins développé quoique aussi très robuste. La croupe est très avalée et forme un angle plus ou moins accusé à la hauteur des iléons. Celte saillie est exagérée par l'ensellement des reins en avant d'elle. La queue courte se termine par un petit flocon qui ne dépasserait guère l'articulation fẻmoro-tibiale; ici elle est rejetée flexueusement sur la hanche; mais sur d'autres sujets elle est tombante. 
Les comes sont marquées de bourrelets en anneaux, qui sont ici figurés par des sillons au nombre de 12 à 13 , mais qui sur d'autres sujets peuvent aller jusqu'à 18 au moins et s'arrêtent vers le $1 / 4$ supérieur, qui est plus ou moins effilé.

Nous avous vu qu'il n'existait aucune trace de ces bourlelets sur les chevilles osseuses. La base des cornes se rapproche bien plus sur le front que ne l'indiquerait la tête osseuse: il se pourrait que la substance cornée débordàt la base des chevilles osseuses, el cela expliquerait le grand développement des rugosités de cette région frontale dans l'entre-deux cornes. Mais cela peut aussi en partie résulter du mode de perspective imaginé par l'artiste pour placer sans trop d'ilrvraisemblance sur un corps vu de profil, une paire de cornes presque présentées de face.

Le museau est épais et fortement busqué et le chanfrein bien creusé en avant des cornes. Lả on trouve deux paires de fossettes en carré, deux grandes supérieures rapprochées, deux petites inférieures plus distantes entr'elles el occupant un espace plus étendu que les supérieures. A premiẻre vue on pourrait croire qu'elles sont destinées à figurer les yeux, passe encore pour les supérieures, malgré qu'elles soient trop rapprochées entr'elles et trop en avant des cornes; mais que pourraient bien représenter les inférieures? peut-être des verrues; il me paraît difficile de faire là dessus une hypothèse raisommable.

Le panneau, si l'on peut ainsi dire, qui porte ce curieux dessin, montre également: 1' l'image d'un grand échassier de la famille des cigognes et des grues, mais qui diffère des espèces connues par un bec arqué d'ibis; $2^{\circ}$ l'image un peu grotesque d'un animal quadrupède à faciès de phacochère; $3^{\circ}$ celle d'un petit quadrupède à faciès de chien avec queue retroussée. Ces dessins rupestres proviennent de Ksar el Ahmar. M. Flamand a rapporté du même lieu la photographie d'un autre sujet faisant partie de ce qu'on pourrait appeler le même tableau et ayant l'air de suivre le sujet précédent. Il est plus 
petit, n'ayant que $1^{\mathrm{m}} 44$ au lieu de $1^{\mathrm{m}} 98$ de long. La hauteur au garrot est de $1^{\mathrm{m}} 26$ au lieu de $1^{\mathrm{m}} 53$; à la croupe elle est de $1^{\mathrm{m}}$ au lieu de $1^{\mathrm{m}}$ 35 ; mais les sabots n'y sont pas même ébauchés, de sorte que ces rapports ne sont pas bien certains. Figurée réduite au 1/22, Pl. X, fig. 5, cette image diffère en outre de la précédente par les particularités suivantes.

Le garrot est sensiblement plus anguleux, les reins plus ensellés. et la croupe a son angle plus reculé avec des tubérosités ischiatiques comme effacées; les membres sont moins épais, plus atténués à l'extrémité, du reste mal terminés; la queue est portée de la même manière. La têle est assez semblable et montre en avant des cornes les mêmes fossettes en deux paires inégales. Il n'y a aucune trace de barbe sous la ganache, mais en arrière on remarque une figure triangulaire à bords bien limités, à pointe dirigée en arrière et marquée de trois sillons convergents vers le sommet, qui me semblent représenter plutôt une oreille un peu tombante qu'un faisceau de. poils. Il faut cependant reconnaître que sur le sujet de fig. 2 il serait difficile de justifier la même interprétation ; mais il est ici manifestequ'il y a eu tentative de correction mal réussie pour toute cette partiede la tête.

Il y a lieu d'appeler l'attention sur la figuration des organes sexuelsmâles avec des formes bien différentes de celles des bœufs, si ce n'est pour le scrotum dont la forme didyme est accusée par une vue oblique, du moins pour le pénis qui, sans fourreau apparent et en état d'érection plus ou moins complète, est en forme de massue subobtuse au lieu d'être longuement acuminée. Il paraît que c'est uneorganisation particuliẻre aux buffles signalée par divers auteurs, mais sur laquelle je ne peux m'étendre, en l'absence de matériaux de. comparaison, pour rechercher si la conformation est identique ou seulement approximativement représentée. La figure 1 de la même planche semble présenter un fourreau tronqué en avant et un pénis. 
rentré formant une faible bosse, le scrolum étant supposé caché entre les cuisses.

La fig. 4 de la mème planche représente une autre photographie rapportée du même lieu de Ksar el Ahmar par M. Flamand; le sujet est un peu plus petit el montre une autre facture. Les jambes, encore trop robustes, sont mal terminées aux pieds; l'antérieure montre un essai de mise en perspective de la jambe opposée dans l'attitude de la marche, mais que l'artiste, sans doute impuissant, a renoncé à terminer. La tête est très penchée, sans aucune indication de barbe. Un point enfoncé marque sans doute l'oeil à sa place normale, près et au dessous de la base de la corne.

On voit un autre point situé en dessous de cet ceil qui pourrait représenter une verrue? mais qui n'est peut-être qu'un accident de la roche. Toutefois, ce point problématique pourrait expliquer les quatre fossettes des frontaux des deux sujets précédents qui auraient eu peut-être la prétention de représenter les yeux et leurs verrues vus de face mais sur un profil qui s'harmonisent mal entr'eux. Ici la naissance de la corne opposée n'empiète pas sur le profil du front et les deux cornes sont bien séparées. Le dos de l'animal est régulièrement convexe en arrière du cou, sans saillie marquée à la croupe qui est moins fortement avalée. La queue est portée de même.

Une autre figure provenant de Ksar el Ahmar donne une légère variante; les cornes sont un peu moins longues et leurs anneaux moins nombreux. Le scrotum est bizarrement représenté de face devant le pli et en dehors de la cuisse; le fourreau est en avant à sa place, court et tronqué au bout; la tête ressemble beaucoup à celle de fig. 1, mais elle n'a que la paire supérieure de fossettes pour représenter les yeux, de même hors place. La ganache est fimbriée, à partir du menton, de poils qui paraissent raides et peu serrés et en arrière sur une sorte d'appendice appuyé sur l'épaule. Quelques àuIres poils de même forme fimbriant son bord postérieur, cela me 
paraît encore représenter une oreille bordée de poils. Les dimensions paraissent intermédiaires à celles des fig. 1 et 5 .

La localité de Tazina montre aussi des représentations du buffle antique; j'ai fait figurer 2 et 3 de la planche $\mathbf{X}$ deux de ces sujets; celui du $n^{\circ} 3$ n'a que $1^{\text {m }}$ de haut et celte image est certainement réduite. La tête est portée comme dans la fig. 1. Elle ne montre qu'un ceil à peu près à sa vraie place. Au cou il semble y avoir un commencement de fanon. Les membres sont très robustes, les ergots sont saillants en éperon; la queue est pendante; le dos est droit, incliné en avant vers un garrot un peu effacé, arrondi. La croupe est plus avancée que dans les images précédentes et saillante comme si elle était plus élevée que le garrot, puis longuement avalée.

La fig. 2 représente un dessin un peu plus grand, $1^{\text {na }} 31$ de hauteur; le dos est déclive en avant, la croupe placée plus en arriẻre; du reste il y a une très grande analogie dans le profil. Le bord inférieur de la -ganache et le cou jusqu'au défaut de la jambe sont finement et également fimbriés. L'oil n'est pas figuré, ou peu distinctement. On ne comprend pas trop la manière dont sont représentés les organes génitaux, surtout le fourreau.

Un troisième dessin du même lieu, de $1^{\text {tw }} 31$ de hauteur, donne à peu près le même profil à l'animal que celui de fig. 2 et la queue est également tombante. Cependant le garrot est plus élevé, la ligne dorsale plus horizontale. Les cornes sont courtes, à anneaux peu nombreux; le chanfrein est fortement creusé et le nez très busqué. Il y a un faisceau de poils figuré sur l'origine du cou, mais tout cela porte l'empreinte d'inexactitude; pas de trace de l'œil ; thorax certainement trop élevé.

Nous avons un quatrième dessin assez -semblable au précédent, mais avec un thorax moins disproportionné. Les cornes sont moins courtes, un oeil est placé à peu près où il doit être; le chanfrein est aussi excavé devant l'œil, le mufle très busqué, allongé outre mesure et la ganache barbue derrière le menton. 
A Guebar Rechim nous retrouvons une représentation mutilée montrant la queue flexueuse, rejelée sur la hanche, une portion de tête dont la corne paraît projetée en avant, mais qui rappelle la manière dont sont figurés tous les croissants; la corne du côté de l'observateur est rejetée en arrière et tomberait sur une partie détruite du dessin, tandis que son opposée est au contraire projetée en avant comme ici. Un coil assez grand est presque à sa place comme distance de la base de la corne; le mulle est très peu busqué ; il y a des poils à la ganache. En somme, c'est bien encore une représentation du buffle antique, mais mauvaise et mutilée; la hauteur de l'image est de $0^{\mathrm{m}} 90$ à la croupe.

A Garet Touïdjin on trouve une représentation d'un animal dans l'attitude de la frayeur ou de la surprise et reculant. Le dessin est petit, $0^{\mathrm{m}} 60$ de hauteur, incorrect, ses cornes formant ensemble une ligne continue, très flexueuse, sont grêles, non terminées au bout. La queue est représentée dans ses deux attitudes, flexueuse sur la han-. che, et tombante en arrière comnıe si elle était double; le garrot est arrondi, la tête penchée, le dos droit, la croupe anguleuse, très avalée; les jambes sont difformes, les organes génitaux rappellent tout à fait ceux de la fig. 5 de Ksar el Ahmar.

De ce même lieu de Garet Touïdjin on possède un dessin très incomplet d'une partie de l'animal et à plus grande échelle que le précédent, puisqu'il mesure $1^{\mathrm{m}} 65$ de hauteur; on peut y reconnaitre la partie basilaire d'une corne fortement annelée avec un wil très arrondi sous son insertion. La jambe est robuste et exagérée en épaisseur, comme dans les sujets de Ksar el Ahmar. Les parties génitales sont figurées comme dans le dessin précédent : deux testicules placés l'un devant l'autre et non l'un à côté de l'autre, suivant lá facture habituelle de ces dessinateur's, une verge sans apparence de fourreau, subcylindrique obtuse. En somme, tous ces dessins ont un cachet d'originalité indiquant qu'ils sont l'œuvre d'un groupe restreint d'ar- 
tistes, on pourrait presque dire d'une école, s'il n'existait entre les images d'une même localité des nuances de facture et d'incorrections spéciales qui autorisent à penser que cette école avait au moins des groupes indépendants.

Nous avons ainsi passé en revue les documents graphiques qui ont été recueillis sur les formes extérieures de cet antique animal, de manière à pouvoir presque en esquisser une diagnose comme pour un animal vivant. Il serait sans doute très audacieux de soutenir que ces anciens dessins donnent une vraie représentation de l'animal - il faut évidemment tenir compte de l'imperfection des procédés employés pour tracer ces images, de l'état d'enfance de cet art et conclure que les hommes qui nous les ont transmises avaient des aptitudes artistiques bien supérieures à celles des races qui les ont supplantés dans la région atlantique. La moyenne de ces représentations doit s'approcher beaucoup de la vérité et nous fournir, à l'aide d'interprétations raisonnées, des indications précieuses sinon précises sur les formes extérieures d'animaux que, sans eux, nous ne connaitrions que par leur charpente osseuse. 


\section{CONCLUSION}

Il résulte des descriptions et des considérations qui précèdent que le buffle antique constitue un type très bien spécialisé dans son groupe sous-générique, ne se rattachant pas plus particuliẻrement à l'un qu'à l'autre de ses congénères.

Ses grandes cornes en croissant le feraient rapprocher de l'Arni : mais elles ont leur croissant bien plus ouvert et étalé avec les pointes plus dirigées en dehors. La position de l'orbite trẻs près et sous la base antérieure des cornes ne se retrouve dans aucune autre espéce. Un profil rentrant subanguleux à la hauteur des yeux, un chanfrein très fortement busqué, un mufle très développé et épais, une ganache barbue constituent ensemble un attribut spécial au buffle antique.

Les longues cornes fortement annelées, sauf à leur tiers supérieur, ayant leurs chevilles bien séparées par un front convexe, mais plus bombé dans le sens longitudinal, paraissent avoir empiété sur ce front, si l'on en juge d'après les représentations imparfaites que nous en possédons et d'après la nature du tissu rugueux et adventice qui envahit cet intervalle. On observe quelque chose d'anialogue chez certains buffles et ce ne serait ici qu'une forme spéciale de cet envahissement.

Une forte tête portée basse et oblique, un garrot trẻs élevé en s'arrondissant, un rein large, une croupe plus ou moins anguleuse et très avalée, une queue courte, grêle, poilue au bout, pendante ou rejetée flexueusement sur la fesse, des membres très robustes et épais 
avec charpente puissante donnent à cet animal une physionomie caractéristique et constituent les points les plus remarquables de son signalement.

Il n'y a point là de dérogation importante à la physionomie propre au tyre buffle et il n'y a pas de raison pour ne pas admettre que les mœus de notre fossile ne devaient pas beaucoup diffẻrer de celles de ses congénères vivants. Ce ne devait certainement pas être un habitant habituel de forêts; il y aurait été trop embarrassé pour ses mouvements par sa grande envergure des cornes, sa grande et lourde stature et ses pieds mastocs.

C'était bien plus naturellement un hòte des grandes plaines, plus ou moins dépourvues de broussailles et riches en herbages, ne pouvant s'écarter des eaux soit de rivières, soit, et plus probablement, de marécage, pour s'y immerger en plein pendant toute la journée et se vautrer dans la fange, comme ses congénéres. Il est fortement à présumer que si le squelette du sujet de Djelfa nous a été si complẻtement conservé, c'est parce que la bête s'est accidentellement enlisée dans le marécage. L'espèce devait y vivre en grandes troupes et nos dessins rupestres semblent nous les montrer voyageant en file indienne.

Mais quel contraste entre le climat indispensable à de pareilles existences et celui de la région où l'on trouve maintenant leurs débris. On peut admettre que c'est, du moins en partie, à la détérioration de ce climat qu'est due la disparition de cet hôte passager. Le rôle qu'il occupe sur les tableaux rupestres du sud de l'Atlas indique gu'il en jouait un considérable dans la faune de son époque et avait vis-à-vis de l'homme autant au moins, sinon plus, d'importance que l'éléphant son contemporain et divers autres grands mammifères disparus comme eux de la région.

Il faut done ajouter à l'influence de la détérioration du climat cellede la guerre incontestable que l'homme lui a faite pour subvenir à 
son alimentation. Il n'est pas probable qu'un pareil et si puissant colosse ait pu être domestiqué à aucun degré, surtout à l'époque oủ le climat le plus approprié à ses mœurs et à ses besoins battait son plein, que la misére physiologique qui pouvait plus tard l'atteindre ne l'avait pas encore affaibli dans ses instincts de sauvage liberté et qu'aucun intérêt humain n'a dù essayer de retarder l'extinction de la race, mais bien plutôt de la favoriser.

Il est donc naturel de faire remonter cette disparition à l'époque du changement climatérique qui en est une des causes. Or, cette époque est celle du passage des derniers temps néolithiques aux préludes des temps historiques, dont toutes les phases sont loin de nous être connues. C'est celle pendant laquelle les atterrissements alluvionnaires des grandes vallées ont été restreints à des proportions semblables à celles des temps actuels et oủ le sol appauvri de son alimentation pluviale s'est plus ou moins asséché dans les grandes plaines et n'a pu conserver ses marécages indispensables à bon nombre des espèces qui constituaient la faune d'alors. C'est probablement pendant une des phases de l'instauration du climat saharien dans le nord de l'Afrique, c'est-à-dire au commencement des temps modernes. 


\section{.}




\section{TABLE ANALYTIQUE}

Payes.

Lat thte....................................... 7

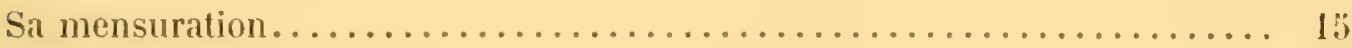

I.es dents superieures.............................. 18

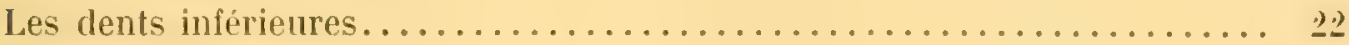

Le Rachis. Athas............................. .

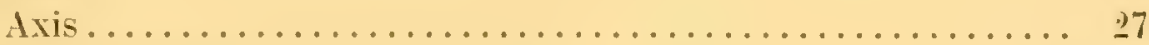

Autres cervicales.........................

Jorsales............................. 30

Lombaires............................. 34

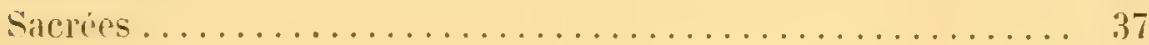

Les cotes..................................... 40

Leur mensuration............................

Lc membre antiriems. Omoplate..................... 17

Humerus..................... phi

Radius....................... 4s

Cubitus ....................... 50

Metacarpe et pied ..................

Le membre postérieur. Bassin .........................

Fimur ......................

Tiljia..........................

Astragale.........................

Calcaneum ........................ 6il

Metatarse.......................

Phalanges........................ 6i 
Allinités du butlle anlique ........................... 69

Proportions génerales........................... 71

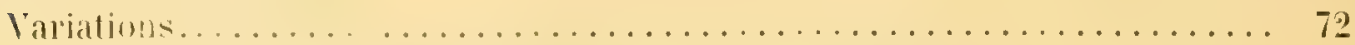

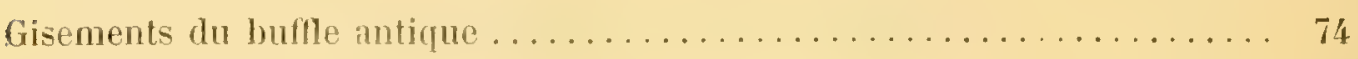

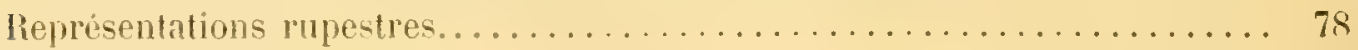

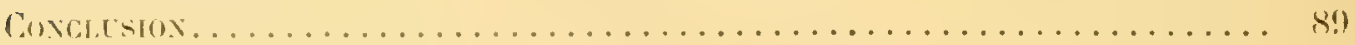







\section{LE BUFFLE ANTIQUE - PL. I}

Figure 1. 1/10. Tête vue de face. On a complété par un retournement d'image photographique, pour figurer la corne gauche; les extrémilés ont été restaurées au trait d’après un tronçon provenant du même gisement de Djelfa.

- 2. 1/כ̆. Tête vue de face. Un défaut de préparation de la pierre lithographique a afiaibli la représentation des rugosités du frontal.

- 3. 1/5. Tête vue par la face palatine montrant deux arriẻre-molaires d'un côté, trois de l'autre et les alvéoles des autres dents.

- 1. I 5. Atlas, vu par la face posterieure.

- 5. $\quad 1_{i} \ddot{3}$. La même vertèbre vue par devant.

- 6. 1/3. La mème vue par derrière. 


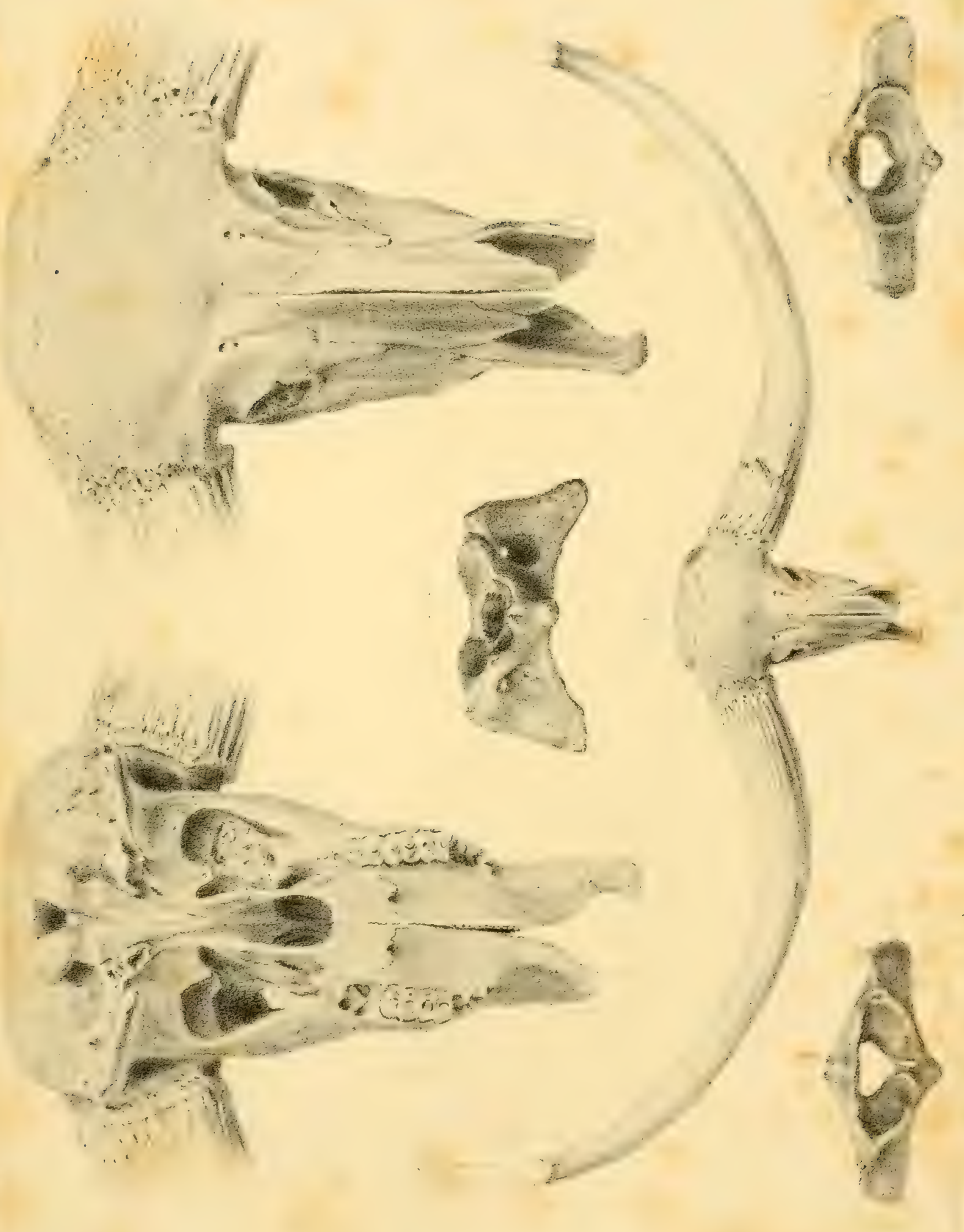






\section{LE BUFFLE ANTIQITE - PL. II}

Figure 1. 1/10. Crâne vu de profil oblique (3/4 en arrière) en perspective pour montrer le mouvement des cornes, dont le volume est par suite exagéré par rapport au crâne.

- 2. 1/5. Tête vue de profil ; la base de la corne brisée, découvrant la fosse post-orbitaire, montre la section triquètre. L'intermaxillaire gauche s'est détaché.

- 3. 1/5. Tête vue par la face occipitale, montrant les rugosités tubéreuses qui séparent le frontal du pariétal en partant de la base des cherilles.

- 4. G. N. Molaires supérieures et alvẻoles des avant-molaires. La couronne des dẹnts est un peu détériorée.

- 5. 1/5. Axis vu de profil.

- 6. 1/5. Axis vu par la face antérieure.

- 7. 1/5. Axis vu par la face postérieure. 


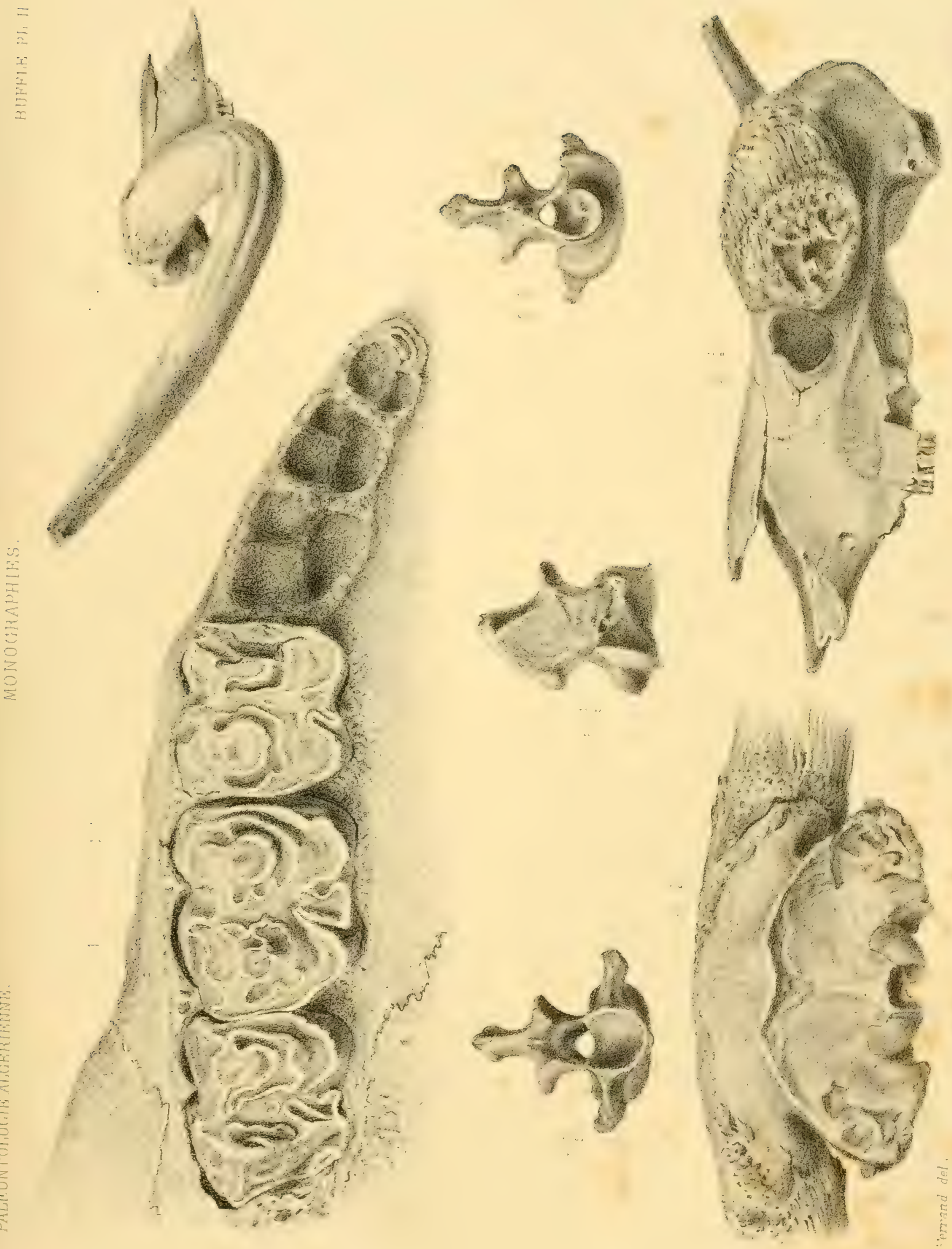






\section{LE BUFFLE ANTIQUE - PL III}

\section{$1 / 3$}

Figure 1. Sixième vertèbre cervicale vue de profil.

- 2. La même vue en dessous.

- 3. La même vue par devant.

- 4. La même vue par derrière.

- 5. Série des vertèbres dorsales de la cinquième à la treizième, vue de profil.

- 6. Série des six lombaires et du sacrum vue de profil.

- ᄀ. La même série vue par dessus. Les apophyses transverses détério. rées ont été restituées au trait d’après leurs correspondantes du côté opposé. 

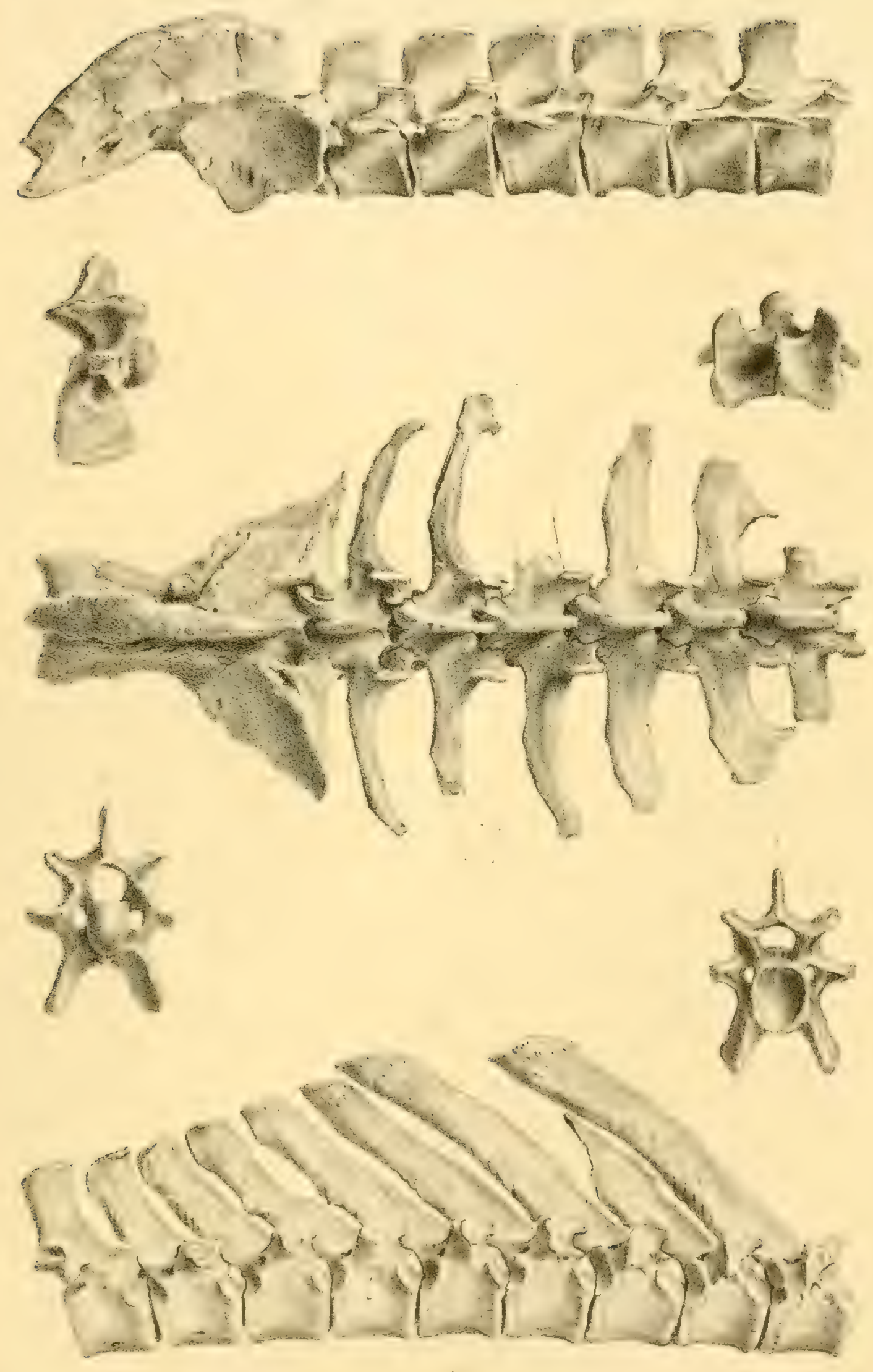




\section{LE BUFlLE ANTIQUE - PL. IV}

Figure 1. 3/5. Première ? arrière-molaire gauche, vue sous quatre faces, provenant de Brédéa.

(1) Face externe.

b) Face postérieure.

c) Face interne.

d) Face antérieure.

- 2. 3/3. Troisième avant-molaire supérieure vue sous quatre faces, trouvée à Brédéa.

a) Face externe.

b). Face postérieure.

c) Face interne.

d) Face antérieure.

- 3. 1/3̆. 13 Côtes de profil en série continue, restaurèe d'après les connexions avec les vertèbres. La 12 laisse quelque doute et vient peut-être d'un autre sujet. La $1^{\text {re }}$ a été complétée au trait par sa correspondante du côté opposé. 

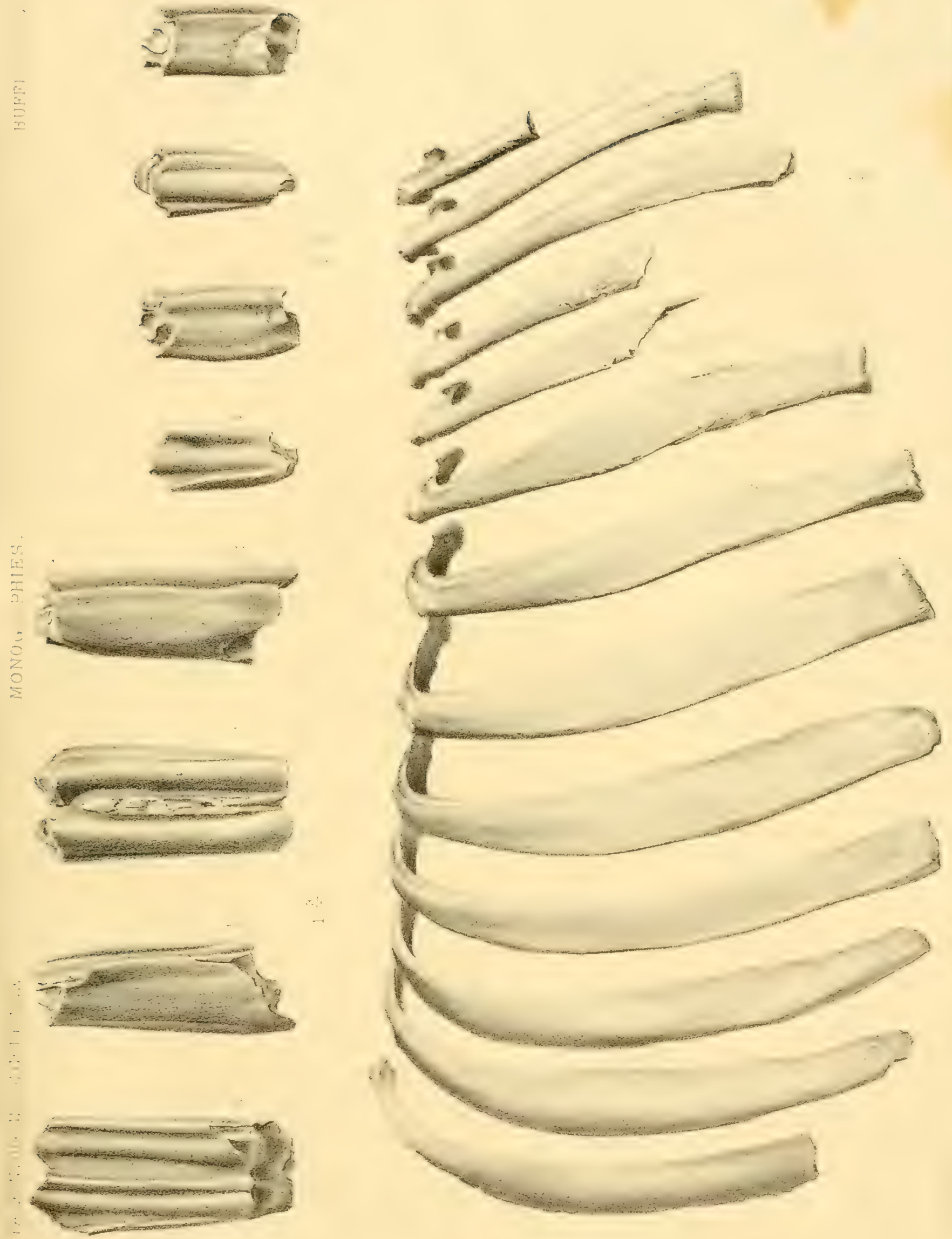




\section{I.E BUFFLE ANTIQUE - PL. V}

\section{$1 ;$}

Figure 1. Omoplate, vu par la face externe.

- 2. - sa facette glénoïde.

- 3. Humérus, vu par devant.

- 4. Le même, vu par derrière.

- $\quad$ \#. Le même, vu du côté externe

- 6. Humérus, tète articulaire supérieure.

- 7. Humérus, tête articulaire inférieure.

- 8. Radio-cubitus, vu par devant.

_. 9. Le même, vu par derrière.

- 10. Le même, vu du côté externe.

- 11. Radius, arliculation supérieure.

- 12. Le même, articulation inférieure. 

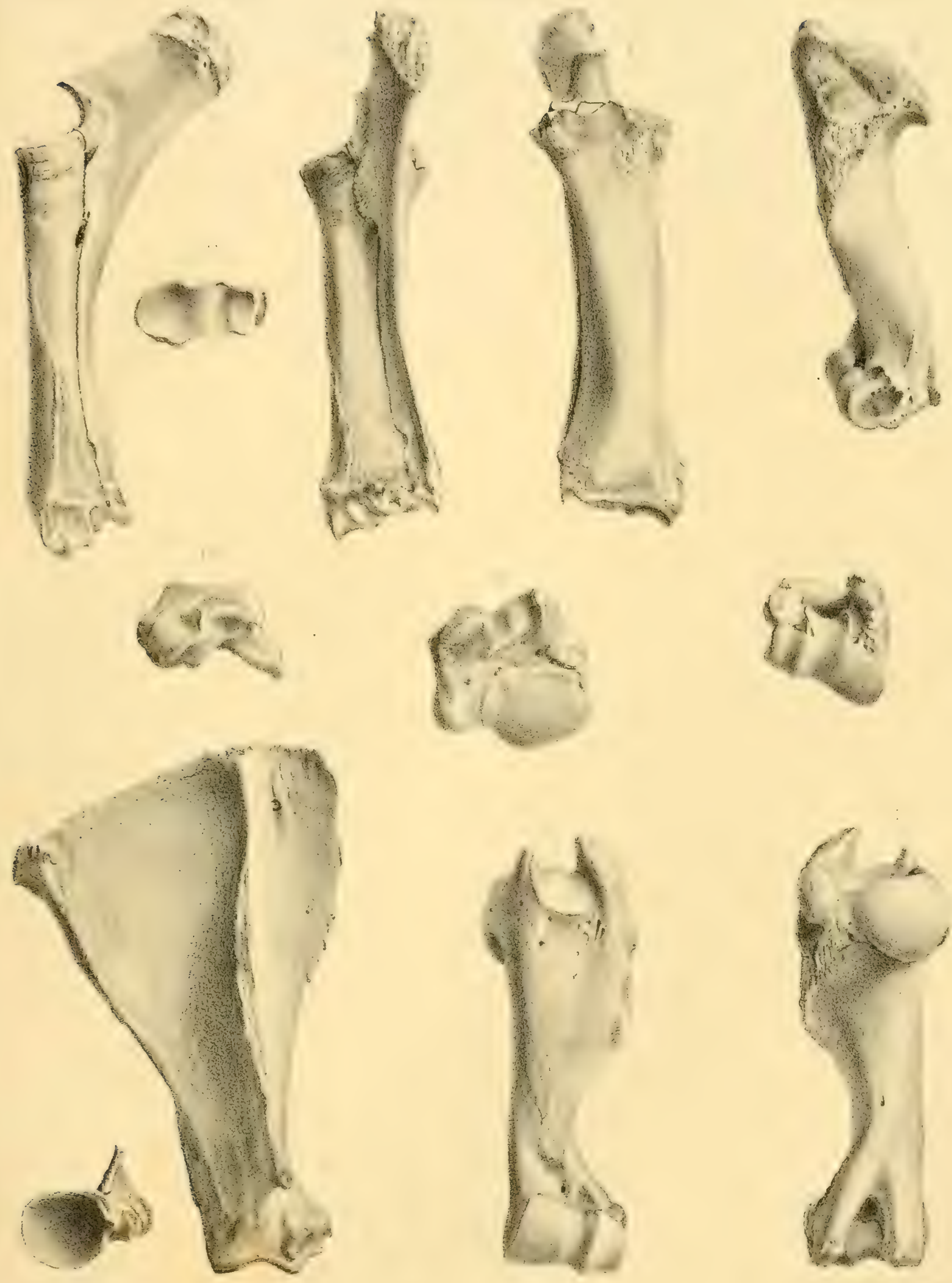

Ferrand del. 




\section{LE BUFFLE AN'TIQUE - PL. VI}

\section{$1 / 3$}

Figure 1. Bassin, vu par l’arrière, avec le sacrum en place figuré au trait.

2. Le mème, vu de profil, avec le sacrum figuré au trait.

- 3. Fémur, vu de profil du côté externe.

- 4. Le mème, vu par derrière.

- :. Le même, vu par devant.

- i. Tête supérieure du fémur.

- т. Têle infériente du fémur. 

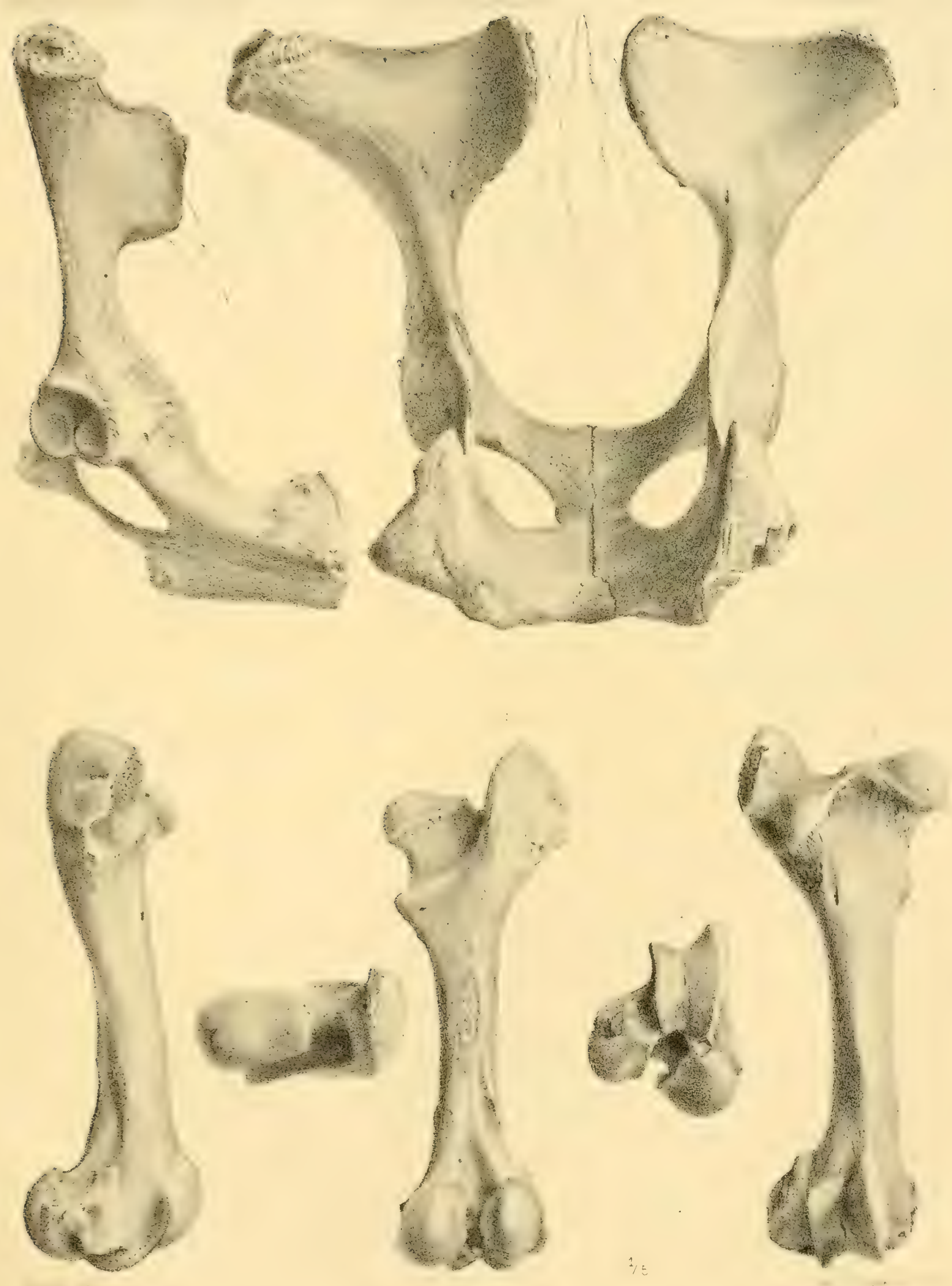




\section{LE BUFFLE 1 NTIOUE - PL. VII}

Figure 1. 1'\%. Tibia, vu de profil par la face interne.

- 2. 1/5. Tilià, vu par la face postérieure.

- 3. 1.3. Le même. vu par la face antéricure.

- 4. 1:ว. Tête supérieure du tibia.

- \%. 1/3. Tête inférieure du tibia.

- 6. 1/5. Tarse vu extéricurement: astragale, calcanéum et cubo-scaphoïdien; manque le cunéiforme.

- 7. 1/3. Le mime, vu par devant.

- 8. 1/5. Métatarse, vu de profil du côté interne.

- 9. 1/3. Le même, avec les phalanges, vu par devant.

- 10. 1/3. Le même, articulation supérienre.

- 11. 13. Lè même, articulation inférieure.

- 13. 1/2. Cineiforme du carpe, vu par la face externe.

- 14. 1/2. Deuxième phalange, rue par sa face externe.

- 13. 1:2. La même, par sa face antérieure.

- 16. 1\%. La mème, par sa face postérieure.

- 17. 1,2. La même, par sa facelte articulaire supérieure.

- 18. 1/2. Phalange onguéale du pied de devant? vue de profil interne.

- 19. 1:2. La mème, vue en dessous.

- 20. 1/2. La mème, vue par devant. 

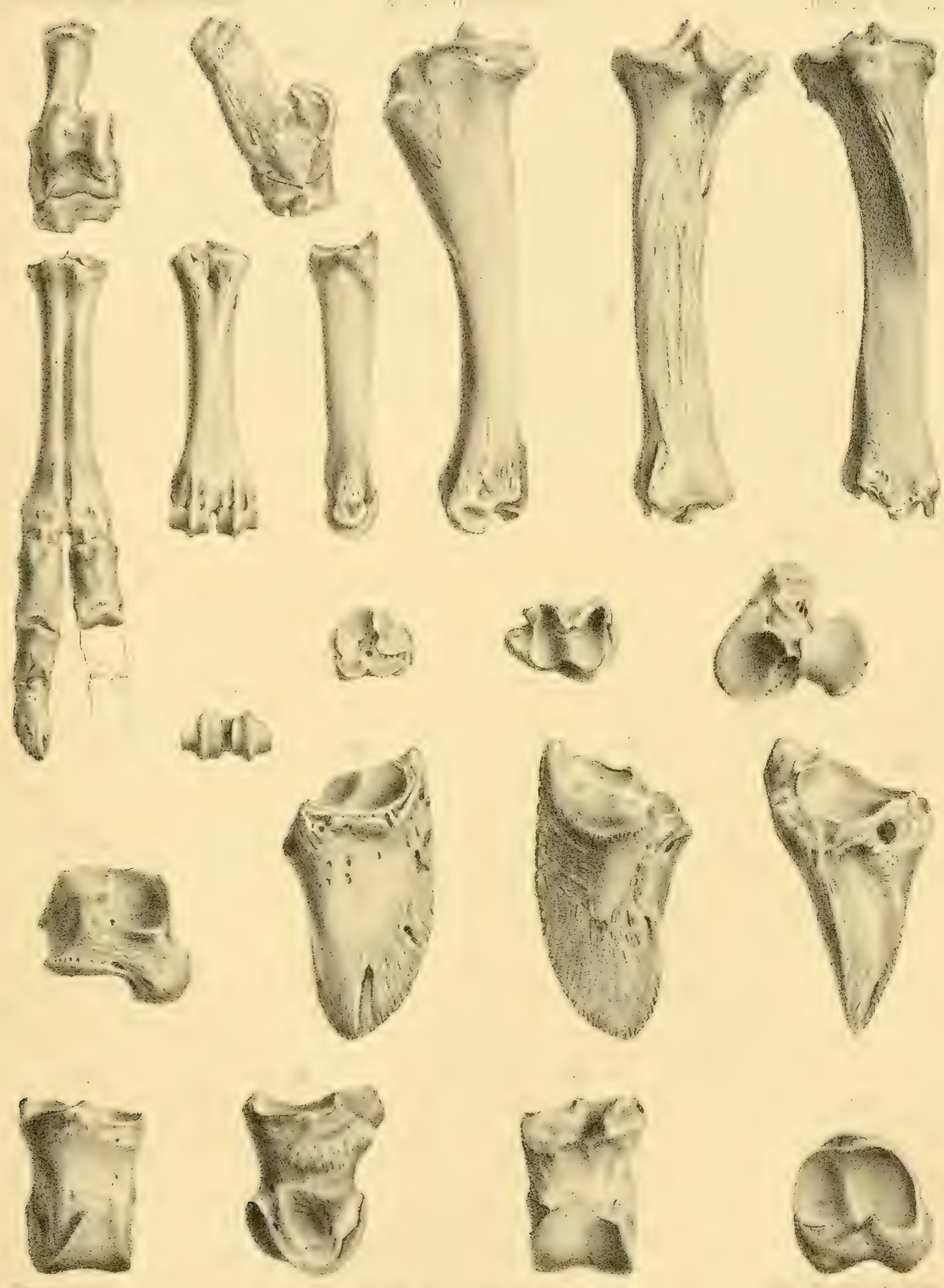




\section{LE BUFFLE ANTIQUE - PL。VIII}

\section{$1 / 2$}

Figure 1. Astragale, vu par devant.

- 2. Astragale, vu de profil du côté interne.

- $3 . \quad$ - vu du côté postérieur.

- 4. Calcanéum, vu de profil du côté interne.

- 5. Le même, vu par devant.

- 6. Cubo-scaphoïdien, vu par dessus.

- 7. Le mème, vu par dessous.

- 8. Première phalange, vue par devant.

- 9. La même, vue du côté interne.

- 10. Deuxième et troisième phalanges. vues par clevant.

- 11. Les mèmes, vues par derrière.

- 12. Les mêmes. vues du còté interne.

- 14. Sésamoïde du métatarse, vu par sa facette.

- 15. Sésamoïde de la plıalange onguéale, vu par sa facette. 

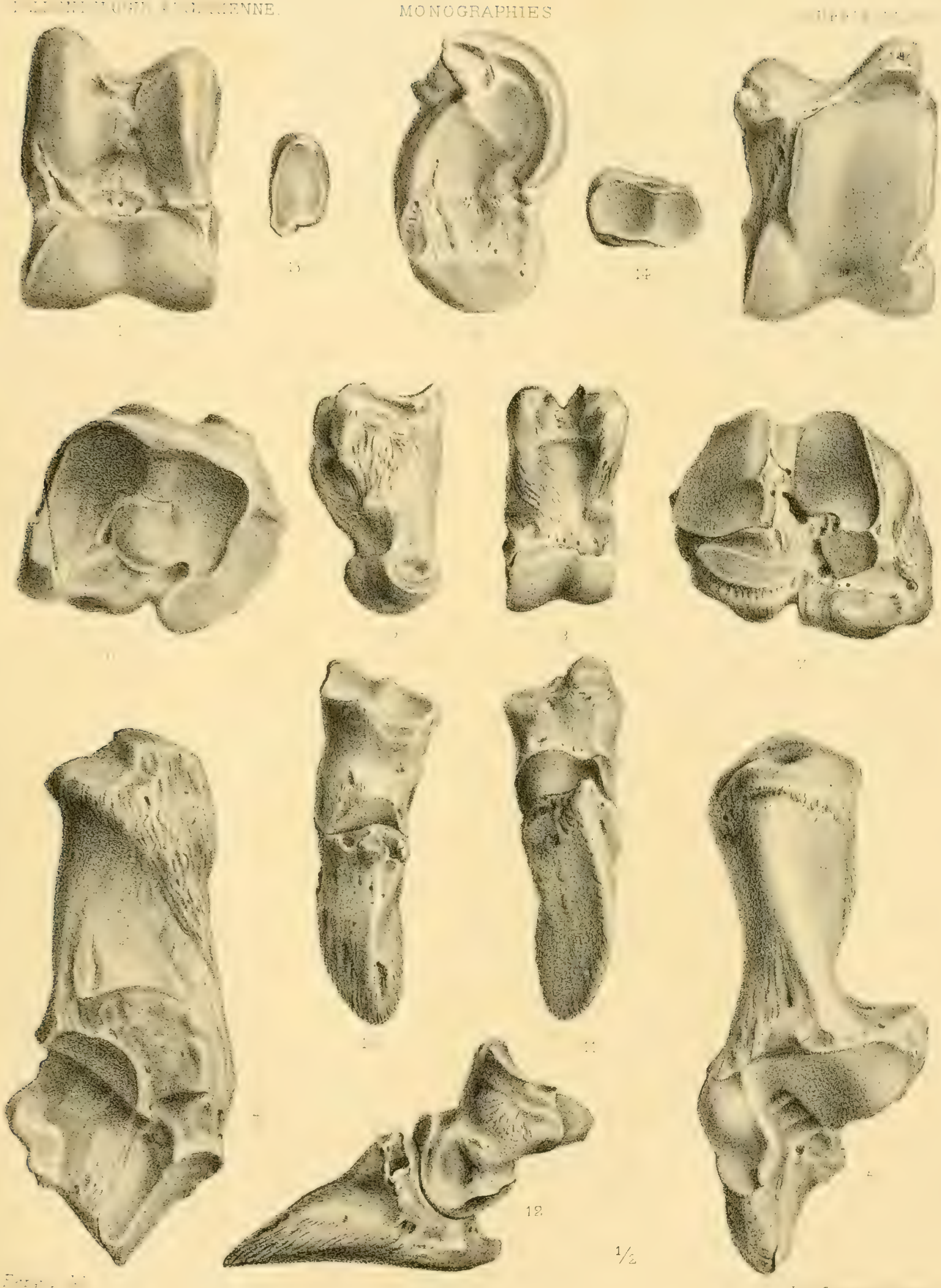



\section{LE BUFFLE ANTIQUE - PL. IX}

\section{G. N.}

Figure 1. Première arrière-molaire inférieure de l'Oued Seguen sous cinq faces,

a) Face interne.

b) Face postérieure.

c) Fice antérieure.

d) Face postérieure.

c) Jace supérieure (couronne).

- 2. Deuxiène arrière-molaire inférieure de la grotte du Grand Rocher sous cinif faces.

a) Face interne.

b) Face postérieure.

c) Face antérieure.

d) lace externe.

e) Face supérieure (couronne).

- 3. Deuxième arrière-molaire inférienre vue par la face interne d'un bouf du gisement d'Aboukir.

- 4. La même, du gisement de l'Oued Knis, près d'Alger

- ¿ La mème, d'un bœuf? du Coupet (Hante-Loire). 

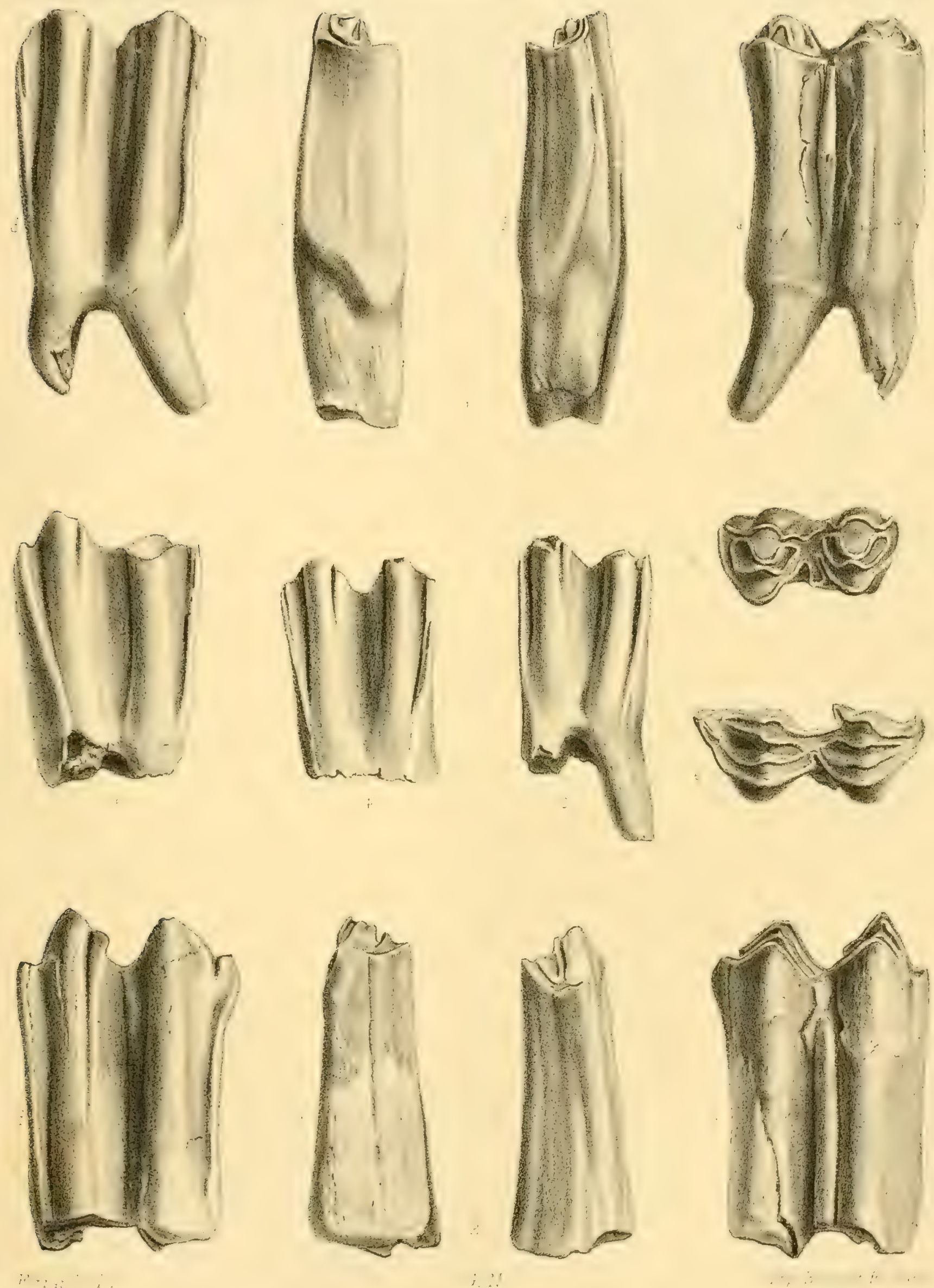




\section{LE BUFFLE ANTIQUE - PL. X REFRÉSENTATIONS RUPESTRES}

Higure 1. 1/19. Image reproduite d'après une photographie d'une portion de tableau représenlant un buffle comme sujet principal, et en outre:

a) Un animal bizarre rappelant le phacochère.

b) Un échassier à faciès de cigogne, mais à bec arqué et synciput subanguleux. Inconnu.

c) Petit quadrupède mal défini, probablement un chien.

$$
\text { De Ksar el Ahmar. }
$$

Figure 2. 1/16. Buffle au trait de Tazina.

- 3. 1/15. Autre buffle au trait de Tazina.

- 4. 1/19. Buffle au trait de Ksar el Ahmar.

- 5. 122. Autre buflle au trait de Ksar el Ahmar.

N. B. - Les chiffres fractionnaires $8 / 10$ indiquent des réductions de clichés et non de l'image réelle. 
PALEONTOLOGIE ALGERIENNE

MONOGRAPHIES

$1 \because 2.21 x$

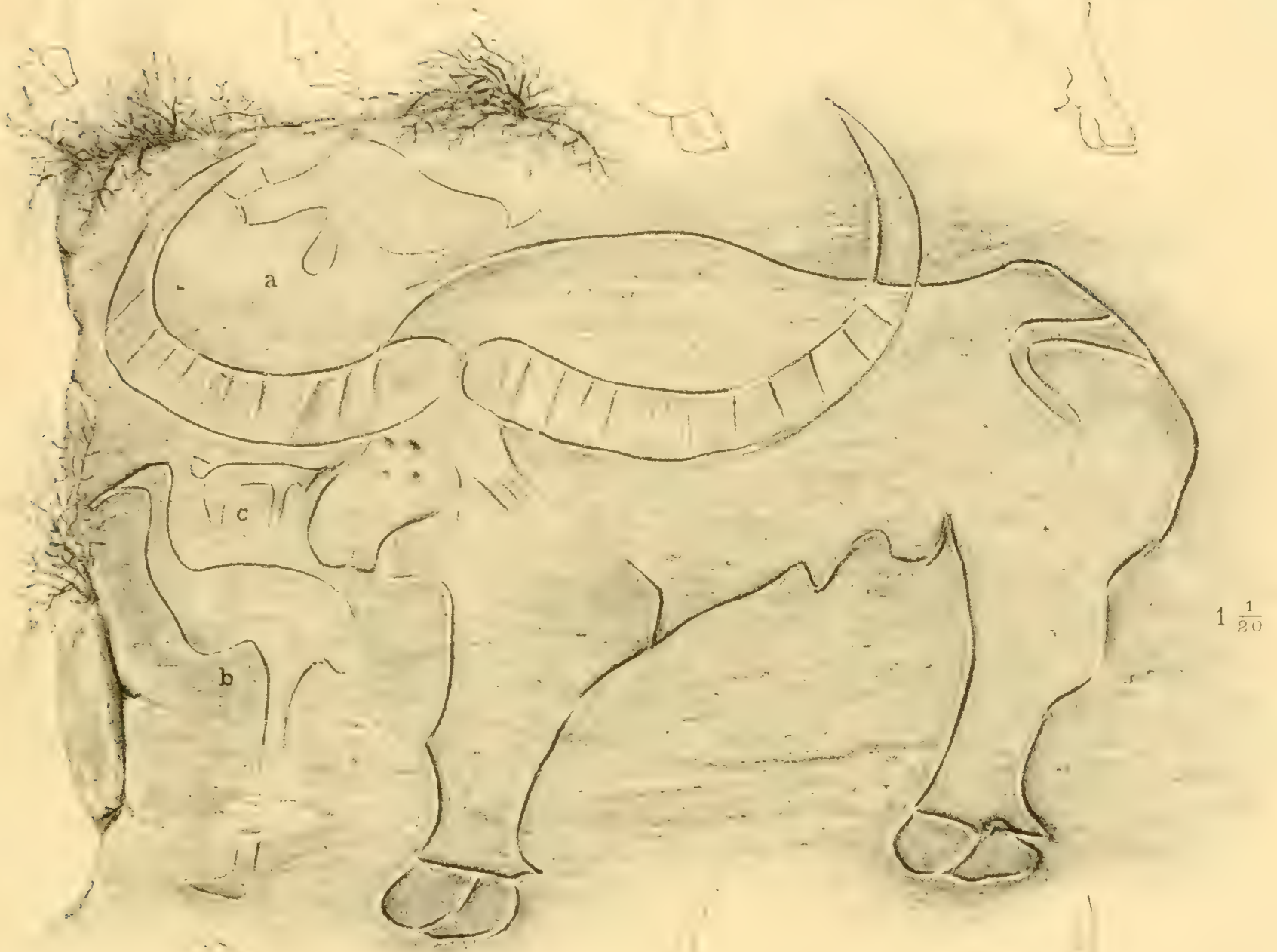

Flamand photog. Ferrand del.

Imp Becquet if. Paris. 







